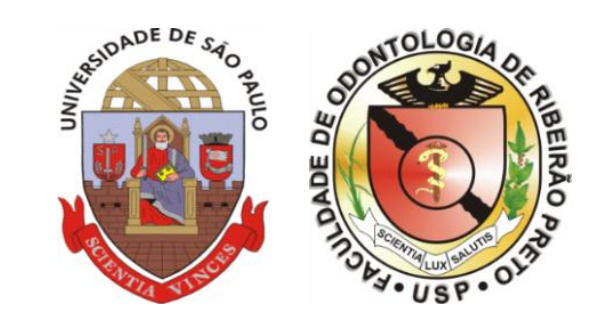

UNIVERSIDADE DE SÃO PAULO

FACULDADE DE ODONTOLOGIA DE RIBEIRÃO PRETO

MARINA PERIS VOMERO

AVALIAÇÃO DA INFLUÊNCIA DA PIGMENTAÇÃO, OPACIFICADOR E ENVELHECIMENTO NAS PROPRIEDADES FÍSICAS E MECÂNICAS DE UM SILICONE EXPERIMENTAL PARA PRÓTESE BUCOMAXILOFACIAL

Ribeirão Preto 


\title{
AVALIAÇÃO DA INFLUÊNCIA DA PIGMENTAÇÃO, OPACIFICADOR E ENVELHECIMENTO NAS PROPRIEDADES FÍSICAS E MECÂNICAS DE UM SILICONE EXPERIMENTAL PARA PRÓTESE BUCOMAXILOFACIAL
}

\begin{abstract}
Dissertação apresentada à Faculdade de Odontologia de Ribeirão Preto da Universidade de São Paulo, para obtenção do título de Mestre, junto ao Departamento de Materiais Dentários e Prótese.
\end{abstract}

Área de concentração: Reabilitação Oral

Orientadora: Profa. Dra. Claúdia Helena Lovato da Silva

Ribeirão Preto 
AUTORIZO A REPRODUÇÃo E DIVULGAÇÃO DO TEOR TOTAL OU PARCIAL DESTE TRABALHO, POR QUALQUER MEIO CONVENCIONAL OU ELETRÔNICO, PARA FINS DE ESTUDO E PESQUISA, DESDE QUE CITADA A FONTE.

\section{FICHA CATALOGRÁFICA}

Elaborada pela Biblioteca Central do Campus USP - Ribeirão Preto

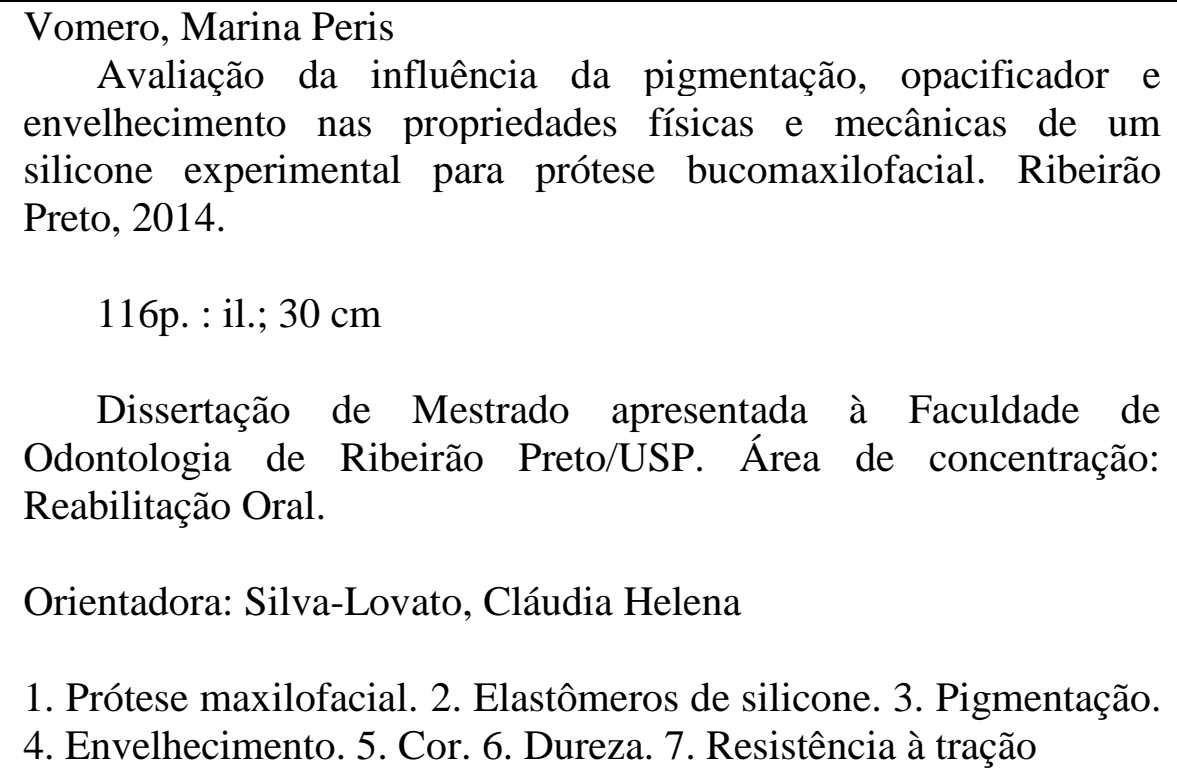
envelhecimento nas propriedades físicas e mecânicas de um silicone experimental para prótese bucomaxilofacial. Ribeirão Preto, 2014.

116p. : il.; $30 \mathrm{~cm}$

Dissertação de Mestrado apresentada à Faculdade de Odontologia de Ribeirão Preto/USP. Área de concentração: Reabilitação Oral.

Orientadora: Silva-Lovato, Cláudia Helena

1. Prótese maxilofacial. 2. Elastômeros de silicone. 3. Pigmentação.

4. Envelhecimento. 5. Cor. 6. Dureza. 7. Resistência à tração 


\section{FOLHA DE APROVAÇÃO}

\section{MARINA PERIS VOMERO}

Avaliação da influência da pigmentação, opacificador e envelhecimento nas propriedades físicas e mecânicas de um silicone experimental para prótese bucomaxilofacial

Dissertação apresentada à Faculdade de Odontologia de Ribeirão Preto da Universidade de São Paulo, para obtenção do título de Mestre.

Área de concentração: Reabilitação Oral

Aprovado em:

\section{Banca Examinadora}

1) Prof.(a). Dr.(a).:

Instituição:

Julgamento: Assinatura:

2) Prof.(a). Dr.(a).:

Instituição:

Julgamento: Assinatura:

3) Prof.(a). Dr.(a).:

Instituição:

Julgamento: Assinatura: 


\section{Dedicatóría}


À Deus, por sempre guiar meu caminho, iluminar e reger minha vida, proporcionando-me o desfrutar de momentos como este.

Aos meus pais, Fernando e Vânía, meu porto seguro, que estão presentes em todos os momentos, me fogem as palavras para agradecer tanto amor e carinho. Serei eternamente grata por sempre estarem ao meu lado, apoiando minhas decisóes, mas muito além disso, por serem meus exemplos de amor, dignidade, trabalho e uniáo. Obrigada por confiarem em mim. A vitória desta conquista dedico com todo meu amor, a vocês!

Ao meu querido irmão, Fernando (Fefe), por todo carinho, amizade e torcida. Você também foi fundamental para essa conquista.

Ao meu namorado Francísco, pelo amor, amizade, companheirismo, paciência e ajuda neste trabalho. Obrigada por todos os momentos, tristes e felizes, que esteve ao meu lado, pela segurança e tranquilidade que me transmite. '̇́ muito bom saber que tenho vocè!

À minha tia-amiga Fernanda, por me apresentar a Odontologia e fazer com que eu me apaixonasse. Obrigada por todos os momentos, ensinamentos, conselhos e amizade.

A todos meus familiares, não menos especiais, que participaram dessa etapa da minha carreira e torceram pela realização deste trabalho. 
Agradecimento
Especial 
À Profa Dra Cláudia Helena Lovato da Silva, minha orientadora, exemplo de profissional. Admiro sua delicadeza, paciência e dedicação singular. Obrigada pelos ensinamentos, pela oportunidade e confiança que depositou em mim. Agradeço também por ter contribuido não apenas com meu conhecimento cientifico, mas por me mostrar a perfeição da Odontologia na prática clinica. Sou grata pelos anos de convivéncia, amizade e aprendizado. 
Agradecímentos 
A Faculdade de Odontología de Ríbeirão Preto da Universidade de São Paulo, representada pelo Diretor Prof. Dr. Valdemar Mallet da Rocha Barros, pela oportunidade de cursar o Mestrado dentro da "minha casa".

A Coordenação de Aperfeísoamento de Pessoal de Nivel Superior (CAPES) pela bolsa de estudos concedida no inicio do meu curso de Mestrado.

A Fundação de Amparo à Pesquísa do Estado de são Paulo (FAPESP), pela bolsa de Mestrado concedida e pela confiança na elaboraçâo deste trabalho (no do processo: 2013/05439-o).

A Profa Dra Fernanda C. Panzeri Pires de Souza, Coordenadora do Programa de Pós-Graduação na área de Reabilitação Oral durante meu curso de Mestrado, por sua dedicação sempre buscando a exceléncia do Programa.

A Profa Dra Rossana P. de Almeída Antunes, atual Coordenadora do Programa de Pós-Graduação na área de Reabilitação Oral, por dar continuidade na qualidade do nosso curso.

Ȧ Profa Dra Helena F. Oliveira Paranhos, pela oportunidade de aprender com uma profissional impar. Obrigada pelos ensinamentos, conselhos e amizade.

Ao Prof. Dr. Raphael Freitas de Souza, pelos ensinamentos e amizade. Meus sinceros agradecimentos e admiração. 
Ȧ Profa Dra Andrea Cândído dos Reís, pela disposição em me ajudar. Obrigada pelo carinho que tem comigo e, principalmente, por participar ativamente na melhora da minha timidez.

Aos Professores do Departamento de Materiaús Dentários e Prótese, da Faculdade de Odontologia de Ribeirão Preto da Universidade de São Paulo, pela contribuiçaao para minha formação profissional e pessoal. Obrigada por todas as reflexôes e ensinamentos.

Ȧ Juliana Barchelli Pinheiro, pela amizade e parceria neste trabalho. Obrigada pela grande ajuda em todas as etapas do meu curso de Mestrado. Deixo aqui minha admiração e eterno agradecimento por sempre me mostrar a direção.

Ao Técnico Luiz Sérgío Soares (Serginho), por todo cuidado e preocupação com este trabalho. Obrigada pela ajuda, disposição e amizade.

À responsável pelo Laboratório de Pesquisa de Metrologia Ana Paula Macedo, pela ajuda no meu trabalho. Obrigada pela atenção e pela disposição sempre que preciseí. Foi muito bom trabalhar com vocé.

Aos técnicos do Laboratório Integrado de Pesquisa em Biocompatibilidade de Materiais (LIPEM), Edson Volta e Rícardo de Souza Antunes, por toda ajuda na execução deste trabalho. Obrigada por sempre me atenderem quando precisei. 
À Técnica do Laboratório de Reabilitação Oral, Viviane de Cássía Oliveíra, pelo carinho e amizade. Obrigada pela ajuda sempre que precisei. Deixo aqui meu agradecimento.

Aos meus queridos amigos que levarei para vida toda (Os lindos da R.O.), Carolina $\mathcal{N}$. F. de Arruda, pela amizade e parceria, com quem pude dividir os sufocos dos seminários, Raniel Fernandes Peíxoto, pelas conversas, pontos de vista e pela ajuda na formatação deste trabalho, te admiro por todo seu conhecimento e bondade, Maurício Malheiros Badaró, pela alegria, risadas e palhaçadas, alegrando meus dias e Nathália Ramos da Sílva, pelo afeto, amizade e ajuda sempre que preciseí. Cada um de vocês, à sua forma, fez todos meus momentos serem especiais. Obrigada!

Aos meus amigos do Laboratório, Marcela Moreira Salles, Vanessa M. F. Leite, Tatiana R. Cunha, Maria Paula Della Vecchía, Flávía C. T. Coimbra, Adriana B. Ríbeiro e Danílo B. Sorgini, muito obrigada pelo convivio, risadas, conselhos e por me ajudarem durante essa caminhada. Foi muito Gom partîhar momentos com vocês.

Aos amigos do DAPP, Profa Dra Marilena Chinali Komesu, Profa $^{a}$ Dra Ana Carolina F. Motta, Crístiano Nakao (Cris), Benedita $\mathcal{V}$. Rodrigues (Ditinha) e Fátima Ap. Rizoli (Fá) pela oportunidade de aprender com vocês. $\mathcal{E}$ sempre muito prazeroso e divertido estar na presença de vocês!

Aos Técnicos em Prótese Dentária, Marcelo Ap. Vieira, Fernando Schiavetto, Lícío Firmino Junior, Paulo Sérgío Ferreira e Julio César S. da Matta e Auxiliares de Laboratório, José Henrique Loureíro e Eduardo Destíto, por toda ajuda e carinho que tiveram comigo. 
As Funcionárias da Secretaria do Programa de PósGraduação em Reabilitação Oral da Faculdade de Odontologia de Ribeirão Preto da Universidade de São Paulo, Regiane de C. Tírado Damasceno, Fernanda Talita de Freitas e Ana Paula Xavier, pela paciência, atenção, disponibilidade e amizade durante esses anos.

Aos Funcionários da Seção de Pós-Graduação da Faculdade de Odontologia de Ribeirão Preto da universidade de São Paulo, Isabel Crístina Galino Sola, Regiane Crístina Moí Sacilloto, Leandro Marín Sílva, Mary Possani Carmessano, pela simpatia e presteza nas informaçôes e orientaçóes. Obrigada pela ajuda sempre que precíseí.

A todos colegas da Pós-Graduação, pelos conhecimentos e experiências compartilhados, tornando meu curso de Mestrado muito mais significativo.

A todos que participaram de forma direta ou indireta para que esse trabalho se tornasse realidade, meu eterno e sincero agradecimento. 
Resumo 
VOMERO, M. P. Avaliação da influência da pigmentação, opacificador e envelhecimento nas propriedades físicas e mecânicas de um silicone experimental para prótese bucomaxilofacial. 2014. 116p. Dissertação (Mestrado em Reabilitação Oral) - Faculdade de Odontologia de Ribeirão Preto, Universidade de São Paulo, Ribeirão Preto, 2014.

\section{RESUMO}

O objetivo deste estudo foi propor a utilização de um novo silicone (Bio-Skin - BS) para prótese bucomaxilofacial. Foram analisadas alteração de cor, dureza Shore A, resistência à tração, características de superfície (MEV) e composição química (EDS) frente à diferentes pigmentações e envelhecimentos. Como parâmetro de comparação foi empregado o silicone MDX4-4210. Foram obtidos 120 espécimes para cada material com formato circular e $160 \mathrm{em}$ forma de haltere, a partir de matrizes metálicas de corte, os quais foram distribuídos em 4 grupos: PI - pigmentação intrínseca (pó de maquiagem); OP - opacificador (sulfato de bário, $\mathrm{BaSO}_{4}$ ); PIO - associação de PI + OP; SP - sem adição de PI ou OP. Em seguida, os espécimes foram distribuídos aleatoriamente em 3 subgrupos para exposição ao envelhecimento por luz natural ( $\mathrm{LN}, \mathrm{n}=10)$, luz ultravioleta ( $\mathrm{UV}, \mathrm{n}=10)$ e ausência de luz $(\mathrm{C}$, $\mathrm{n}=10$ ). O período experimental foi de 12 meses. A alteração de cor foi verificada com auxílio de espectrocolorímetro e sistema CIE $\mathrm{L}^{*} \mathrm{a}^{*} \mathrm{~b}^{*}$. Para a dureza foi utilizado um durômetro Shore A e a análise da resistência à tração foi realizada em máquina universal de ensaio. As variáveis de resposta quantitativas foram mensuradas imediatamente após a obtenção dos espécimes e após o período experimental. A análise de superfície foi realizada por microscopia eletrônica de varredura (MEV) e a composição química dos silicones, por espectroscopia por energia dispersiva (EDS). Os dados foram submetidos à análise de variância e teste complementar de Tukey $(\mathrm{p}<0,05)$. Os resultados das análises por MEV e EDS foram apresentados em imagens e gráficos. Houve interação entre todos os fatores $(\mathrm{p}<0,05)$ e ambos os materiais sofreram variações em função das pigmentações e envelhecimentos. Para alteração de cor, o silicone experimental (BS) apresentou as menores variações de cor. Analisando os silicones em função da pigmentação, o MDX apresentou maiores variações com os espécimes SP e com OP envelhecidos por luz natural e luz UV. Para o BS, houve alteração significativa da cor dos espécimes SP e OP somente após o envelhecimento por LN. Os dois materiais apresentaram aumento da dureza frente a todas as condições, sendo que o silicone BS apresentou a maior variação. O silicone experimental apresentou resistência à tração superior ao MDX em todas as situações. O MDX não sofreu influência significativa na resistência à tração por nenhuma das pigmentações ou envelhecimento, exceto quanto pigmentado com pó de maquiagem e envelhecido por UV, onde houve aumento da resistência. Quanto ao silicone BS, os maiores valores de resistência à tração foram encontrados com a PI e PIO em todos os grupos de envelhecimento. Pode-se considerar que o material experimental apresentou resultados favoráveis em relação à alteração de cor, dureza Shore A e resistência à tração para sua aplicação clínica em prótese bucomaxilofacial. A associação da pigmentação intrínseca, por meio de pó de maquiagem com opacificador, protegeu o silicone da alteração de cor e promoveu alterações aceitáveis nas propriedades mecânicas dos materiais. Todos os processos de envelhecimento promoveram alterações nas propriedades dos materiais.

Palavras-chave: Prótese maxilofacial. Elastômeros de silicone. Pigmentação. Envelhecimento. Cor. Dureza. Resistência à tração. 


\section{Abstract}


VOMERO, M. P. Evaluation of the influence of pigmentation, opacifier and aging on physical and mechanical properties of an experimental silicone for maxillofacial prosthesis. 2014. 116p. Dissertação (Mestrado em Reabilitação Oral) - Faculdade de Odontologia de Ribeirão Preto, Universidade de São Paulo, Ribeirão Preto, 2014.

\begin{abstract}
The aim of this study was to propose the use of a new silicone (Bio-Skin - BS) for maxillofacial prosthesis. Color change, Shore A hardness, tensile strength, surface characteristics (SEM) and chemical composition (EDS) were analyzed, regarding different pigmentation and aging methods. The MDX4-4210 silicone was used as parameter of comparison. Specimens (120 circular and 160 dumbbell-shaped) were obtained for each material, from metal cutting molds, which were divided into 4 groups: IP - intrinsic pigmentation (makeup powder); OP - opacifier (barium sulfate, $\mathrm{BaSO}_{4}$ ); IPO - IP + OP association; WP - without adding IP or OP. Then, the specimens were randomly divided into 3 subgroups to aging by exposure to natural light (NL, $n=10)$, ultraviolet light $(\mathrm{UV}, \mathrm{n}=10$ ) and without light $(\mathrm{C}, \mathrm{n}=10)$. The experimental period was 12 months. The color change was observed with spectrocolorimeter and CIE L*a*b* system. For hardness we used a Shore A durometer and the analysis of tensile strength was performed in a universal testing machine. The quantitative response variables were measured immediately after obtaining the specimens and after the experimental period. The surface analysis was performed by scanning electron microscopy (SEM) and the chemical composition of silicones, by energy dispersive spectroscopy (EDS). Data were submitted to ANOVA and Tukey's test ( $p<0.05$ ). SEM and EDS results were presented in pictures and graphics. There was interaction between all factors ( $\mathrm{p}<0.05)$ and both materials varied depending on the pigmentation and aging methods. For color change, the experimental silicone (BS) showed the lowest color variations. Analyzing the silicones due to the pigmentation, the MDX showed higher variation with the WP and OP specimens aged in natural light and UV light. For BS, there was significant change in the color of the WP and OP specimens only after aging for NL. The two materials presented an increase in hardness front of all conditions, and the BS silicone showed the greatest variation. The experimental silicone showed superior tensile strength to MDX in all situations. The MDX was not affected in tensile strength by any pigmentation or aging, except for the group pigmented with makeup powder and aged by UV, where there was an increase of resistance. As to BS silicone, the highest tensile strength values were found for the IP and IPO in all age groups. It can be considered that the experimental material showed favorable results regarding color change, Shore A hardness and tensile strength for clinical use in maxillofacial prosthesis. The association of intrinsic pigmentation through makeup powder and opacifier, protected silicone of color change and promoted acceptable changes in mechanical properties of the materials. All the aging processes promoted changes in material properties.
\end{abstract}

Keywords: Maxillofacial prosthesis. Silicone elastomers. Pigmentation. Aging. Color. Hardness. Tensile strength. 


\section{SUMÁRIO}

\section{RESUMO}

\section{ABSTRACT}

1 INTRODUÇÃO 19

2 REVISÃO DA LITERATURA

3 PROPOSIÇÃO ......................................................................................................................52

4 MATERIAL E MÉTODOS ...........................................................................................54

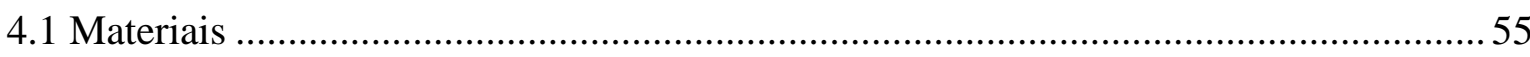

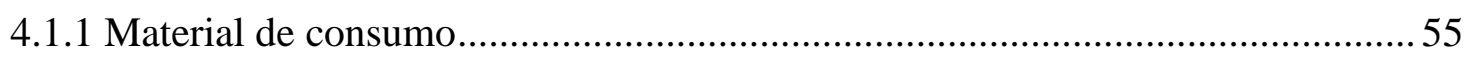

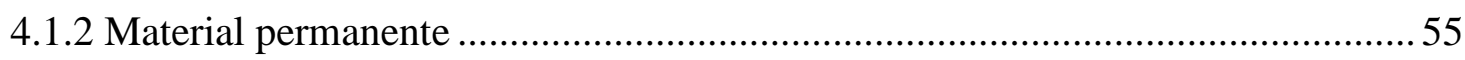

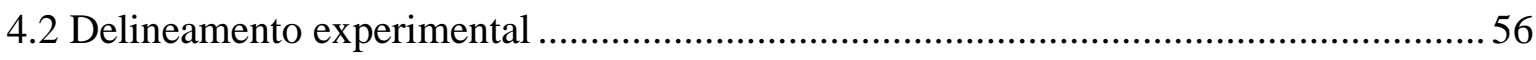

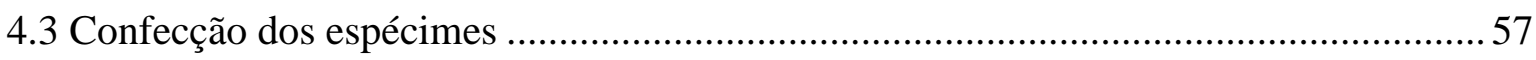

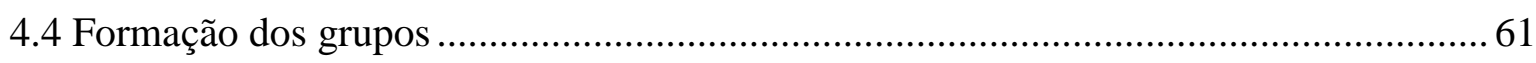

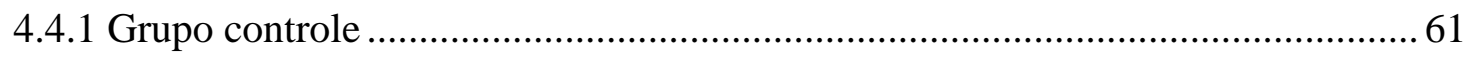

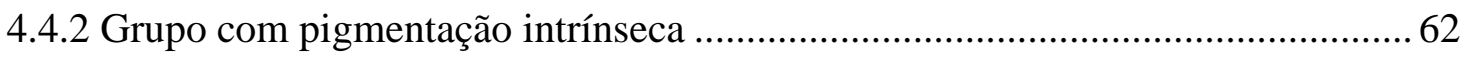

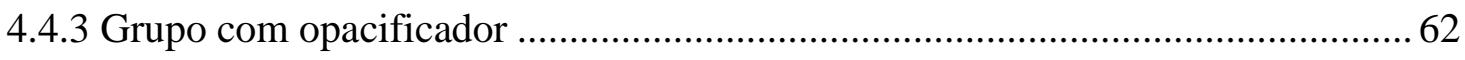

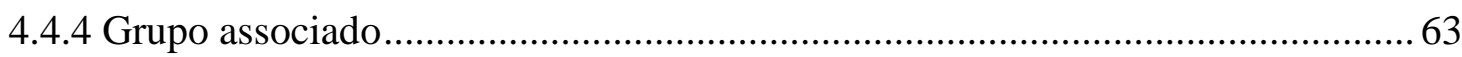

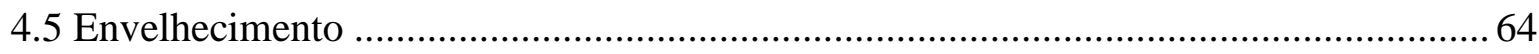

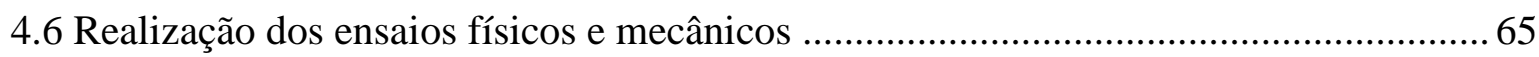

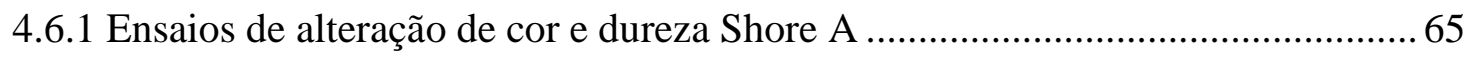

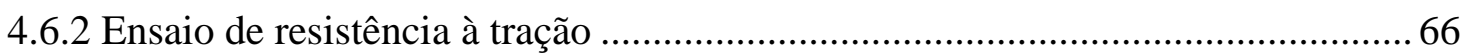

4.7 Ensaio de Microscopia Eletrônica de Varredura e Espectroscopia por Energia

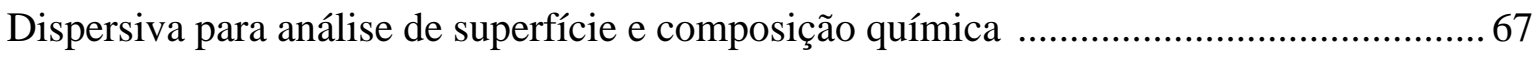

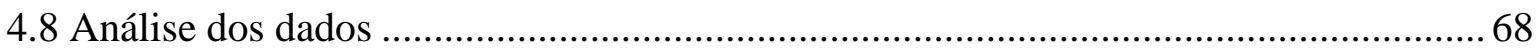

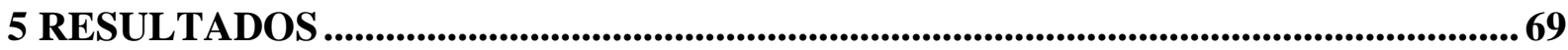

5.1 Resultados para as propriedades físico-mecânicas ...................................................... 70

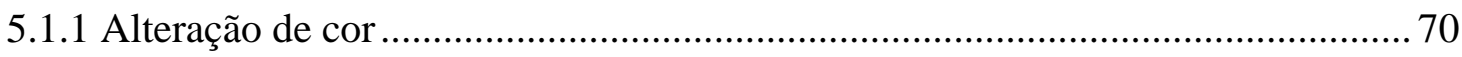

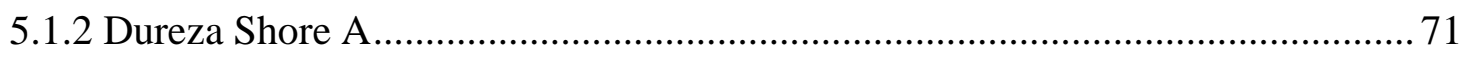

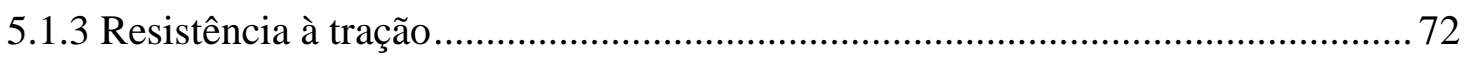

5.2 Resultados para as análises de superfície (MEV) e composição química dos silicones

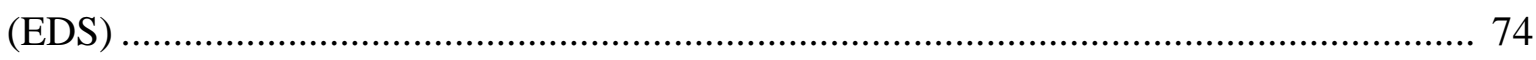

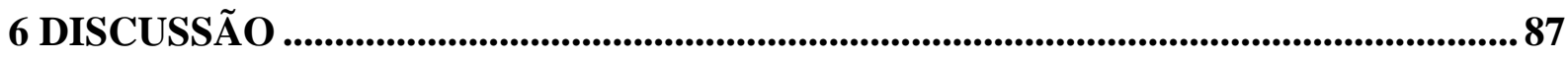

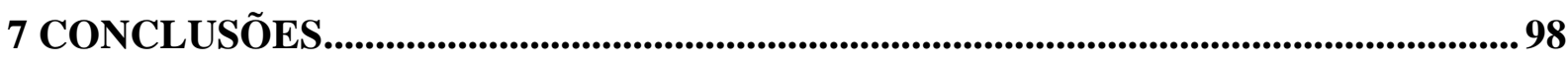

REFERÊNCIAS BIBLIOGRÁFICAS .............................................................................. 100

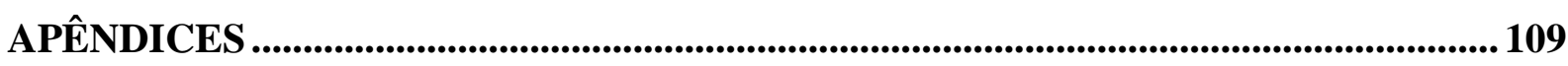


As deformidades bucomaxilofaciais causadas por traumas, oncocirurgias ou malformações congênitas provocam problemas estéticos e funcionais graves que, consequentemente estão associados a efeitos psíquicos, familiares e sociais. Com o objetivo de minimizar os danos aos indivíduos, a cirurgia plástica é o tratamento de escolha (Rezende, 1997; dos Santos et al., 2011). No entanto, mesmo com o avanço dos recursos técnicocirúrgicos, esta opção de tratamento pode ser contraindicada em virtude de mutilações muito extensas ou tratamentos radioterápicos, tornando a prótese bucomaxilofacial uma opção satisfatória para a reintegração social dos pacientes (Kiat-Amnuay et al., 2006; Eleni et al., 2009; dos Santos et al., 2010; Eleni et al., 2011).

A prótese bucomaxilofacial tem como objetivo restaurar perdas de substâncias e deformidades da região da cabeça e pescoço corrigindo a estética e as funções perdidas ou alteradas (Kiat-Amnuay et al., 2009; Kheur et al., 2012), melhorando a qualidade de vida dos pacientes (dos Santos et al., 2010; dos Santos et al. 2011; Nguyen et al., 2013). Pode ser considerada um tratamento acessível, de baixo custo e não invasivo (Hatamleh et al., 2011).

Ao longo do tempo, muitos materiais como madeira, marfim, cera e metais foram utilizados na confecção dessas próteses (Andres et al., 1992; Polyzois, 1999). Atualmente, os materiais mais comumente empregados incluem a resina termicamente ativada e o silicone (Guiotti; Goiato; dos Santos, 2010; Montgomery; Kiat-Amnuay, 2010; dos Santos et al., 2012; Pinheiro et al., 2014). Embora a resina acrílica tenha custo menor do que os silicones, as próteses faciais confeccionadas com materiais rígidos não mimetizam a consistência e textura dos tecidos perdidos prejudicando a estética e o conforto do indivíduo se comparadas àquelas confeccionadas com silicone, os quais apresentam textura e maciez que favorecem tais aspectos (Maida et al., 2011; dos Santos et al., 2012) e que, clinicamente, contribuem para o conforto e adaptação dos pacientes (Andres et al., 1992; dos Santos et al., 2010 Pinheiro et al., 2014).

Os silicones são materiais constituídos por uma repetição de unidades básicas de silício e oxigênio que formam cadeias cíclicas gerando compostos de alto peso molecular (Bell; Chalian; Moore, 1985). Pela variação no tamanho dessas cadeias, suas características podem variar desde uma consistência totalmente sólida, até um líquido viscoso, quimicamente inertes. Por serem desprovidos de átomos de carbono em sua cadeia principal, esses polímeros não são considerados orgânicos, embora apresentem radicais orgânicos importantes ligados ao átomo de silício, ou seja, grupo metila $\left(-\mathrm{CH}_{3}\right)$ nos metil-silicones e o fenila $\left(-\mathrm{C}_{6} \mathrm{H}_{5}\right)$ nos fenilsilicones. 
Podem ser classificados segundo a forma de polimerização em silicones polimerizados pelo calor (HTV) e silicones polimerizados em temperatura ambiente (RTV). O HTV é mais durável e resistente, apresenta as vantagens de uma excelente estabilidade térmica e propriedades físicas, juntamente com a estabilidade de cor em comparação com o RTV, mas exige uma técnica de manipulação muito mais sofisticada (Bell; Chalian; Moore, 1985; Lontz, 1990; Hatamleh et al., 2011). Apresentam biocompatibilidade, sendo bem tolerados pela mucosa e pele. São flexíveis e não condutores de calor e devido às suas propriedades químicas apresentam resistência à tração, durabilidade e facilidade de manipulação (Haddad et al., 2011; Kheur et al., 2012; Han; Powers; Kiat-Amnuay, 2013). No entanto, estas características podem ser alteradas quando do uso clínico do material em função dos hábitos pessoais do indivíduo, do clima (Polyzois; Eleni; Krokida, 2011a) e da adição de pigmentos que visam à obtenção de cor próxima a da região a ser restaurada.

Com relação à cor, uma prótese facial deve apresentar-se esteticamente agradável, imitando ou reproduzindo o órgão perdido de forma quase imperceptível àqueles que observam o portador dessas próteses (Guiotti; Goiato; dos Santos, 2010). Para que esse objetivo seja alcançado é necessário que se faça a coloração do material, uma vez que o silicone é incolor (Gary; Huget; Powell, 2001; Pinheiro et al., 2011). Segundo Rezende (1997), a coloração da prótese facial é formada por um conjunto de meios técnicos e artísticos empregados no sentido de imprimir à prótese a cor mais condizente com o matiz e tonalidade de pele do paciente, podendo ser obtida por meio da pigmentação intrínseca e/ou extrínseca do material. A coloração intrínseca é aquela obtida pelo acréscimo de pigmentos corantes ao material durante a fase de polimerização. Já a coloração extrínseca consiste na pintura da superfície da prótese, após a polimerização do material (Johnston et al., 1995; Khindria; Bansal; Kansal, 2009). Uma vantagem apreciável do silicone é permitir uma coloração intrínseca pela adição de pigmentos modificadores de cor durante o preparo, antes da aplicação do agente catalisador, já que a pintura da prótese depois de vulcanizada apresenta limitações e o resultado nem sempre é satisfatório (Johnston et al., 1995; Al-Dharrab; Tayel; Abodaya, 2013).

Comercialmente, podem ser encontrados diferentes tipos de pigmentos para pigmentações intrínsecas e extrínsecas dos materiais utilizados para confecção das próteses faciais, sejam eles à base de resina acrílica ou de silicone. Os pigmentos podem ser classificados de acordo com a cor e origem de seu componente principal. O termo "orgânico" pode ser aplicado ao pigmento de origem animal, vegetal ou a pigmentos orgânicos sintéticos. 
Por outro lado, o termo "inorgânico" pode ser aplicado a pigmentos de terra natural, de terra natural calcinada ou de origem sintética (Yu; Koran; Craig, 1980a; Mayer, 1991).

Além de pigmentos corantes, a literatura tem estudado a adição de opacificadores ao silicone com o objetivo de aumentar sua durabilidade, diminuir a degradação e reduzir a instabilidade de cor bloqueando a radiação ultravioleta (Tran; Scarbecz; Gary, 2004; KiatAmnuay et al., 2006; Han et al., 2010; Haddad et al., 2011). Existem vários opacificadores comumente utilizados, cada um com diferentes tonalidades que podem afetar a coloração desses elastômeros de maneiras diferentes (Kiat-Amnuay et al., 2006; Kiat-Amnuay et al., 2009; Goiato et al., 2009a; Han; Powers; Kiat-Amnuay, 2013; Nguyen et al., 2013; Bangera; Guttal, 2014) resultando em próteses com uma maior intensidade de cor (Kiat-Amnuay et al., 2006), exigindo maior habilidade do protesista. Entre os opacificadores utilizados pode-se encontrar o sulfato de bário $\left(\mathrm{BaSO}_{4}\right)$ que consiste em um pó branco, insolúvel em água e fluidos orgânicos, utilizado em loções de proteção solar criando uma barreira física contra os raios UV e proporcionando uma melhor aparência do produto (Janousek, 1997). Também é usado na indústria para atingir a cor branca em tintas, vidros e papéis fotográficos. $\mathrm{Na}$ odontologia, é usado como um opacificador de cimentos endodônticos e na medicina como contraste radiológico (Goiato et al., 2011). Embora estudos tenham sido desenvolvidos associando-se o silicone com o sulfato de bário (Goiato et al., 2010a; Goiato et al., 2010b; dos Santos et al., 2011; Goiato et al., 2011; Haddad et al., 2011), sua influência nas propriedades físicas e mecânicas ainda não foi completamente esclarecida.

A dureza e resistência à tração (Saboya et al., 1997) são propriedades que podem sofrer alterações após a incorporação de pigmentos (Yu; Koran; Craig, 1980a; Goiato et al., 2008). A dureza é indicativa da textura e mede a flexibilidade do material (Saboya et al., 1997; Guiotti; Goiato; dos Santos, 2010) e deve situar-se entre 25 a 35 unidades Shore A (Lewis; Castleberry, 1980; Guiotti; Goiato, 2008). Já a resistência à tração é a mais elevada quantidade de tensão que um material pode suportar antes de falhar (Nguyen et al., 2013). Esta propriedade é de extrema importância, pois confere resistência global ao material, além de ser indicativa da sua durabilidade clínica (Rowe; Forrest, 1978; Aziz, 2003a; Hatamleh; Watts, 2010; Nguyen et al., 2013).

Com relação às características ambientais que podem causar degradação do silicone, as principais são a luz solar (exposição aos raios ultravioleta), temperatura, umidade, vento, poeira e poluentes e vários estudos tem considerado métodos artificiais de envelhecimento para a avaliação do silicone. A literatura cita termociclagem (Kulak-Ozkan et al., 2003; 
Ribeiro Pinto et al., 2004; Hermann et al., 2008, Pinheiro et al., 2011), envelhecimento por luz artificial (Craig et al., 1978; Seluk et al., 1987; Han et al., 2010) e envelhecimento por luz natural (Takamata et al., 1989; Haug et al., 1992; Eleni et al., 2011; Polyzois; Eleni; Krokida, 2011a; Polyzois; Eleni; Krokida, 2011b). Para uma prótese facial, acredita-se que todos esses métodos de avaliação sejam pertinentes uma vez que estará sob a ação da temperatura e sob a ação do meio ambiente (luz do sol e orvalho noturno). No entanto, a metodologia de avaliação é variada.

A estabilidade das propriedades físicas e mecânicas é essencial para a escolha do material para a confecção de próteses bucomaxilofaciais. Vários estudos foram propostos para obtenção de um material ideal, estudos estes que avaliaram silicones já comercializados (Aziz et al. 2003a; Kiat-Amnuay et al., 2009; Haddad et al., 2011; Han; Powers; Kiat-Amnuay, 2013), experimentais (Craig; Koran; Yu, 1980; Lai et al., 2002; Bellamy et al., 2003; Turner et al., 1984; Wolfaardt et al. 1985,) e modificados (Udagama; Drane, 1982; Aziz et al., 2003b; Karayazgan et al., 2003) e ainda não há um material que preencha todos os requisitos listados por Bulbulian (1945), como biocompatibilidade, flexibilidade, leveza, translucidez, baixa condutibilidade térmica, durabilidade, amoldabilidade, fácil duplicação, boa caracterização e facilidade de higiene.

Assim, considerando os efeitos psicológicos e sociais das falhas das próteses bucomaxilofaciais aos pacientes que delas precisam, é necessário o estudo de novos materiais, potencialmente indicados para confecção dessas próteses quando submetidos a diferentes protocolos de pigmentação e envelhecimento. A associação entre opacificadores e agentes pigmentantes, tais como pó de maquiagem (Goiato et al., 2009a; Maida et al., 2011; Pesqueira et al., 2011; Pinheiro et al., 2011; Pinheiro et al., 2014), poderia ser sugerida e avaliada.

Como um novo material, este estudo propõe a análise de um silicone indicado para reabilitação de membros amputados, o qual apresenta-se como sendo um material resistente, passível de pigmentação e com grande durabilidade, com o intuito de obtermos uma opção de material nacional com custo acessível. 


\section{Revisão de Líteratura}


Craig et al. (1978) avaliaram a estabilidade de cor de elastômeros para prótese bucomaxilofacial em condições de envelhecimento acelerado com o objetivo de compreender as razões do fracasso no ambiente de serviço. Três categorias de materiais foram avaliadas: um cloreto de polivinil plastificado (Prototype III), um poliuretano (Epithane) e quatro silicones, três vulcanizados a temperatura ambiente (Silastic 382, Silastic 399, e Silastic 44210, Dow Coming Corporation, Midland, MI) e um vulcanizado pelo calor (Silastic 4-4515, Dow Corning Corp., Midland, MI). Cinco amostras de cada material foram confeccionadas e a cor inicial foi avaliada por espectrofotometria de refletância. Em seguida, as amostras foram levadas a uma câmara de envelhecimento acelerado artificial e nova análise de cor, exceto do poliuretano, foi realizada após 100, 300, 600 e 900 horas de envelhecimento. O intemperismo do poliuretano foi interrompido após 300 horas devido a uma grave deterioração. A comparação das médias foi realizada pelo cálculo dos intervalos de Tukey. O cloreto de polivinil apresentou clareamento depois de 100 horas de envelhecimento. O poliuretano teve a intensidade de cor ligeiramente aumentada, no entanto, o principal problema foi a severa degradação das suas propriedades mecânicas com o envelhecimento após 300 horas. Todos os materiais apresentaram boa estabilidade de cor, porém o silicone 44210 aparentou ter as melhores propriedades globais. A seleção do silicone vai depender da opacidade desejada, das propriedades físicas e mecânicas e se a polimerização pelo calor ou química é desejada. Todas as alterações de cor observadas foram pequenas, considerando os problemas com a manutenção da estética dessas próteses em ambiente de serviço.

Koran et al. (1979) avaliaram a estabilidade cromática de 11 pigmentos minerais usados em próteses bucomaxilofaciais. Os espécimes foram confeccionados com o silicone MDX 4-4210 (Dow Corning, USA), contendo os diferentes pigmentos, e submetidos ao envelhecimento acelerado por 900 horas em uma câmara de envelhecimento, com umidade e temperatura controlada. Um espectrofotômetro de reflexão foi utilizado para as mensurações e todos os pigmentos demonstraram alterações significantes em ao menos um parâmetro de cor. 7 pigmentos (sombra escura, marrom médio, marrom leve, marrom vermelho, preto, vermelho e azul) apresentaram pequenas alterações de cor; 1 pigmento (laranja leve) demonstrou alteração moderada de cor após o envelhecimento e, por fim, 3 pigmentos (branco, amarelo e laranja-amarelo) apresentaram pouca estabilidade cromática. Os autores concluíram que os dados não foram correspondentes às observações clínicas de alteração de cor pertinentes ao longo do tempo de uso das próteses. 
Yu, Koran e Craig (1980a) avaliaram um elastômero pigmentado quando submetido ao envelhecimento artificial acelerado utilizando uma câmara de intemperismo. Silastic 44210 foi pigmentado com 11 pigmentos (branco (W), amarelo (Y), bege escuro (DBF), marrom médio $(\mathrm{MB})$, marrom claro $(\mathrm{LB})$, marrom avermelhado $(\mathrm{RB})$, preto $(\mathrm{Bl})$, vermelho $(\mathrm{R})$, azul (Bu), laranja claro (LO) e laranja amarelado (OY)). Todos os pigmentos foram incorporados ao silicone a $0,2 \%$ em peso e manipulados de acordo com as orientações do fabricante. Amostras controle foram preparadas e testadas juntamente com as amostras pigmentadas para comparação. Os valores da resistência máxima à tração, máximo alongamento (\%), força de cisalhamento, dureza Shore A e deformação permanente foram determinados antes e depois do envelhecimento por 900h. Os resultados indicaram que a incorporação dos pigmentos alterou as propriedades físicas e mecânicas do elastômero de silicone. O envelhecimento acelerado não teve efeito sobre a combinação de pigmentos e elastômero. A adição de pigmentos pode variar as propriedades físicas e mecânicas de um material bucomaxilofacial, no entanto, as mudanças observadas neste estudo, não foram grandes o suficiente para comprometer a utilização clínica do material, já que as propriedades das amostras sofreram pouca ou nenhuma alteração depois de 900 horas de envelhecimento.

Bell, Chalian e Moore (1985) compararam as propriedades físicas de silicones experimentais (Q7-4635, Q7-4650, Q7-4735 e SE-452JU) com silicones rotineiramente utilizados - controle (MDX 4-4210 e MDX 4-4514) com o objetivo de encontrar materiais mais aceitáveis para aplicação bucomaxilofacial. Resistência à tração e ao rasgamento, alongamento e dureza foram mensuradas imediatamente após a obtenção dos espécimes. A resistência à tração dos materiais experimentais foi significativamente maior do que os materiais controle, com exceção do MDX 4-4515 e Q7-4635. A resistência ao rasgamento apresentou diferenças significativas entre todos os materiais, exceto Q7-4635 e SE-4525U. Com exceção do MDX-4-4515, os silicones experimentais apresentaram maior alongamento do que os materiais controle. A análise de dureza não revelou nenhuma diferença significativa entre MDX-4-4515, Q7-4650 e SE-4524U, ou entre Q7-4635 e Q7-4735. No entanto, houve diferença significativa nos valores de dureza para os dois grupos de materiais. Embora todos os materiais tenham ficado dentro de um intervalo de aceitabilidade clínica, os materiais controle, exibiram um maior grau de maciez. Em geral, as propriedades físicas dos materiais experimentais foram superiores a dos materiais controle, particularmente em termos de resistência e alongamento. 
Haug, Moore e Andres (1999) avaliaram a resistência ao rasgamento, alongamento, resistência à tração e dureza de polímeros (adesivo Silastic tipo A, Silastic 4-4210 e A-2186) combinados com pigmentos em função da passagem do tempo e exposição às intempéries ambientais. Foram utilizados espécimes em forma de halteres $(n=15)$ para avaliar a resistência à tração e alongamento e em forma de calças $(n=15)$ para medir a dureza e resistência ao rasgamento. 540 amostras foram distribuídas em 6 combinações de corantes (pigmentos de terra seca, fibra de rayon, tintas a óleo, caulino, cosmético facial líquido e sem corante) e envelhecimentos (controle - avaliados dentro de 1 mês de fabricação, passagem do tempo e envelhecimento natural). $\mathrm{O}$ grupo que sofreu a passagem do tempo foi selado em recipientes de vidro e mantido no escuro e o que sofreu envelhecimento natural foi colocado no telhado da faculdade, ambos durante 6 meses para posterior realização dos ensaios. O efeito da exposição à ação do tempo indicou que as propriedades de uma prótese podem sofrer alterações com o tempo de uso clínico. Houve alteração das propriedades físicas tanto nas amostras pigmentadas como nas amostras sem pigmento que foram mantidas em recipientes fechados e no escuro.

Haug, Andres e Moore (1999) avaliaram a densidade óptica e a cor de diferentes combinações entre corantes e silicones (adesivo Silastic tipo A, Silastic 4-4210 e A-2186) para próteses bucomaxilofaciais, quando expostos ao envelhecimento natural. Os espécimes ( $n=270 ; 90$ de cada material) foram divididos em 6 grupos em função do corante: pigmentos de terra seca, fibras de rayon, tinta a óleo, caulino, cosmético facial líquido e sem corante. Cada grupo foi exposto a 3 condições: controle - avaliados dentro de 1 mês de fabricação, envelhecimento natural e passagem de tempo. O grupo passagem do tempo foi selado em recipiente de vidro e mantido no escuro e o grupo de envelhecimento natural foi colocado no telhado da faculdade, ambos por 6 meses. Os autores concluíram que o envelhecimento, bem como a adição de pigmentos alteraram as propriedades ópticas e de cor dos silicones. Os corantes inorgânicos (pigmentos de terra seca, caulino, tinta a óleo e cosmético líquido) foram os mais estáveis ao longo do tempo, ao passo que o corante orgânico (fibras de rayon) foi o menos estável.

Gary, Huget e Powell (2001) avaliaram as alterações de cor quando três pigmentos (um pigmento inorgânico natural, siena queimado; e dois pigmentos orgânicos sintéticos, amarelo Hansa e vermelho alizarina) foram incorporados individualmente ao silicone A-2186 (Fator II, Inc). Foram estabelecidos 8 grupos $(n=10)$ : grupos 1 e 2 - controle: espécimes sem pigmento; grupos 3 e 4: espécimes com pigmento siena queimado; grupos 5 e 6: espécimes 
com pigmento amarelo Hansa e grupos 7 e 8: espécimes com pigmento vermelho alizarina. Os grupos ímpares foram levados a um local de teste em Miami, na Flórida, enquanto que os grupos pares foram para Phoenix, Arizona. Um espectrofotômetro (Technidyne Corp, New Albany, Indiana.) foi usado para determinar o parâmetro de cor antes e após a exposição dos espécimes às ações do tempo. Os espécimes receberam exposições de luz solar de 1.305,7 $\mathrm{MJ} / \mathrm{m}^{2}$ em Maimi e 1.310,2 MJ/m² em Phoenix, respectivamente, por aproximadamente 3 meses. As alterações de cor dos espécimes que permaneceram no Arizona foram significativamente maiores do que a dos espécimes da Flórida e as diferenças variaram de 0,4 (grupo vermelho alizarina) para 2,36 unidades dos 2 grupos controle não pigmentados. Este estudo forneceu dados comparativos úteis sobre as alterações de cor de um elastômero bucomaxilofacial específico, seja não pigmentado ou pigmentado. Futuras pesquisas sobre mudanças de cor em elastômeros bucomaxilofaciais e seus respectivos agentes de coloração em diferentes regiões são necessárias.

Kiat-Amnuay et al. (2002) avaliaram o efeito da adição de opacificadores em diferentes proporções, na estabilidade de cor do silicone A-2186, antes e após envelhecimento acelerado. Foram confeccionados 60 grupos $(n=5)$ do elastômero combinando 4 opacificadores (caulino da Geórgia em pó, caulino calcinado em pó, Artskin branco e pigmento seco branco de titânio) em diferentes concentrações $(5 \%, 10 \%, 15 \%)$ com 1 dos 5 pigmentos [nenhum pigmento (controle), vermelho, amarelo ocre, siena queimado, e uma mistura de todos os pigmentos]. Os espécimes foram colocados em uma câmera de envelhecimento artificial e expostos à luz, spray de água, temperaturas flutuantes e umidade e, então avaliados por espectrofotometria. A mistura de pigmentos com opacificadores não protegeu o silicone da degradação de cor ao longo do tempo, especialmente no caso do pigmento vermelho, que teve um efeito significativo em todos os grupos. O grupo em que os pigmentos foram misturados com Artskin branco $10 \%$ apresentou as menores alterações de cor ao longo do tempo, seguido pelos grupos em que os pigmentos foram misturados com pigmento seco branco de titânio $10 \%$, caulino calcinado em pó $10 \%$ e caulino da Georgia 5\%. O pigmento amarelo ocre foi o mais estável ao longo do tempo.

Leow et al. (2002) avaliaram a descoloração de próteses de mão e bucomaxilofaciais confeccionadas em silicone. 21 pigmentos (suspensões, pastas e pigmentos secos) foram testados quando expostos a 9 meses de envelhecimento por luz ultravioleta, diferentes temperaturas (ambiente, $35^{\circ} \mathrm{C}$ e $50^{\circ} \mathrm{C}$ ) e diferentes soluções salinas $(0,15 \mathrm{M}$ e $5,0 \mathrm{M})$. Ao final do experimento, os autores concluíram que a descoloração foi significativa quando os 
pigmentos foram expostos à luz ultravioleta; em relação à temperatura, os pigmentos expostos a uma temperatura elevada de $50^{\circ} \mathrm{C}$ mostraram a maior alteração de cor; a imersão dos pigmentos em solução salina não provocou alteração de cor significativa e os pigmentos em suspensão apresentaram a menor alteração de cor quando comparados aos pigmentos em pasta ou secos.

Aziz, Waters e Jagger (2003a) analisaram uma série de propriedades clinicamente importantes para os materiais bucomaxilofaciais disponíveis comercialmente, a fim de ajudar na concepção de um novo material. Os materiais utilizados foram: Cosmesil high compliance (HC), Cosmesil standard (St), A-2186 (Factor II), Premium facial and body elastomer (Prestige) e MED-4920 (Nusil). As variáveis avaliadas foram dureza, resistência à tração, resistência ao rasgamento, absorção de água e ângulo de contato dinâmico. A resistência ao rasgamento dos silicones Fator II, Cosmesil HC e Nusil foi significativamente maior do que a dos silicones Cosmesil St e Prestige $(\mathrm{p}<0,001)$. Nusil apresentou resistência à tração e alongamento significativamente maior dos que os demais materiais $(\mathrm{p}<0,001)$ e Cosmesil St e Cosmesil HC foram significativamente mais duros $(\mathrm{p}<0,001)$. Fator II apresentou a menor absorção de água enquanto Prestige e Cosmsesil St apresentaram absorção significativamente maior em comparação aos outros materiais. Os autores concluíram que nenhum dos materiais de silicone disponíveis comercialmente apresentou propriedades ideais. Fator II, no entanto, mostrou propriedades mais favoráveis devido à sua alta resistência à tração, maciez e facilidade de manipulação.

Tran, Scarbecz e Gary (2004) avaliaram a estabilidade de cor de um silicone RTV (A2186; Factor II Inc, Lakeside, Arizona), pigmentado ou não (pigmento inorgânico natural siena queimado ou pigmentos orgânicos sintetizados, amarelo Hansa e vermelho de alizarina), quando misturado a 2 protetores contra a ação de raios ultravioletas. As amostras $(n=160)$ foram fabricadas e expostas às intempéries locais em Miami e Phoenix por aproximadamente 3 meses. As leituras de cor foram obtidas antes e após o envelhecimento a partir de um espectrocolorímetro. Os autores concluíram que os protetores dermatológicos adicionados às amostras retardaram a alteração cromática das amostras, nas circunstâncias experimentais do estudo.

Mancuso et al. (2005) realizaram uma revisão de literatura sobre estudos que avaliaram a alteração da cor dos materiais utilizados em próteses bucomaxilofaciais em função da pigmentação e do envelhecimento. Dentre os materiais estudados, o silicone Silastic MDX 4-4210 apresentou os melhores resultados de estabilidade de cor, sendo 
considerado como um ótimo material. A pigmentação intrínseca resultou em menor alteração de cor bem como o envelhecimento ao ar livre quando comparado ao envelhecimento acelerado. Segundo os autores, novas pesquisas sobre as propriedades dos materiais são necessárias em função da diversidade de materiais e pigmentos disponíveis nos diferentes países e da falta de padronização dos ensaios.

Kiat-amnuay et al. (2006) avaliaram os efeitos de pigmentos a óleo e opacificadores (a $5 \%, 10 \%$ e $15 \%$ ) na estabilidade de cor de um elastômero bucomaxilofacial médico MDX44210/tipo A antes e após o envelhecimento artificial. Na primeira parte do estudo, cada 1 dos opacificadores (pó neutro de caulino da Geórgia, caulino calcinado em pó, Artskin branco, pigmento seco branco de titânio (Ti), ou tinta a óleo cor Ti branco) a 10\% foram combinados com cada pigmento (sem pigmento, cádmio-bário vermelho profundo, amarelo ocre, siena queimado, ou uma mistura dos três pigmentos) formando 25 grupos experimentais. $\mathrm{Na}$ segunda parte do estudo, 50 grupos experimentais foram formados pela combinação de 1 dos 5 opacificadores nas concentrações de $5 \%$ ou $15 \%$ e 1 dos 5 pigmentos como na Parte 1 . As amostras foram colocadas em câmara de envelhecimento artificial e a alteração de cor $\left(\Delta \mathrm{E}^{*}\right)$ foi avaliada por espectrofotômetro. Os resultados indicaram que a tinta a óleo a 5\%, 10\% e $15 \%$ apresentou a maior alteração de cor enquanto os demais não foram significativamente diferentes uns dos outros. Em geral, a alteração de cor do Artskin branco a 5\% foi menor do que a $15 \%$, enquanto que o pigmento seco branco de Ti a $15 \%$ apresentou menor alteração que a $5 \%(\mathrm{p}<0,001)$. As concentrações de $5 \%$ e $15 \%$ dos demais opacificadores não foram significativamente diferentes. Dentro das limitações deste estudo, os autores concluíram que a associação de pigmentos à maioria dos opacificadores ajudou a proteger o silicone MDX44210 da degradação de cor ao longo do tempo. O pigmento seco branco de Ti foi o mais estável ao longo do tempo, seguido, em ordem, pelos pigmentos misturados com caulino calcinado em pó, caulino da Georgia, Artskin branco e tinta a óleo cor Ti branco.

Han et al. (2008) investigaram os efeitos da incorporação de partículas de óxidos nanométricos $\left(\mathrm{TiO}_{2}, \mathrm{ZnO}\right.$, ou $\left.\mathrm{CeO}_{2}\right)$ ao silicone A-2186. A hipótese nula foi que as propriedades mecânicas do silicone não seriam afetadas pela adição de nano-óxidos. As variáveis analisadas foram resistência à tração, alongamento, resistência ao rasgamento (máquina universal de ensaios, AG Series-50NJ; Shimadzu Corp, Kyoto, Japão) e dureza (durômetro do tipo Shore A, Shore Instrument \& Mfg Co, Jamaica, NY). 18 grupos foram formados combinando o silicone com várias concentrações dos três nano-óxidos: 0,5\%, 1,0\%, $1,5 \%, 2,0 \%, 2,5 \%$ e $3,0 \%$, as quais estão dentro da gama de $0 \%$ a $3 \%$ recomendada pelo 
fabricante dos nano-óxidos (Nanostructured Materials \& Amorfo, Inc, Houston, Texas). Uma amostra sem adição de nano-óxidos serviu como grupo controle. 5 amostras em forma de haltere de cada combinação foram confeccionadas para avaliar a resistência à tração e alongamento e 5 em forma de calça, para avaliar a resistência ao rasgamento e dureza. Um microscópio eletrônico de varredura (S-3400; Hitachi, Tóquio, Japão) foi utilizado para observar a superfície das secções de tração. Os grupos de todos os nano-óxidos a 2,0\% e 2,5\% apresentaram valores de resistência à tração e ao rasgamento e alongamento percentual maiores do que o grupo controle $(\mathrm{p}<0,001) . \mathrm{CeO}_{2}$ mostrou resistência à tração significativamente menor do que $\mathrm{TiO}_{2}$ e $\mathrm{ZnO}(\mathrm{p}<0,05)$. O grupo de $\mathrm{ZnO}$ apresentou resistência ao rasgamento maior do que os demais $(\mathrm{p}<0,05)$. A maioria das amostras tornou-se um pouco mais dura quando comparadas com o grupo controle. $\mathrm{O}$ grupo $\mathrm{CeO}_{2}$ apresentou dureza maior do que $\mathrm{TiO}_{2}$ e $\mathrm{ZnO}(\mathrm{p}<0,001)$. Não houve diferença significativa do percentual de alongamento entre os tipos de nano-óxidos. A análise de MEV indicou que todos os nanoóxidos se distribuíram uniformemente ao longo das amostras de silicone, com exceção dos grupos a 3,0\%, que ficaram parcialmente aglomerados. A adição de partículas de nano-óxidos ao elastômero de silicone melhorou as propriedades mecânicas avaliadas quando as concentrações variaram entre $2,0 \%$ e $2,5 \%$.

Eleni, Krokida e Polyzois (2009) investigaram os efeitos do envelhecimento artificial por radiação de luz ultravioleta sobre a estrutura e propriedades mecânicas e térmicas de três tipos de polidimetilsiloxanos comerciais (Elastomer 42 - A, Tech-Sil 25 - B e Cosmesil M511 - C) e de um polietileno clorado experimental (CPE - D). 8 amostras de cada material para sete períodos de avaliação diferentes $(8,24,48,72,120,168$ e 216h) foram colocadas em uma câmara de envelhecimento artificial. Os ensaios de compressão e tração foram realizados (Máquina de Teste Universal Zwick, Z2.5/TN1S, Alemanha) com velocidade de $5 \mathrm{~mm} / \mathrm{min}$. O ensaio de dureza foi realizado com durômetro Shore A (CV-DSAS001, Maastricht, Países Baixos). As mensurações foram obtidas 1 semana após a confecção (controle) e ao final do tempo de exposição. Medidas de calorimetria diferencial de varredura (DSC) foram realizadas (PerkinElmer aDiamond DSC) para avaliar a temperatura de transição vítrea. Os resultados mostraram diferenças significativas no comportamento mecânico como resultado da fotodegradação que ocorre devido ao envelhecimento acelerado. Os materiais A e $\mathrm{B}$ apresentaram aumento da dureza e resistência à tração e compressão, contrariamente aos materiais $\mathrm{C}$ e $\mathrm{D}$. 
Eleni et al. (2009) avaliaram os efeitos do envelhecimento natural (exposição às condições ambientais) sobre o comportamento mecânico de quatro elastômeros protéticos. Modelos matemáticos, com parâmetros físicos, foram utilizados para cada propriedade medida, a fim de correlacionar os dados experimentais com o tempo de radiação solar. Foram avaliados 3 silicones: Elastomer 42 (A); TechSil S25 (B); Cosmesil M511 (C); e um polietileno clorado (D). 20 espécimes retangulares $(15 \times 20 \times 35 \mathrm{~mm})$ foram confeccionados para análise de compressão e dureza, e 20 em forma de haltere tipo II para análise de tração. Os espécimes foram expostos às condições ambientais sobre o telhado da Universidade Aristóteles de Tessalônica durante 1 ano. Os ensaios de compressão (ASTM D 395-03) e tração (ASTM D 412/05) foram realizados utilizando uma máquina universal de ensaios (Zwickmodel Z2.5/TN1S, Alemanha), com taxa de deformação constante de $5 \mathrm{~mm} / \mathrm{min}$. Os testes de dureza foram realizados com o durômetro Shore A digital (CV-DSAS001, Maastricht, Países Baixos) de acordo com a norma ASTM D 2240-05. Alterações foram observadas nas propriedades mecânicas de todos os materiais à medida que o tempo de radiação solar foi aumentando. Os dois polidimetilsiloxano, A e B, tornaram-se mais duros devido à foto-oxidação, contrariamente ao silicone $\mathrm{C}$ e ao polietileno clorado $\mathrm{D}$, os quais se tornaram mais macios.

Goiato et al. (2009a) verificaram a estabilidade de cor de 2 silicones para uso em próteses bucomaxilofaciais sob a influência da desinfecção e tempo de armazenamento. 28 espécimes foram obtidos e divididos em 4 grupos (n=7): Grupo 1 -Silastic MDX 4-4210 desinfetado com comprimidos efervescentes Efferdent; Grupo 2 - Silastic MDX-4-4210 desinfetado com sabão neutro; Grupo 3 - Silastic 732 RTV desinfetado com comprimidos efervescentes Efferdent e Grupo 4 - Silastic 732 RTV desinfetado com sabão neutro. O teste de estabilidade da cor foi realizado com espectrofotômetro e os dados foram calculados de acordo com o método CIE L*a*b*. Todos os espécimes foram armazenados num recipiente de plástico, sem cobertura, em ambiente com temperatura controlada durante 60 dias, recebendo luz artificial. Os espécimes foram desinfetados diariamente com sabão neutro e água (grupo controle) ou com Efferdent, 3 vezes por semana. Após os períodos de desinfecção e armazenamento, uma nova leitura foi realizada. Os dados foram comparados por Análise de variância (ANOVA), seguido pelo teste de Tukey com 1\% de confiabilidade. Os autores concluíram que os fatores tempo de armazenamento e desinfecção com Efferdent influenciaram a estabilidade de cor. A desinfecção atua como um agente clareador em materiais de silicone. 
Goiato et al. (2009b) avaliaram a dureza Shore A e a rugosidade de 2 silicones para uso em prótese bucomaxilofacial sob a influência da desinfecção química e do tempo de armazenamento em temperatura ambiente. 28 espécimes foram divididos em 4 grupos $(n=7)$ : Grupo 1 - MDX Silastic 4-4210 desinfetado com comprimidos efervescentes; Grupo 2 - MDX Silastic 4-4210 desinfetado com sabão neutro; Grupo 3 - Silastic 732 RTV desinfetado com comprimidos efervescentes e Grupo 4 - Silastic 732 RTV desinfetado com sabão neutro. A dureza Shore A foi avaliada por durômetro digital (GSD 709 Teclock, Osaka, Japão) e a rugosidade da superfície, por rugosímetro digital portátil (modelo RP100, Tonka Sul Americana Ltda., Amparo, SP, Brasil). Todos os espécimes foram armazenados num recipiente de plástico sem tampa em ambiente com temperatura controlada $\left(23 \pm 2^{\circ} \mathrm{C}\right)$ durante 60 dias, recebendo luz artificial. Os espécimes foram desinfetados diariamente com sabão neutro pH e água (grupo controle) ou com comprimidos Efferdent 3 vezes por semana. Após a desinfecção e período de armazenamento, novas leituras foram realizadas. O tempo de armazenamento influenciou $(\mathrm{p}<0,01)$ as propriedades de dureza e rugosidade dos materiais. MDX 4-4210 (28,59 Shore A, 0,789 Ra) apresentou valores mais elevados do que o Silastic 732 RTV (18,08 Shore A, 0,656 Ra) para ambas as propriedades. No que diz respeito ao período de desinfecção, não houve diferença significativa em qualquer um dos materiais testados.

Kiat-amnuay et al. (2009) avaliaram a estabilidade de cor do elastômero de silicone bucomaxilofacial A-2000 em função da adição de pigmentos, diferentes concentrações de opacificadores e do envelhecimento. A hipótese nula foi que o envelhecimento artificial não influenciaria na cor do silicone, independentemente dos pigmentos e opacificadores utilizados. 75 grupos $(\mathrm{n}=5)$ combinaram 4 opacificadores (caulino da Geórgia - GR; caulino calcinado - Ck; branco Artskin - Aw; pigmento seco branco de titânio - Td) em diferentes concentrações $(5 \%, 10 \%$ e 15\%) e pigmento branco de silicone ( $\mathrm{Sw}$ ) com 1 dos 5 pigmentos (sem pigmento - controle, vermelho, amarelo, siena queimado e uma mistura de vermelho + amarelo + azul). As leituras de cor por espectrofotômetro foram realizadas antes e após o envelhecimento das amostras em câmara de envelhecimento artificial (Ci35 Weather-Ometer; Atlas Electronics, Chicago, IL). O pigmento amarelo associado com todos os opacificadores aumentou os valores de $\Delta \mathrm{E}^{*}$ de 0,7-2,1 até 3,8-10,3. As menores diferenças de cor foram observadas para os grupos opacificadores: Gk 5\%, e Td e Aw 10\% e 15\%. No geral, Td 15\% exibiu a menor alteração, ao passo que $\mathrm{Ck} 5 \%$ exibiu alteração de cor mais acentuada após o envelhecimento artificial. Todos os valores de $\Delta \mathrm{E}^{*}$ estavam abaixo do limiar de aceitação, 
indicando estabilidade de cor aceitável. As alterações de cor para Aw e Td a $10 \%$ e $15 \%$ foram abaixo do limiar de perceptibilidade, indicando uma excelente estabilidade de cor. Os autores concluíram que os pigmentos de silicone misturados com 10\% e 15\% dos opacificadores Artskin branco e pigmento seco branco de titânio protegeram o silicone A2000 da degradação de cor ao longo do tempo. O pigmento amarelo afetou significativamente a estabilidade da cor de todos os opacificadores especialmente do pigmento branco de silicone e caulino calcinado.

Mancuso, Goiato e dos Santos (2009) avaliaram a estabilidade de cor do silicone Silastic MDX4-4210 (próprio para prótese bucomaxilofacial) e do Silastic 732 (desenvolvido para uso industrial) pigmentados ou não, após o envelhecimento acelerado. Para pigmentação intrínseca foram utilizados pó de maquiagem, pó cerâmico e óxido de ferro em quantidade equivalente a $0,2 \%$ do peso do silicone. 24 amostras foram distribuídas em três grupos em função do agente de pigmentação. A análise de cor (espectrofotômetro de reflexão, modelo UV-2450, Shimadzu, Kyoto, Japão) foi realizada antes e após 163, 351, 692 e 1000 horas de exposição dos espécimes ao envelhecimento artificial em câmara de envelhecimento para amostras não-metálicas, usando luz UV-B/condensação. Todos os materiais apresentaram algum tipo de alteração cromática $(\Delta \mathrm{E}>0)$, independentemente do período de tempo analisado. As amostras de ambos os silicones sem pigmentação apresentaram os menores valores de alteração de cor após 1.000 horas de envelhecimento. Não foram encontradas diferenças significativas entre os diferentes períodos de envelhecimento para as amostras pigmentadas com pó cerâmico, independentemente do silicone usado. No entanto, foi observada diferença significativa entre os valores de alteração de cor para as amostras de ambos os silicones pigmentadas com pó de maquiagem. Os autores concluíram que os dois silicones apresentaram instabilidade de cor durante os diferentes períodos de tempo analisados. Os materiais sem a incorporação de pigmentos apresentaram valores semelhantes de alteração de cor e não diferiram estatisticamente. O pó de maquiagem usado neste estudo foi o pigmento que mais alterou a cor das amostras.

Dos Santos et al. (2010) avaliaram a estabilidade de cor de resinas acrílicas e de um silicone para próteses bucomaxilofaciais após envelhecimento acelerado artificial. 10 amostras de cada material foram fabricadas com a associação de pigmentos e distribuídas em 6 grupos $(n=10)$ : Rapidaflex, Lentaflex, Classico incolor, Classico pigmentada, Silastic incolor e Silastic pigmentado. As resinas acrílicas Lentaflex e Rapidaflex apresentam pigmentos orgânicos e inorgânicos. Considerando-se que o silicone e a resina acrílica Classico 
são incolores, dois pigmentos diferentes foram misturados com os materiais: pó de maquiagem, como pigmento orgânico e pó cerâmico, como pigmento inorgânico. A pigmentação seguiu a relação de 1:1 de acordo com o padrão de coloração apresentada pelo fabricante das resinas acrílicas Rapidaflex e Lentaflex. Os materiais foram pesados para que os pigmentos representassem $0,2 \%$ do peso da resina e do silicone. Todas as amostras foram submetidas a análise cromática inicial (espectrofotômetro, UV-modelo 2450; Shimadzu, Kyoto, Japão) e após o envelhecimento acelerado para amostras não-metálicas por 252, 504 e 1.008 horas. Uma análise visual para avaliação de cor foi realizada por dois operadores, previamente calibrados, para verificar a viabilidade do uso clínico de cada material. Três amostras foram fabricadas para cada grupo como controle, sendo que a primeira não foi submetida ao processo de envelhecimento, e foi mantida em uma caixa escura para representar um parâmetro clínico para as amostras submetidas ao envelhecimento de 252, 504 e 1.008 horas. A segunda amostra foi submetida a um envelhecimento de 252 horas, e foi mantida numa caixa escura para comparação com aquelas que sofreram envelhecimento de 504 e 1008 horas. A última amostra foi submetida a um envelhecimento de 504 horas, e foi mantida numa caixa escura para ser comparada com as amostras submetidas a um envelhecimento de 1.008 horas. As amostras de cada grupo foram colocadas individualmente num prato metálico escuro ao lado da amostra de controle e as alterações visíveis foram registradas. Os valores de $\Delta \mathrm{E}$ foram submetidos à análise de variância e as médias comparadas pelo teste de Tukey $(\mathrm{p}<0,05)$. Os resultados demonstraram alteração de cor entre os materiais em todos os períodos de envelhecimento. Houve diferença significativa $(p<0,05)$ na alteração de cor entre o Silastic pigmentado e incolor nos três períodos de envelhecimento (252, 504 e 1008 horas), bem como entre a resina acrílica Classico pigmentada e incolor. Não houve diferença significativa na alteração de cor $(p>0,05)$ entre os períodos de envelhecimento acelerado para os grupos do silicone Silastic. O envelhecimento por 1.008 horas promoveu maior alteração de cor do que os períodos de 252 e 504 horas para Rapidaflex, Lentaflex e Classico pigmentada. No entanto, não houve diferença significativa para a resina acrílica Clássico incolor neste período. Quanto ao método de análise visual, todos os materiais apresentaram alteração cromática nas primeiras 252 horas. Não foram detectadas alterações no padrão cromático após 504 horas de envelhecimento. No período de 1008 horas, somente Rapidaflex, Lentaflex e Clássico incolor apresentaram alteração de cor visível, ficando visualmente mais amarelas. Considerando a espectrofotometria, as resinas acrílicas e o silicone apresentaram instabilidade da cor em todos os períodos de 
envelhecimento com a percepção visual após 252 horas de envelhecimento acelerado. Os materiais não pigmentados apresentaram os menores valores de alteração de cor. A incorporação do pigmento parece ser a principal causa de instabilidade de cor das resinas e do silicone.

Goiato et al. (2010a) avaliaram o efeito de 2 opacificadores sobre a dureza do silicone Silastic MDX4-4210 após desinfecção química e envelhecimento acelerado. 90 amostras foram divididas em três grupos $(\mathrm{n}=30)$ : GI - sem opacificador, GII - pigmentado com sulfato de bário $(0,2 \%)$ e GIII - pigmentado com dióxido de titânio $(0,2 \%)$. A mensuração da dureza Shore A foi realizada (durômetro Teclock, Osaka, Osaka, Japão) antes e após a desinfecção realizada 3 vezes por semana durante 60 dias com Efferdent, sabão neutro ou gluconato de clorexidina a 4\%. Depois da desinfecção o envelhecimento acelerado foi realizado (câmara de envelhecimento, Equilam, Diadema, SP, Brasil) e os testes de dureza foram repetidos após 252, 504 e 1008 horas de envelhecimento. Os fatores opacificador, desinfecção e envelhecimento foram significativos no que diz respeito à dureza $(\mathrm{p}<0,05)$. Os grupos GI e GII aumentaram a dureza ao longo do experimento, por outro lado, GIII apresentou uma redução significativa da dureza após a desinfecção e 252 horas de envelhecimento acelerado, exceto para as amostras desinfetadas com clorexidina. Depois de 1.008 horas de envelhecimento, a dureza das amostras GIII aumentou independente do agente desinfetante utilizado. Após 60 dias de desinfecção com Efferdent, os grupos GII e GIII apresentaram valores de dureza inferiores ao grupo GI. Os valores de dureza de GIII foram menores do que de GI e GII, após 252 e 504 horas de envelhecimento, independentemente do procedimento de desinfecção, no entanto, as amostras GIII apresentaram aumento da dureza depois de 1008 horas. A desinfecção química e o envelhecimento acelerado, não influenciaram estatisticamente na dureza de GI, mas quando foi adicionado um opacificador tanto a desinfecção como o envelhecimento acelerado produziram alterações significativas na dureza. Os autores concluíram que a utilização da desinfecção e do opacificador em próteses de silicone pode ser indicada, uma vez que os valores de dureza se mantiveram no intervalo clinicamente aceitável.

Goiato et al. (2010b) investigaram a estabilidade dimensional e reprodução de detalhes de um silicone para próteses bucomaxilofaciais manipulado com e sem a incorporação de opacificadores, e submetido à desinfecção e ao envelhecimento acelerado. As amostras foram fabricadas com o silicone Silastic MDX4-4210 associado com os opacificadores, sulfato de bário e dióxido de titânio. 90 amostras foram divididas em 9 grupos $(n=10)$ de acordo com o 
opacificador: nenhum (L), sulfato de bário ( $\mathrm{Ba}$ ) e dióxido de titânio (Ti) e método de desinfecção: sabão (S), Efferdent (E) e clorexidina (C). Os opacificadores foram adicionados a uma concentração de $0,2 \%$ em peso de silicone. Os testes de estabilidade dimensional e reprodução de detalhes foram realizados inicialmente, após 60 dias de desinfecção e após diferentes tempos de envelhecimento acelerado (252, 504 e 1008 horas). As amostras foram desinfetadas três vezes por semana durante 60 dias. O envelhecimento acelerado foi realizado em câmara de envelhecimento (Equilam, Diadema, SP, Brasil). Os processos de desinfecção e de envelhecimento simularam 1 ano de uso da prótese. Todos os grupos exibiram alterações dimensionais ao longo do experimento. Tanto os opacificadores quanto o tempo $(p<0,0001)$ afetaram estatisticamente a estabilidade dimensional do silicone. A interação entre o período e o tipo de opacificador ( $\mathrm{p}=0,0041)$ foi estatisticamente significativa. Alterações dimensionais ocorreram entre a mensuração inicial, após 60 dias de desinfecção e após 1008 horas de envelhecimento acelerado. A incorporação de opacificadores alterou a estabilidade dimensional da prótese de silicone facial, mas parece não ter influenciado na reprodução de detalhes. O envelhecimento acelerado foi responsável pelas alterações dimensionais, porém as alterações mantiveram-se dentro dos limites de estabilidade necessários para aplicação clínica.

Guiotti, Goiato e dos Santos (2010) investigaram a dureza Shore A de um silicone específico para próteses bucomaxilofaciais (Silastic MDX4-4210), sem e com pigmentos (pó de maquiagem - orgânico e óxido de ferro - inorgânico) sob a influência do tempo de armazenamento e da ação de desinfetantes. Os pigmentos foram pesados em balança digital representando $0,2 \%$ do peso de silicone. 30 espécimes foram obtidos e divididos em 6 grupos: sem pigmentação, pigmentado com pó de maquiagem e pigmentado com óxido de ferro, avaliando a ação ou não do desinfetante. Como agente de desinfecção foi utilizado o gluconato de clorexidina a 4\%. A análise foi realizada de acordo com o período de armazenamento, desinfecção química e pigmentação. A dureza foi mensurada com um durômetro Shore A (especificação D2240, ASTM) após a obtenção dos espécimes e após 6 meses e 1 ano de armazenamento. Os valores de dureza foram submetidos à análise de variância e as médias comparadas pelo teste de Tukey $(\mathrm{p}<0,05)$. O silicone exibiu um aumento da dureza no primeiro período de tempo, tornando-se estável a partir de 6 meses a 1 ano. O silicone apresentou valores de dureza Shore A dentro dos relatados na literatura, independentemente do período de armazenagem, pigmentação e desinfecção química.

Han et al. (2010) estudaram os efeitos de opacificadores (nano-óxidos) e pigmentos na estabilidade de cor de um silicone bucomaxilofacial (A-2186, Fator II Inc., Lakeside, AZ) 
submetido ao envelhecimento. 45 grupos foram formados combinando 1 dos 3 opacificadores $\left(\mathrm{TiO}_{2}, \mathrm{ZnO}\right.$ e $\left.\mathrm{CeO}_{2}\right)$ com cada 1 dos pigmentos (Fator II Inc., Lakeside, AZ) de silicone (vermelho, amarelo, azul, e uma mistura destes três pigmentos) que equivaliam a $0,2 \% \mathrm{em}$ peso do silicone. O grupo controle foi estabelecido sem acréscimo de pigmento ou opacificador. Os nano-óxidos foram adicionados separadamente a 1\%,2\%, e 2,5\% em peso de silicone. A análise de cor (espectrofotômetro, Color Eye 7000; Macbeth, Newburgh, NY) foi realizada antes e depois do envelhecimento artificial (Ci35 Weather-Ometer; Atlas Electronics, Chicago, IL). Os limiares de perceptibilidade $\left(\Delta \mathrm{E}^{*}=1,1\right)$ e aceitabilidade $\left(\Delta \mathrm{E}^{*}=3,0\right)$ foram utilizados na interpretação das alterações de cor obtidas. Os grupos com $\mathrm{CeO}_{2}$, em geral, tiveram a maior alteração de cor e os grupos com $\mathrm{TiO}_{2}$ tiveram a menor. Todos os valores de $\Delta \mathrm{E}^{*}$ dos grupos mistos estavam abaixo do limiar de aceitação $\left(\Delta \mathrm{E}^{*}=1,2-\right.$ 2,3), exceto o $\mathrm{CeO}_{2}$ a $2 \%\left(\Delta \mathrm{E}^{*}=4,2\right)$. Os opacificadores $\mathrm{CeO}_{2}$ a $1 \%$ e $\mathrm{TiO}_{2}$ a $2 \%$ e $2,5 \%$ associados com os pigmentos exibiram as menores alterações de cor após o envelhecimento artificial. O pigmento de silicone amarelo e os três nano-óxidos afetou significativamente a estabilidade de cor do silicone e deve ser usado com cautela.

Hatamleh e Watts (2010) investigaram as propriedades mecânicas de silicones bucomaxilofaciais (TechSil S25, Cosmesil M511 e Cosmesil Z004) e sua força de ligação ao substrato acrílico. Foram confeccionados 8 espécimes de cada material para os ensaios de resistência à tração e ao rasgamento, porcentagem de alongamento e módulo de elasticidade e 5 espécimes para o teste de dureza. Também foi avaliada a adesão dos silicones à superfície de resina acrílica por meio do ensaio de cisalhamento. A resistência à tração do S25 foi maior do que M511 e Z004 ( $\mathrm{p}<0,05)$. S25 apresentou maior porcentagem de alongamento em comparação com os outros materiais $(\mathrm{p}<0,05)$. Z004 e S25 apresentaram maior dureza $(\mathrm{p}<0,05)$ do que M511. Todos os materiais tiveram a mesma resistência ao rasgamento e módulo de elasticidade ( $p>0,05$ ). Z004 teve maior resistência ao cisalhamento do que S25 $(\mathrm{p}<0,05)$. Os autores concluíram que todos os elastômeros de silicone apresentaram propriedades desejáveis, embora os melhores resultados de resistência à tração e alongamento, resistência ao rasgamento e dureza tenham sido encontrados com o silicone TechSil S25 caracterizando-o como um silicone com propriedades promissoras na fabricação de próteses bucomaxilofaciais. O Cosmesil Z004 apresentou os melhores resultados quanto à resistência ao cisalhamento.

Montgomery e Kiat-Amnuay (2010) analisaram materiais utilizados para confecção de próteses bucomaxilofaciais bem como as suas vantagens e desvantagens, tendo como 
objetivos reforçar o conhecimento científico, gerar ideias de pesquisa e, possivelmente, levar à produção de novos materiais alternativos. Um questionário com 47 questões foi entregue via e-mail a 260 membros da Associação Americana de Anaplastologia (AAA) e da Academia Americana de Próteses Maxilofaciais (AAPM), para avaliação das preferências pessoais envolvendo os materiais protéticos em relação a: silicones pigmentados intrínseca e extrinsecamente, corante/pigmento utilizado, processo de polimerização, vantagens e desvantagens do material mais frequentemente utilizado, característica mais importante do material e técnica utilizada. Os resultados indicaram que: o material mais comumente utilizado é o silicone vulcanizado à temperatura ambiente (RTV); os pigmentos de silicone para pigmentação intrínseca e pastas de silicone para pigmentação extrínseca foram mais indicados que os pigmentos à base de óleo ou pigmentos de terra seca; as cinco principais vantagens dos materiais foram boa estética, facilidade de coloração e de manipulação, margens finas e compatibilidade com adesivos; as cinco principais desvantagens citadas foram a descoloração ao longo do tempo, sensibilidade da técnica, dificuldade de reparo, falta de corantes extrínsecos e baixa longevidade; materiais não tóxicos e não alérgicos, com alta resistência e estabilidade de cor foram as características mais importantes na escolha de um material protético. As respostas obtidas neste estudo indicam que a maioria dos membros da AAA e AAPM usa ou usou uma variedade de silicones RTV, pigmentos e corantes que contribuem para o melhor resultado possível no que diz respeito à confecção de próteses faciais. Outras pesquisas são necessárias para aperfeiçoar e melhorar os materiais para a confecção dessas próteses extra-orais.

Dos Santos et al. (2011) avaliaram a influência de dois pigmentos (pó de cerâmica e óleo de pintura) e um opacificador (sulfato de bário) na estabilidade de cor do silicone MDX4-4210 quando submetido ao envelhecimento acelerado. 60 amostras distribuídas em 6 grupos (n=10): G1 - incolor, G2 - incolor + opacificador, G3 - pó de cerâmica, G4 opacificador + pó de cerâmica, G5 - tinta a óleo, G6 - opacificador + tinta a óleo. Os pigmentos e opacificador corresponderam a $0,2 \%$ do peso do silicone. As amostras foram submetidas à análise cromática inicial (espectrofotômetro, Shimadzu, Kyoto, Japão) e após 252, 504 e 1.008 horas de envelhecimento acelerado (câmara de envelhecimento, Equilam, Diadema, Brasil) para amostras não-metálicas (ASTM 53). A alteração de cor foi avaliada com o sistema CIE L*a*b*. O método de análise visual da cor foi utilizado para avaliar a viabilidade clínica de cada material. Então, três amostras adicionais (controle) foram feitas para cada grupo. A primeira não foi submetida ao processo de envelhecimento e foi mantida 
em uma caixa escura para evitar a incidência de luz, para que fosse comparada com as amostras que sofreram envelhecimento por 252, 504 e 1.008 horas. A segunda foi submetida ao envelhecimento por 252 horas e mantida em uma caixa escura para comparação com aquelas que sofreram o envelhecimento por 504 e 1.008 horas. As demais amostras foram submetidas ao envelhecimento de 504 horas e mantidas em uma caixa escura para ser comparadas com aquelas submetidas ao envelhecimento por 1.008 horas. Dois operadores calibrados realizaram a análise visual entre os espécimes de um mesmo grupo. As amostras de cada grupo foram colocadas sobre uma chapa metálica escura individualmente ao lado da amostra de controle. Alterações de cor visíveis foram registradas para posterior análise dos resultados. Os valores de $\Delta \mathrm{E}$ foram submetidos à análise de variância e as médias comparadas pelo teste de Tukey, em nível de 5\% de significância. A alteração de cor não foi perceptível durante a análise visual das amostras, embora todos os grupos tenham apresentado alteração cromática, independentemente do período de avaliação. Os grupos com opacificador apresentaram os valores mais baixos de $\Delta \mathrm{E}$ com uma diferença significativa quando comparados com os demais grupos, independentemente do período de envelhecimento. Nos grupos sem opacificador, o grupo pigmentado com tinta a óleo apresentou os valores mais baixos de $\Delta \mathrm{E}$ durante o envelhecimento. $\mathrm{O}$ envelhecimento acelerado gerou alterações cromáticas após 252 horas em todos os grupos, exceto para o incolor e para os grupos de tinta a óleo, ambos com opacificador. O opacificador protegeu o silicone contra a degradação da cor e a tinta a óleo apresentou-se como um pigmento estável mesmo sem a adição de opacificador.

Eleni et al. (2011) investigaram as propriedades mecânicas e térmicas de quatro materiais protéticos frente ao envelhecimento natural. Assim, modelos matemáticos e parâmetros físicos foram utilizados para cada propriedade medida, a fim de correlacionar os dados experimentais com o tempo de radiação solar. Três diferentes polidimetilsiloxanos de grau médico (Elastomer 42 - A, TechSil 25 - B e Cosmesil M511 - C) e um polietileno clorado, CPE - Polietileno Clorado Experimental (D) foram utilizados. A partir de cada material, 20 amostras retangulares foram fabricadas para análise térmica, de compressão e dureza, e 20 em forma de halteres tipo II foram fabricadas para o ensaio de tração. As amostras foram colocadas no telhado da Universidade Aristóteles de Tessalônica durante 1 ano, onde ficaram expostas à ação do tempo. As amostras não submetidas ao intemperismo foram usadas como controle. Os ensaios de compressão uniaxial e tração foram realizados com uma máquina de teste (Zwick Universal, modelo Z2.5/TN1S, Alemanha). Para o ensaio 
de tração, as garras da máquina foram ajustadas para um comprimento padrão de $20 \mathrm{~mm}$. A velocidade para ambos os ensaios foi de $5 \mathrm{~mm} / \mathrm{min}$. Para o teste de dureza foi utilizado um durômetro Shore A (modelo CV-DSAS001, Países Baixos). Medidas de calorimetria diferencial de varredura (DSC) foram realizadas nas amostras com um instrumento de diamante (Perkin Elmer) a uma taxa de aquecimento constante de $10^{\circ} \mathrm{C} / \mathrm{min}$. A temperatura de transição vítrea, $\mathrm{Tg}$, foi definida como o ponto médio da capacidade de alteração de calor durante o aquecimento. Para os dados de compressão e tração, os materiais A e B apresentaram uma diminuição no seu estresse e tensão máxima, em contraste com os materiais $\mathrm{C}$ e D, que mostraram um aumento em ambos os parâmetros. Os parâmetros de elasticidade e viscoelasticidade dos materiais A e B aumentaram com o tempo de radiação solar. Os materiais C e D exibiram um comportamento inverso na análise de compressão, embora na análise de tração o parâmetro de viscoelasticidade tenha aumentado com o tempo de radiação solar. Para o material $\mathrm{D}$, tanto o estresse como a tensão, diminuíram com o tempo de radiação solar. Os materiais A e B tornaram-se mais duros com o tempo de radiação solar, enquanto que $\mathrm{C}$ e $\mathrm{D}$, mais macios. A temperatura de transição vítrea para os materiais $\mathrm{A}$ e $\mathrm{B}$ aumentou, tal como a cadeia principal tornou-se mais rígida. Os materiais C e D mostraram um comportamento oposto. Os resultados mostraram que foram observadas diferenças significativas no comportamento mecânico entre o controle (não irradiados) e amostras irradiadas, como um resultado da fotodegradação que ocorreu durante o envelhecimento natural.

Goiato et al. (2011) avaliaram o efeito de métodos de desinfecção química e envelhecimento acelerado sobre a estabilidade de cor do silicone MDX4-4210 pigmentado com dióxido de titânio e sulfato de bário como opacificadores. A hipótese nula foi que a adição destes opacificadores promove a estabilidade de cor do material, mesmo após a desinfecção e envelhecimento acelerado. 90 amostras divididas em três grupos (n=30): GI incolor; GII - sulfato de bário e GIII - dióxido de titânio. O peso dos opacificadores era equivalente a $0,2 \%$ do peso total do silicone. Todas as amostras foram submetidas à análise cromática inicial (espectrofotômetro de reflexão, UV-2450, Shimadzu, Kyoto, Japão) e foram armazenadas em uma caixa preta sem luz. As amostras foram desinfetadas três vezes por semana, durante 2 meses, com comprimidos efervescentes, sabão de pH neutro ou gluconato de clorexidina a 4\%. Após a desinfecção, uma nova análise cromática foi realizada. Em seguida, as amostras foram colocadas em uma câmara de envelhecimento (Equilam, Diadema, Brasil). O grau de alteração da cor aumentou depois de cada período de envelhecimento 
acelerado. Em geral, o grupo GII apresentou a menor alteração de cor, enquanto que o grupo GIII apresentou a maior alteração. Os autores concluíram que a clorexidina promoveu a maior alteração de cor do silicone bucomaxilofacial em comparação com os outros desinfetantes. O envelhecimento acelerado afetou a estabilidade da cor de todos os grupos. O opacificador sulfato de bário foi mais estável em todos os períodos.

Haddad et al. (2011) investigaram a estabilidade dimensional e reprodução de detalhes de um silicone bucomaxilofacial, com e sem a incorporação de opacificador e/ou pigmento, quando submetido à desinfecção e ao envelhecimento acelerado. As amostras foram confeccionadas com Silastic MDX4-4210 associado ao opacificador sulfato de bário. 120 amostras foram divididas em 12 grupos $(n=10)$ de acordo com opacificador e/ou teor de pigmentos: nenhum $(\mathrm{L})$, pó cerâmico $(\mathrm{Ce})$, sulfato de bário $(\mathrm{Ba})$, pó cerâmico e sulfato de bário (Ceba) e método de desinfecção: sabão (S), Efferdent (E) ou clorexidina (C). Os pigmentos e/ou agente de opacificação foram adicionados a uma concentração de 0,2\% em peso do silicone. A estabilidade dimensional e os testes de reprodução de detalhes foram realizados inicialmente, após 60 dias de desinfecção e após diferentes tempos de envelhecimento acelerado (252, 504 e 1008 horas). Para o teste de estabilidade dimensional, as amostras foram digitalizadas através de um scanner (Genius; Langenfeld, NordrheinWestfalen, Alemanha) com uma resolução de 800 dpi. As amostras foram desinfetadas três vezes por semana durante 60 dias com Efferdent, sabão neutro ou com gluconato de clorexidina a 4\%. O envelhecimento foi realizado em câmara de envelhecimento (Equilam, Diadema, São Paulo, Brasil). Ambos os processos simularam um período de 1 ano de uso das próteses. Todos os grupos exibiram alterações dimensionais ao longo do experimento. Em geral, os grupos L e Ceba exibiram as menores variações dimensionais. A incorporação de pigmento cerâmico e/ou opacificador alterou a estabilidade dimensional do silicone mas pareceu não ter influência na reprodução de detalhes. Os desinfetantes não promoveram alterações significativas na estabilidade dimensional e reprodução de detalhes do silicone. $\mathrm{O}$ envelhecimento acelerado foi responsável pela maioria das alterações dimensionais, porém todas elas mantiveram-se dentro dos limites necessários para a aplicação clínica do silicone.

Hatamleh et al. (2011) investigaram o efeito das condições humanas e ambientais sobre as propriedades mecânicas do silicone bucomaxilofacial TechSil S25. Foram confeccionadas 21 amostras, sendo 8 para o teste de tensão, 8 para o teste de rasgamento e 5 para análise de dureza. As amostras foram expostas a 7 condições com diferentes tempos de exposição: 1 - controle (24 horas), 2 - armazenamento no escuro (6 meses), 3 - solução de 
sebo (6 meses), 4 - transpiração ácida (6 meses), 5 - envelhecimento acelerado da luz do dia (360 horas), 6 - envelhecimento ao ar livre, no telhado da Faculdade de Odontologia em Manchester, UK (6 meses), 7 - solução de limpeza antibacteriana (30 horas) e 8 envelhecimento misto, armazenamento na solução de sebo sob a luz (360 horas). Os períodos de análise simularam um tempo de uso de 12 a 18 meses, considerando que os pacientes utilizam a prótese de 8 a 12 horas, o que se espera que essa fique exposta a pelo menos 1 hora de luz, condições ambientais normais, sebo e transpiração contínua. Além disso, foram considerados 5 minutos gastos com a limpeza das próteses. Os ensaios de tração e rasgamento foram realizados na máquina universal de ensaios (Zwick/Roell Z020, Leominster, Reino Unido) com velocidade de $500 \mathrm{~mm} / \mathrm{min}$ e $100 \mathrm{~mm} / \mathrm{min}$, respectivamente. As amostras que se romperam fora da porção estreita ou fora do comprimento de teste foram descartadas. A dureza foi determinada com um durômetro Shore A (MFG Co., NY, EUA), de acordo com a especificação ASTM D2240. Diferenças significantes foram evidentes entre todas as propriedades testadas. A condição de armazenamento mista de sebo sob o envelhecimento acelerado da luz do dia degradou significativamente as propriedades mecânicas do silicone, em comparação com o grupo controle $(\mathrm{p}<0,05)$. Dentro das limitações deste estudo in vitro, pode-se concluir que as propriedades do elastômero de silicone TechSil S25 foram melhoradas ou adversamente afetadas por diferentes fatores ambientais. A dureza foi a propriedade mais sensível, uma vez que foi reforçada após a transpiração ácida, envelhecimento acelerado da luz do dia e intemperismo ao ar livre, contudo, foi degradada após a armazenagem em sebo com ou sem envelhecimento acelerado da luz do dia. $\mathrm{O}$ envelhecimento misto por 360 horas foi o fator mais degradante para todas as variáveis analisadas.

Maida et al. (2011) avaliaram a influência da pigmentação e do envelhecimento acelerado na dureza Shore A de um silicone médico (Ortho Pauher) quando comparado a um material padrão comumente utilizado (MDX 4-4210). Foram formados 2 grupos ( $n=30)$ : PI pigmentação intrínseca com pó de maquiagem, na proporção de 2:100 de silicone; PIE pigmentação intrínseca e extrínseca onde o mesmo pigmento foi incorporado à massa na proporção acima indicada e, posteriormente à polimerização do material, os espécimes receberam uma camada uniforme de pigmento extrínseco que foi dissolvido no silicone na proporção de 2:20 e aplicado na superfície com auxílio de um pincel. Cada grupo foi distribuído aleatoriamente em outros 3 subgrupos: envelhecimento por termociclagem, envelhecimento por luz ultravioleta e, como grupo controle, 10 espécimes para cada 
combinação material/pigmentação, os quais foram mantidos em um recipiente hermeticamente fechado na ausência total de luz por 12 meses consecutivos. O ensaio de dureza foi realizado com o durômetro Shore A (Instrument and Manufacturing Co Inc, Frieport, N.Y.) após a obtenção dos espécimes e após os processos de envelhecimento. Os testes ANOVA e Tukey ( $\mathrm{p}<0,05)$ indicaram que o silicone MDX 4-4210 apresentou a menor variação da dureza, independente do envelhecimento e pigmentação. Quanto ao envelhecimento, a termociclagem promoveu a menor variação da dureza se comparada aos grupos envelhecidos por luz ultravioleta e controle. Os resultados sugerem que, para a prática clínica, próteses bucomaxilofaciais confeccionadas com o silicone MDX 4-4210 apresentariam maior estabilidade da dureza quando expostas à radiação ultravioleta e às variações de temperatura.

Pesqueira et al. (2011) avaliaram a estabilidade de cor do silicone MDX4-4210 submetido à desinfecção química e envelhecimento acelerado de 252, 504 e 1.008 horas. 60 espécimes foram fabricados: 20 pigmentados com pó cerâmico, 20 com pó de maquiagem e 20 incolores. Metade dos espécimes de cada grupo foi submetida à desinfecção com comprimidos efervescentes e a outra metade com sabão neutro, três vezes por semana, durante 60 dias. Os espécimes foram, então, submetidos ao envelhecimento acelerado em uma câmara de envelhecimento acelerado (Equilam, Diadema, Brasil). A cor dos espécimes foi avaliada antes e após 60 dias de desinfecção, e com 252, 504 e 1008 horas de envelhecimento, totalizando cinco medições. Todos os fatores (pigmento, período e tratamento) e a interação entre eles foi estatisticamente significativa $(\mathrm{p}<0,01)$. Foi observada alteração de cor entre os materiais, independentemente do período de envelhecimento. Os espécimes desinfetados com sabão neutro apresentaram valores mais elevados de $\Delta \mathrm{E}$, independentemente do tipo de pigmentação. Os espécimes incolores e os pigmentados com cerâmica exibiram diferença significativa entre os métodos de desinfecção em todos os períodos, no entanto, os espécimes pigmentados com pó de maquiagem não demonstraram essa diferença. Os fatores pigmentação, desinfecção e envelhecimento acelerado foram significativos na estabilidade de cor do silicone pigmentado. O pigmento de cerâmica apresentou maior estabilidade de cor, independente da desinfecção e do período, em comparação com o pó de maquiagem, que exibiu os maiores valores de alteração cromática.

Pinheiro et al. (2011) avaliaram a influência da pigmentação e do envelhecimento na alteração de cor de um silicone médico (Ortho Pauher). Os resultados foram comparados aos de um silicone próprio para próteses faciais (MDX 4-4210). Foram confeccionados 60 
espécimes de acordo com a pigmentação, intrínseca (PI) e extrínseca (PIE), distribuídos em subgrupos $(\mathrm{n}=10)$ para exposição aos processos de envelhecimento (termociclagem, luz ultravioleta e controle). Para o grupo PI, o pigmento de pó de maquiagem foi pesado e incorporado a massa na proporção de 2:100 de silicone. Para o grupo PIE, o mesmo pigmento foi incorporado à massa na proporção acima indicada e, posteriormente à polimerização dos materiais, foi aplicada uma camada uniforme dos respectivos silicones com pigmento extrínseco incorporado na proporção de 2:20, promovendo a caracterização. Os protocolos de envelhecimento simularam um período de 12 meses e o grupo controle foi mantido em um recipiente hermeticamente fechado na ausência total de luz, por 12 meses. A alteração de cor $(\Delta \mathrm{E})$ foi determinada com um espectrocolorímetro portátil modelo Color Guide 45/0, utilizando o sistema CIE LAB. Os testes ANOVA e Tukey $(\mathrm{p}<0,05)$ indicaram diferença significante entre o grupo controle e os grupos envelhecidos por termociclagem e luz ultravioleta, sendo que estes se mostraram iguais. Em relação aos materiais, não houve diferença entre eles. Houve diferença entre as pigmentações. Na interação, o Ortho Pauher sofreu maior variação de cor causada pela luz ultravioleta, enquanto o MDX, pela termociclagem. Comparando-se os materiais com pigmentação intrínseca, nos 3 grupos de envelhecimento houve diferença entre o controle e a luz ultravioleta, sendo que a maior alteração foi encontrada para o Ortho Pauher. Para os materiais com pigmentação intrínseca e extrínseca, houve diferença nos 3 grupos de envelhecimento, com maior variação para o MDX. Notam-se comportamentos distintos dos materiais em função da pigmentação e do envelhecimento, devendo-se considerar a associação entre material, tipo de pigmento e tipo de exposição para que se faça a indicação clínica corretamente, podendo-se considerar o Ortho Pauher na confecção de próteses bucomaxilofaciais.

Polyzois, Eleni e Krokida (2011a) investigaram as propriedades ópticas, alterações de cor $\left(\Delta \mathrm{E}^{*}\right)$ e translucidez (TP) de 2 elastômeros de silicone (Mollomed e Episil) em diferentes tonalidades de cor, antes e após várias condições de envelhecimento (passagem do tempo, envelhecimento acelerado interior e envelhecimento acelerado exterior). As alterações de cor $\left(\Delta \mathrm{E}^{*}\right)$ e TP foram avaliadas com um colorímetro (Micro Cor; Bruno Lange $\mathrm{GmbH}$, Berlin, Alemanha). Os valores de cada amostra foram medidos antes e depois do envelhecimento. As amostras que sofreram envelhecimento natural (passagem do tempo) foram armazenadas no escuro à temperatura ambiente durante 14 dias. Para os envelhecimentos acelerados interno e externo, uma câmara de envelhecimento (Suntest CPS +; Atlas Material de Teste Technology $\mathrm{GmbH}$, Linsengericht, Alemanha) foi utilizada, e as amostras foram expostas a radiação UV e 
luz visível contínua durante 168 horas. No final dos períodos de envelhecimento, os espécimes foram removidos e testados. Os valores do parâmetro de translucidez para a maioria das amostras foram alterados significativamente após o envelhecimento e os valores de $\Delta \mathrm{E}^{*}$ foram caracterizados como inaceitáveis. Tanto o envelhecimento quanto o tipo de silicone afetaram as mudanças que ocorreram. A passagem do tempo não afetou significativamente os valores de TP ao contrário dos outros 2 processos de envelhecimento acelerado. Entre envelhecimento interior e exterior, não foram detectadas diferenças significativas. Pode-se concluir que os valores de $\Delta \mathrm{E}^{*}$ e TP foram significativamente afetados pelo tipo de material. As condições de envelhecimento afetaram significativamente apenas o $\Delta \mathrm{E}^{*}$. O envelhecimento pela passagem do tempo e envelhecimento exterior não provocaram alterações significativas sobre os valores de TP. As alterações de cor foram maiores após o envelhecimento interior e exterior. Nas amostras de Mollomed, foram registradas alterações de cor visualmente inaceitáveis, já nas amostras Episil, as alterações de cor foram aceitáveis e mais estáveis.

Polyzois, Eleni e Krokida (2011b) investigaram o efeito da passagem do tempo após a armazenagem no escuro, nas propriedades (resistência à tração, módulo de elasticidade, alongamento em relação a ruptura, resistência ao rasgamento, dureza, estabilidade, cor e relação de contraste - opacidade) de 2 silicones bucomaxilofaciais, Silasto 30 e Premium 2. 20 amostras de cada material foram testadas para cada variável, exceto para a dureza e alteração de cor $(n=10)$. As amostras foram armazenadas em um recipiente de vidro selado e escuro à temperatura ambiente durante 12 meses. A resistência à tração, alongamento e módulo de alongamento e resistência ao rasgamento foram avaliados com uma máquina de ensaio (Modelo T10; Monsanto Ltd, Swindon, Inglaterra) a uma velocidade de $500 \mathrm{~mm} / \mathrm{min}$. A dureza foi determinada com um durômetro Shore A (GS-806; Teclock Corp, Osaka, Japão) em amostras de 25x25x10mm de acordo com a especificação D2240 da ASTM. A alteração de cor $\left(\Delta \mathrm{E}^{*}\right)$ foi calculada com um espectrocolorímetro (Micro Color; Bruno Lange $\mathrm{GmbH}$, Berlin, Alemanha) com base no sistema CIE L*a*b*. A alteração de cor $\left(\Delta \mathrm{E}^{*}\right)$ foi determinada a partir dos dados obtidos antes do armazenamento (baseline) e após 1 ano. Pode-se concluir que as propriedades dos elastômeros de silicone foram alteradas significativamente esse período. O módulo de elasticidade, alongamento de ruptura, dureza e cor, foram as propriedades mais sensíveis e apresentaram maiores alterações. A resistência à tração, resistência ao rasgamento e opacidade não foram significativamente alteradas com a passagem do tempo. Os materiais apresentaram comportamento semelhante quanto às 
mudanças nas propriedades mecânicas em questão. No entanto, o material Premium 2 é mais estável em relação a cor do que o Silasto 30, sem alterações significativas na opacidade. Para ambos os materiais, foram registradas alterações de cor visualmente inaceitáveis.

Dos Santos et al. (2012) avaliaram a estabilidade de cor de resinas acrílicas e de um silicone para próteses faciais após envelhecimento natural de 180 dias. 10 amostras de cada material foram confeccionadas de acordo com seis grupos $(n=10)$ : Rapidaflex, Lentaflex, Classico incolor, Classico pigmentada, Silastic incolor e Silastic pigmentado. As resinas acrílicas Lentaflex e Rapidaflex têm pigmentos orgânicos e inorgânicos. Como o silicone facial e a resina acrílica Classico são incolores, dois pigmentos diferentes foram misturados aos materiais: pó de maquiagem (pigmento orgânico) e pó cerâmico (pigmento inorgânico). A pigmentação seguiu a proporção de 1:1 de acordo com o padrão de coloração apresentado pelo fabricante das resinas acrílicas Rapidaflex e Lentaflex. Os pigmentos representaram $0,2 \%$ do peso dos materiais. Para o envelhecimento as amostras foram fixadas em uma placa de acrílico e expostas à temperatura diária média de $25^{\circ} \mathrm{C}, \mathrm{UV}$ próximo de 7 , umidade relativa do ar de $50 \%$ e a chuva acumulada de $71 \mathrm{~mm}^{3}$ (Araçatuba, São Paulo, Brasil - Instituto Nacional de Meteorologia). A análise de cor foi realizada por um espectrofotômetro (modelo UV-2450, Shimadzu, Kyoto, Japão) antes e após 2 períodos de 90 dias, totalizando 180 dias. Uma análise visual da cor foi realizada por dois operadores diferentes, previamente calibrados, para verificar a viabilidade do uso clínico de cada material. Assim, 2 amostras adicionais (controle) foram confeccionadas para cada grupo. A primeira amostra não foi submetida ao processo de envelhecimento e foi mantida em uma caixa escura para representar um parâmetro clínico para as amostras submetidas ao envelhecimento natural de 90 dias. A segunda amostra foi submetida ao envelhecimento natural durante 90 dias e foi mantida numa caixa escura para comparação com aquelas que sofreram envelhecimento de 180 dias. A análise visual foi realizada entre as amostras do mesmo grupo, onde foram colocadas individualmente em uma placa metálica escura ao lado da amostra de controle. Alterações de cor visíveis foram registradas para posterior análise dos resultados. De acordo com os resultados, independentemente do intervalo de tempo, todos os materiais sofreram alterações, com exceção da resina Classico pigmentada. A diferença de cor entre o silicone pigmentado e o incolor foi significativa ( $\mathrm{p}<0,01$ ) em ambos os períodos (90 e 180 dias), bem como entre a resina Classico pigmentada e incolor e entre as resinas Rapidaflex e Lentaflex. Pelo método visual, verificou-se que a mudança de cor em todos os materiais testados ocorreu durante os primeiros 90 dias, no entanto, entre 90 e 180 dias, os observadores não conseguiram detectar 
alterações na cor padrão dos materiais analisados. Considerando a espectrofotometria, as resinas acrílicas e o silicone apresentaram instabilidade de cor em todos os períodos de envelhecimento. Os materiais não pigmentados apresentaram os menores valores de alteração de cor. A incorporação de pigmento parece ser a principal causa de instabilidade de cor de resinas e de silicone.

Kheur et al. (2012) avaliaram dois materiais (M511 e Z004) frente à pigmentação (pigmentos de terra seca) e envelhecimento. 60 amostras de cada material foram divididas em grupo A $(n=30)$ e grupo B $(n=30)$, onde 7 amostras eram controle. Para cada $200 \mathrm{~g}$ de silicone foram utilizados: $0,1 \mathrm{~g}$ de carmim, $0,1 \mathrm{~g}$ de amarelo escuro, 0,01g de azul e 0,01 de vermelho. As amostras foram submetidas a um intemperismo simulado no telhado do Dental Institute e os controles armazenados em um recipiente fechado à temperatura ambiente, livre da exposição à luz. A análise da dureza foi realizada para todas as amostras: imediatamente após a confecção - fase 1 (baseline), 3 meses a partir do baseline - fase 2, e 9 meses a partir do baseline - fase 3. No baseline, a dureza inicial do material Z004 foi maior do que do M511, enquanto que no intervalo de 3 meses, a alteração na dureza foi maior para o M511, em comparação com Z004. No intervalo de 9 meses, a variação média da dureza para o M511 foi menor do que do Z004. Durante o período de avaliação de ambos os materiais, esses apresentaram endurecimento, porém as diferenças entre eles não foram significativas.

Han, Powers e Kiat-Amnuay (2013) avaliaram o efeito de uma base mineral protetora de luz UV (LP), usada como opacificador, na estabilidade de cor de um silicone pigmentado, comparado com 2 opacificadores comumente utilizados: pigmento seco branco de titânio (TW) e pigmento de silicone branco (SW). Os opacificadores foram adicionados ao silicone em três concentrações $(5 \%, 10 \%, 15 \%)$ com uma das 5 cores: nenhum pigmento (controle), vermelho, amarelo, azul, ou uma mistura das 3 cores. LP e TW foram combinados com pigmentos de tinta a óleo enquanto que o SW foi misturado com pigmentos intrínsecos de silicone. Foram estabelecidos 45 grupos, com um total de 225 amostras. Um espectrofotômetro foi utilizado para medir os valores de cor antes e após o envelhecimento artificial. Os valores de $\Delta \mathrm{E}^{*}$ de todos os grupos foram abaixo de 3,0 (limiar de aceitabilidade), exceto para o grupo controle do SW a 10\%, que apresentou a maior alteração de cor $\left(\Delta \mathrm{E}^{*}=3,1\right)$. Quando os grupos de pigmentos misturados foram considerados, o valor de $\Delta \mathrm{E}^{*}$ de todos os opacificadores com as três concentrações ficou abaixo de 1,1 (limite de perceptibilidade), exceto para TW a $5 \%(\Delta \mathrm{E} *=1,3)$ que foi significativamente diferente do grupo controle $(\mathrm{p}<0,05)$. Quando os opacificadores foram testados na concentração de $5 \%$, o 
LP apresentou a menor alteração de cor, seguido de SW e TW (p<0,05); em 10\%, não houve diferenças significativas entre os três opacificadores ( $p>0,05)$; em 15\%, o LP ainda mostrou a menor alteração de cor, seguido por TW e SW (P <0,05). Todos opacificadores utilizados neste estudo protegeram o silicone pigmentado da degradação da cor. LP produziu as menores variações, seguido de SW e TW.

Nguyen et al. (2013) avaliaram o efeito de dois opacificadores comumente utilizados, pigmento seco branco de titânio (TW) e silicone intrínseco branco (SW), e de um novo opacificador, agente de base mineral protetor de luz UV (LP), no silicone bucomaxilofacial MDX-4210/Tipo A pigmentado, quando submetido ao envelhecimento artificial. Espécimes do silicone foram fabricados combinando 1 dos 3 opacificadores a $10 \%$ e as seguintes condições de pigmentação: sem pigmento (controle), pigmento vermelho, amarelo ou azul, e uma mistura destes pigmentos. 10 espécimes em forma de haltere e 10 espécimes em forma de calças foram confeccionados para cada grupo, além de um grupo controle sem opacificador e sem pigmento, totalizando 320 espécimes. As variáveis analisadas foram dureza (ASTM D2240), resistência à tração (ASTM D412), resistência ao rasgamento (ASTM D624) e alongamento percentual. As propriedades mecânicas de metade dos espécimes foram testadas no início do estudo, sem envelhecimento artificial, e a outra metade foi colocada numa câmara de envelhecimento e exposta a ciclos de luz, escuridão, pulverização de água e temperaturas flutuantes. Após o envelhecimento acelerado, os valores de dureza Shore A dos grupos LP e controle foram os mais baixos, seguido de SW e TW $(p<0,001)$ e a resistência ao rasgamento, resistência à tração e porcentagem de alongamento diminuíram significativamente $(\mathrm{p}<0,001)$ para o LP, enquanto mudanças para SW e TW variaram de acordo com o pigmento. Pode-se concluir que as propriedades mecânicas avaliadas do MDX4-4210/Tipo A pigmentado foram degradadas após terem sido submetidas ao envelhecimento artificial. Os espécimes preparados com LP como opacificador tiveram degradação considerável de suas propriedades mecânicas após o envelhecimento acelerado. Embora menos popular do que o silicone intrínseco branco, o pigmento branco de titânio seco preservou melhor as propriedades mecânicas do silicone que os demais opacificadores testados. Este estudo mostrou que a avaliação das propriedades físicas das próteses bucomaxilofaciais devem ser combinadas com os estudos sobre as propriedades mecânicas, que podem ser consideravelmente afetadas pelo envelhecimento.

Pinheiro et al. (2014) investigaram as propriedades físicas, mecânicas e térmicas de um material experimental (Ortho Pauher Ind. Com. e Dist. Ltda) com uso potencial em 
prótese bucomaxilofacial depois de envelhecimento e pigmentação, utilizando o silicone MDX 4-4210 como controle. As variáveis de resposta foram dureza, alteração de cor e características microestruturais. 160 espécimes circulares foram fabricados, recebendo pigmentação intrínseca com pó de maquiagem (PI), onde o pigmento foi pesado e incorporado ao silicone na proporção de 2:100. Após a polimerização, metade dos espécimes $(\mathrm{n}=80)$ recebeu uma camada uniforme de silicone para pigmentação extrínseca (PE), a qual foi realizada com o auxílio de um pincel em uma das superfícies do espécime, na proporção de $20 \mathrm{~g}$ de silicone: $2 \mathrm{~g}$ de pigmento. Cada grupo de pigmentação (PI e PE) foi distribuído aleatoriamente em quatro subgrupos de acordo com os métodos de envelhecimento: Termociclagem - T; Luz ultravioleta - UV; Luz natural - NL e Controle - C. Todos os envelhecimentos simularam um período de 1 ano. $\mathrm{O}$ ensaio de dureza foi realizado com um durômetro Shore A (Instrumento e Manufacturing Co. Inc., Freeport, NY), antes (Ti) e após o envelhecimento (Tf). As médias dos resultados são fornecidas em unidades de Shore A e a variação (Tf - Ti) foi considerada na análise estatística. O ensaio de alteração de cor foi realizado em um espectrofotômetro (Color Eye 7000; Macbeth, Newburgh, Nova Iorque), onde a medida da alteração de cor em cada um dos espécimes foi realizada imediatamente após a obtenção das amostras e após os processos de envelhecimento. A variação $(\Delta \mathrm{E})$ foi considerada na análise estatística. As análises térmicas realizadas foram a análise termogravimétrica (TG), espectroscopia por infravermelho (FTIR) e a calorimetria exploratória diferencial (DSC). Para cada análise térmica, amostras de $4 \mathrm{mg}(\mathrm{n}=3)$ foram utilizadas para cada grupo de estudo. Os dados foram analisados por Análise de variância e teste de Tukey $(\mathrm{p}<0.05)$. Para o silicone MDX 4-4210 a dureza diminuiu em função da pigmentação em todos os envelhecimentos e controle. Para o silicone experimental, a dureza diminuiu apenas nas amostras com PI após a termociclagem. Para outros métodos de envelhecimento, o material apresentou maior dureza. Para o silicone MDX 4-4210, no grupo PI não houve alteração de cor resultante em qualquer um dos processos de envelhecimento, enquanto que, no grupo PE, as principais alterações foram promovidas por termociclagem e luz UV ( $\mathrm{p}=0.004)$. Para o material experimental com PI, a maior alteração foi devido a luz UV e, para o grupo PE, foi devido à T e UV. A análise por termogravimetria indicou que ambos os materiais apresentaram uma grande quantidade de compostos inorgânicos. Também pode ser notado que o silicone MDX 4-4210 não apresentou nenhum pico de decomposição inicial, demonstrando comportamento estável a altas temperaturas. A espectroscopia por infravermelho (FTIR) indicou similaridade entre os picos do silicone avaliado quando 
comparado com o material padrão, e também a ausência da formação de novos picos, o que indica que as diferentes pigmentações e envelhecimentos não promoveram a formação de subprodutos. O resultado também demonstra que a reação de polimerização de ambos os silicones estava completa. Os resultados da calorimetria diferencial de varredura indicaram que as amostras extrinsecamente pigmentadas apresentaram maior entalpia de fusão $(\Delta \mathrm{H})$. Os autores concluíram que embora o silicone experimental tenha apresentado as maiores alterações de dureza e cor, a análise microestrutural mostrou que ele tem propriedades térmicas estáveis. No entanto, considerando-se que as propriedades mecânicas e físicas foram avaliadas sob condições laboratoriais controladas, o desempenho do material experimental deve ser avaliado clinicamente antes que possa ser considerado como uma opção para a reabilitação bucomaxilofacial.

Bangera e Guttal (2014) investigaram os efeitos de diferentes concentrações de nanoóxidos de $\mathrm{Zn}$ e Ti como materiais de proteção contra raios UV quando incorporados ao elastômero de silicone Cosmesil M511. 11 grupos ( $\mathrm{n}=10)$ foram fabricados pela combinação de 1 dos 2 nano-óxidos ( $\mathrm{ZnO}$, Grupo B; $\mathrm{TiO}_{2}$, Grupo C) com o silicone. Como grupo controle foi utilizado o silicone sem nano-óxidos adicionados (Grupo A). Os dois nano-óxidos foram adicionados a $0,5 \%, 1 \%, 1,5 \%, 2 \%$ e 2,5\% em peso. Agentes corantes não foram incorporados. Todas as amostras foram submetidas à radiação ultravioleta, com ultravioleta $\mathrm{A}$ (> 315-400 nm) e ultravioleta B (> 280-315 nm), e a porcentagem de transmissão foi medida com um espectrofotômetro de ultravioletas. O fator de proteção ultravioleta foi calculado. A análise espectrofotométrica indicou que os valores de porcentagem de transmissão diminuíram para ambos os grupos de nano-óxido $(p<0,05)$ em comparação com o grupo controle. Os valores do fator de proteção ultravioleta aumentaram consideravelmente quando a concentração percentual de nano-óxidos foi aumentada para ambas as gamas ultravioleta $(\mathrm{p}<0,05)$. Os autores concluíram não só que Zn e Ti podem apresentar uma propriedade de proteção UV para o elastômero de silicone Cosmesil M511, mas também que o óxido de zinco em nano-escala é um material melhor para proteção UV em concentrações menores do que o óxido de Ti. 
3. Proposícão 
Com base na literatura apresentada, o objetivo geral do presente estudo foi propor a utilização de um novo silicone para prótese bucomaxilofacial.

Como objetivos específicos foram avaliados alteração de cor, dureza Shore A, resistência à tração, características de superfície (MEV) e composição química (EDS) quando o silicone foi exposto a:

1. Diferentes pigmentações: Pigmentação intrínseca (PI), adição de opacificador (OP), associação de ambos (PIO) e ausência de pigmentação (SP);

2. Diferentes envelhecimentos: Luz ultravioleta (UV), Luz natural (LN) e ausência de luz (controle - C). 


\section{Material e Métodos}




\subsection{Materiais}

\subsubsection{Material de consumo}

- Copo de Becker graduado, J. Prolab, São José dos Pinhais, PR, Brasil.

- Espátula 36, SS White Duflex Instrumentos Dentários, Juiz de Fora, MG, Brasil.

- Lâmpada de luz ultravioleta B - TL 40W/12RS UV-B Medical, Phillips, Holanda.

- Luva de látex, Satari, Siam Sempermed Corp. Ltda., Hat Yai, Songkhla, Tailândia.

- Máscara descartável, Embramac Empresa Brasileira de Materiais Cirúrgicos, Indústria, Comércio, Importação e Exportação Ltda., Itapira, SP, Brasil.

- Matriz metálica de corte vazada pré-fabricada de alumínio com formato circular, Faculdade de Odontologia de Ribeirão Preto da Universidade de São Paulo, Ribeirão Preto, SP, Brasil.

- Matriz metálica de corte vazada pré-fabricada de alumínio em forma de haltere, Faculdade de Odontologia de Ribeirão Preto da Universidade de São Paulo, Ribeirão Preto, SP, Brasil.

- Opacificador Sulfato de Bário PA $\left(\mathrm{BaSO}_{4}\right)$, Panreac Química S.A.U., Barcelona, Espanha.

- Pó compacto de maquiagem, Riscoti Cosméticos Ind. e Com. Ltda, Cajuru, SP, Brasil.

- Silastic® MDX4-4210, BioMedical Grade Elastomer, Dow-Corning, EUA.

- Silicone experimental, Bio- Skin, Ortho Pauher Ind. Com. e Dist. Ltda, São Paulo, SP, Brasil.

- Touca sanfonada descartável, Protdesc, Desc Life Indústria e Comércio Descartáveis Ltda., Santa Bárbara d' Oeste, SP, Brasil.

\subsubsection{Material permanente}

- Balança analítica de precisão, Mettler Toledo $\mathrm{GmbH}$, Laboratório e Tecnologias de Pesagem, Greifensee, Suiça. 
- Câmara de envelhecimento acelerado, Comexim Mat. Primas Ind. E Com. Ltda, São Paulo, SP, Brasil.

- Cilindro laminador CL 300 SL, G Paniz, Caxias do Sul, RS, Brasil.

- Detector de raios-X, modelo X-MAX ${ }^{\mathrm{N}}$, Oxford Instruments, Reino Unido.

- Durômetro “Shore A”, Instrument and Manufacturing Co Inc, Frieport, NY, EUA.

- Espatulador a vácuo, Turbomix, EDG, São Bernardo do Campo, SP, Brasil.

- Espectrocolorímetro portátil modelo Color Guide 45/0, BYK-Gardner GmbH, Geretsried, Alemanha.

- Estufa, Odontobrás Ind. e Comércio Equip. Med. Odont. Ltda, EL-11, Ribeirão Preto, São Paulo, Brasil.

- Máquina Universal de Ensaios, modelo MEM 2000, EMIC, São Paulo, Brasil.

- Microscópio Eletrônico de Varredura, modelo JSM-6610LV, JEOL ltd., Tóquio, Japão.

- Panela eliminadora de bolhas, VH Equipamentos Médico Odontológicos e Acess Ltda, Araraquara, São Paulo, Brasil.

- Paquímetro digital, CD-6 CSX-B, Mitutoyo Sul Americana Ltda., Suzano, São Paulo, SP, Brasil.

- Vibrador, VH, Soft Line, Araraquara, SP, Brasil.

\subsection{Delineamento experimental}

O presente estudo teve como fatores de variação: materiais (silicone experimental BioSkin - BS e MDX 4-4210 - MDX), pigmentação (sem pigmentação - controle, pigmentação intrínseca com pó de maquiagem, opacificador e associação de ambos) e envelhecimento (ausência de luz - controle, luz natural e luz ultravioleta). As variáveis de resposta quantitativas foram alteração de cor, dureza Shore A e resistência à tração e as variáveis de resposta qualitativa foram a Microscopia Eletrônica de Varredura (MEV) e a Espectroscopia por Energia Dispersiva (EDS). A formação dos grupos para cada material e ensaio foi realizada segundo o fluxograma: 


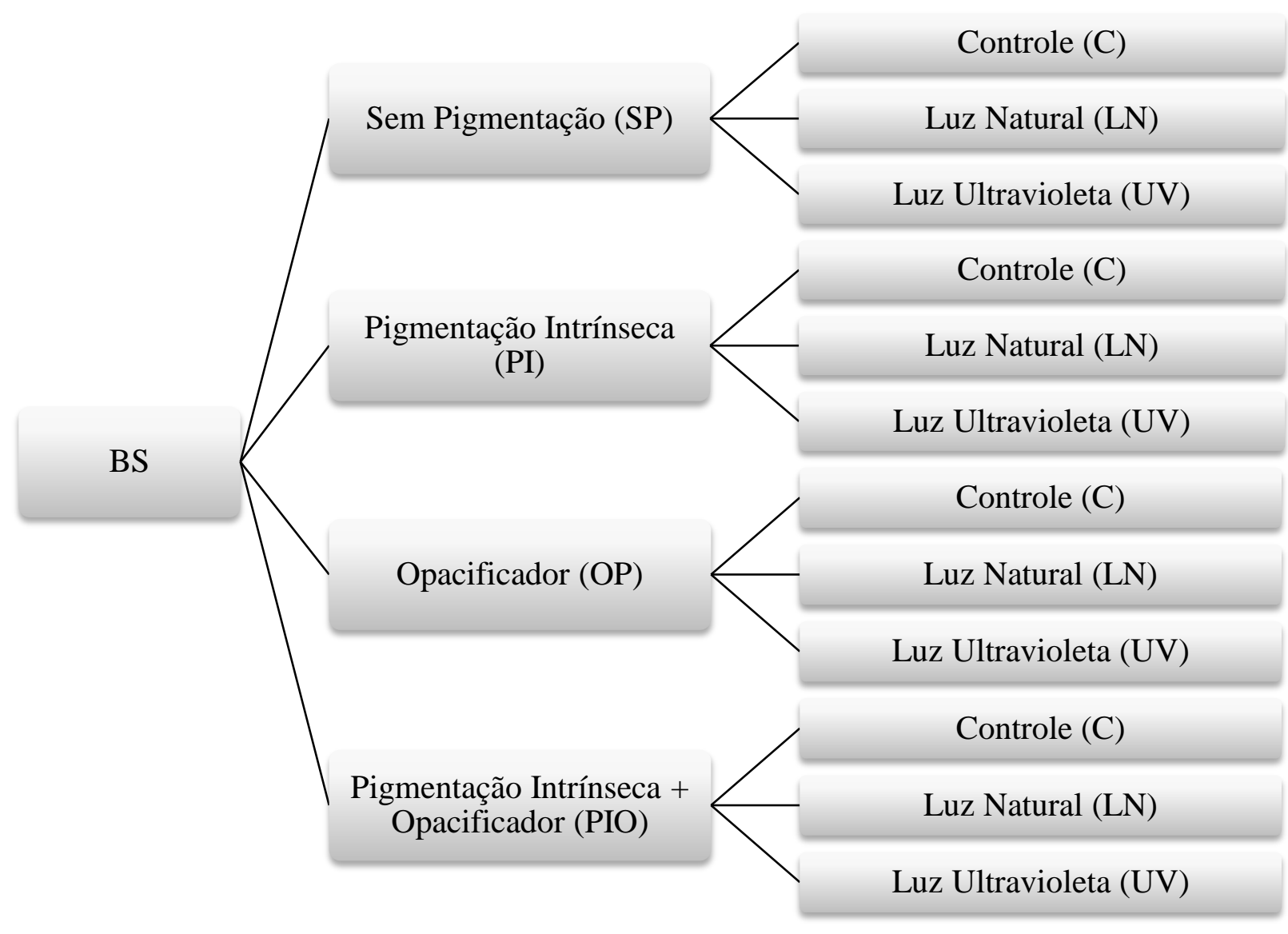

O mesmo fluxograma se aplica ao silicone MDX 4-4210.

\subsection{Confecção dos espécimes}

Para a realização dos ensaios de alteração de cor e dureza Shore A, foram confeccionados 120 espécimes circulares (15 mm de diâmetro x $3 \mathrm{~mm}$ de espessura) com cada material (Figuras 1 e 2). Para o ensaio de resistência à tração, foram confeccionados 160 espécimes em forma de haltere (ASTM D412) com cada material. A escolha do formato dos espécimes para realização dos ensaios de alteração de cor, dureza e resistência à tração foi determinada para que os resultados pudessem ser confrontados com a literatura existente (Haug; Moore; Andres, 1999; Han; Powers; Kiat-Amnuay, 2013; Nguyen et al., 2013). 


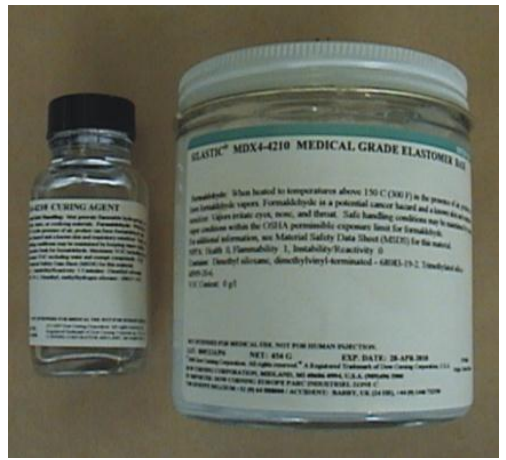

Figura 1 - Silicone MDX 4-4210.

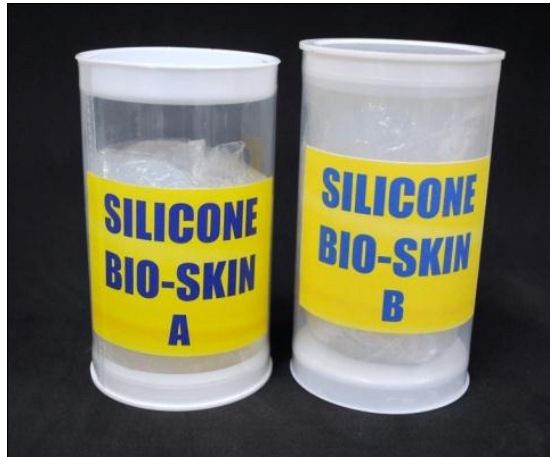

Figura 2 - Silicone experimental BS (Bio-Skin).

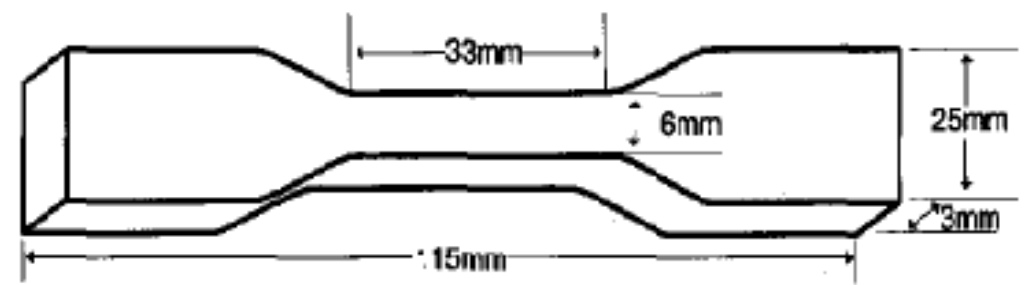

Figura 3 - Representação esquemática dos espécimes em forma de haltere, segundo norma ASTM D412.

Os silicones foram manipulados em ambiente com temperatura de $23 \pm 2{ }^{\circ} \mathrm{C}$. Foi utilizada a proporção indicada pelo fabricante, sendo 10:1 para o silicone MDX e 1:1 para o BS, obtida por meio da pesagem dos materiais em balança analítica de precisão. Para o silicone MDX, as pastas base e catalisadora foram levadas ao espatulador a vácuo (Figura 4) por 120 segundos para prevenir a incorporação de bolhas. Este material apresenta consistência viscosa. Em seguida, com o auxílio de espátula 36, o silicone foi distribuído em uma "caixa" de Teflon contendo 4 moldes com as dimensões 125 × $37 \mathrm{~mm}$ e profundidade de $3 \mathrm{~mm}$ (Figuras 5, 6 e 7). O conjunto foi levado para o interior de uma panela pneumática (Figura 8) por 15 minutos com pressão de 20 libras para eliminação de bolhas, e, posteriormente, em estufa odontológica a temperatura de $100^{\circ} \mathrm{C}$ por 30 minutos para polimerização (Figura 9). 


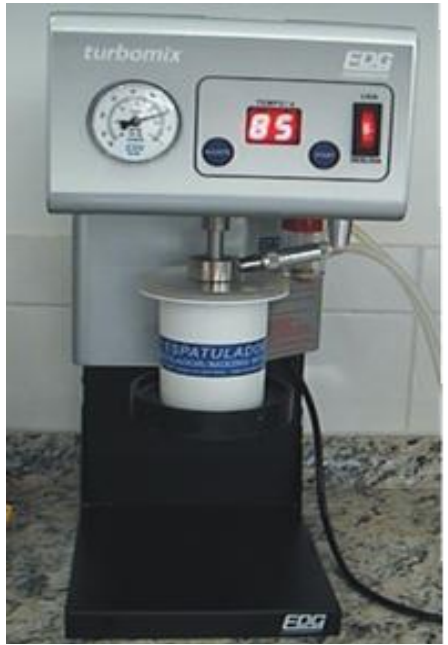

Figura 4 - Espatulador a vácuo.

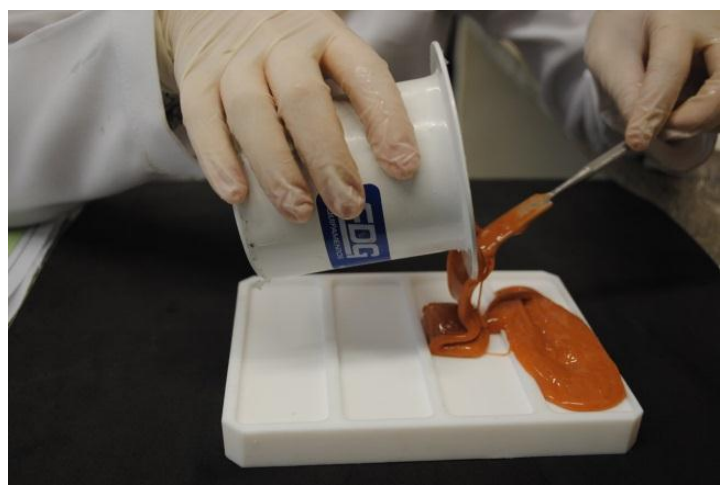

Figura 6 - Inserção do silicone MDX com PI na caixa de teflon.

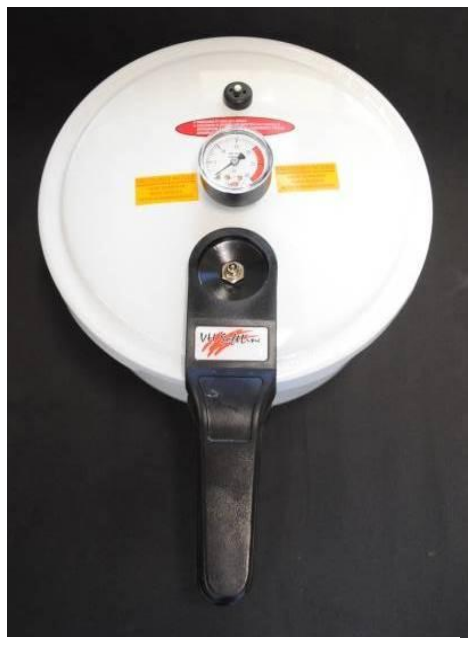

Figura 8 - Panela pneumática para eliminação de bolhas.

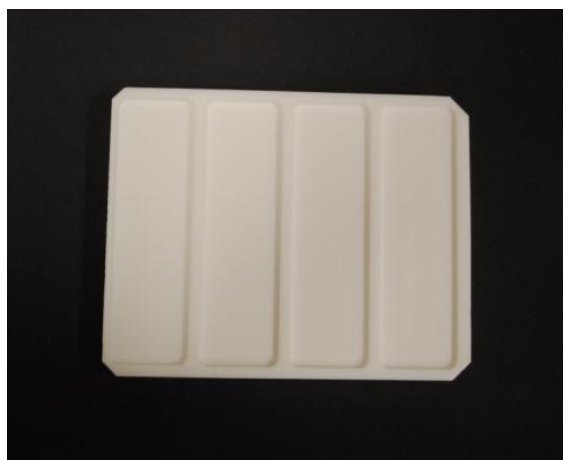

Figura 5 - Caixa Teflon.

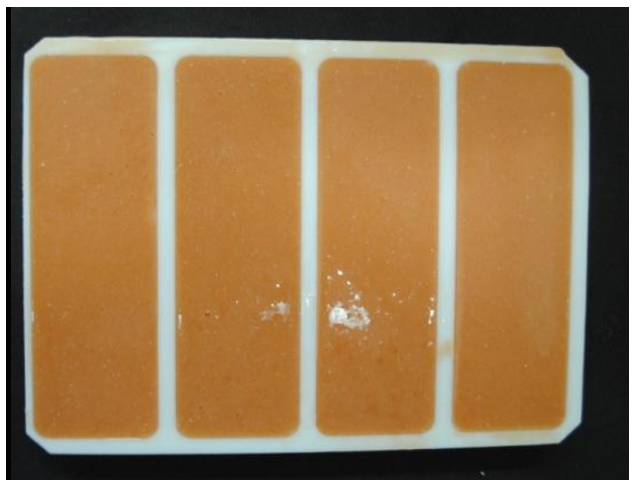

Figura 7 - Silicone MDX inserido na matriz.

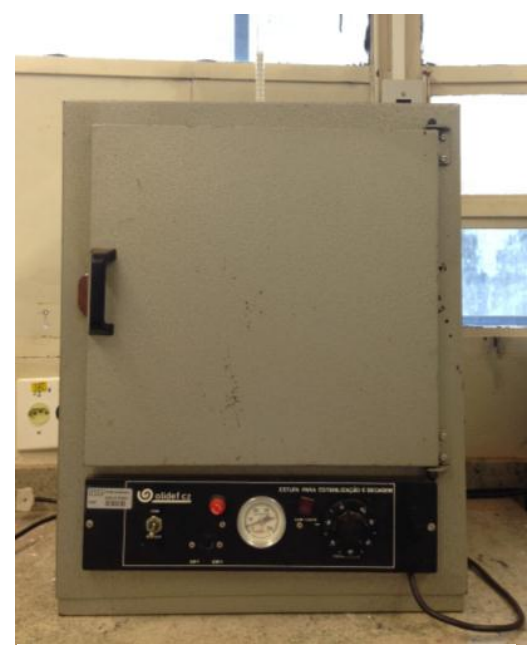

Figura 9 - Estufa odontológica. 
Para o silicone BS, as massas base e catalisadora foram inicialmente aglutinadas com as mãos e em seguida foram levadas a um cilindro laminador por 20 ciclos para homogeneização das massas bem como para incorporação dos pigmentos, quando estes foram acrescentados (Figuras 10 e 11). Este material apresenta duas massas densas, as quais necessitam de manipulação em laminador para a completa homogeneização.

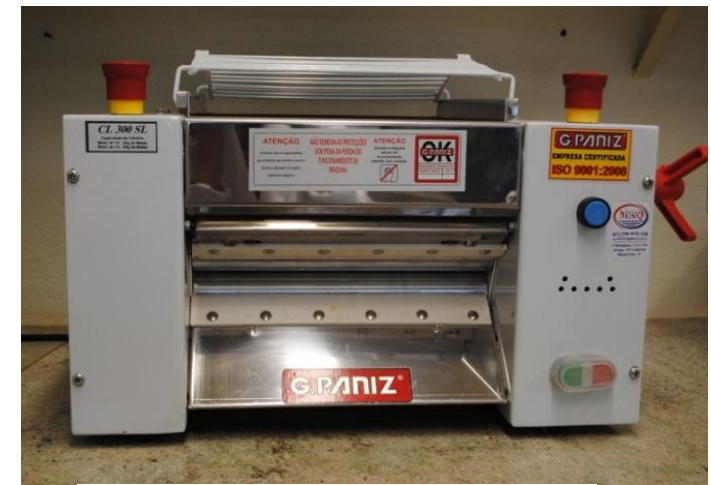

Figura 10 - Cilindro laminador.

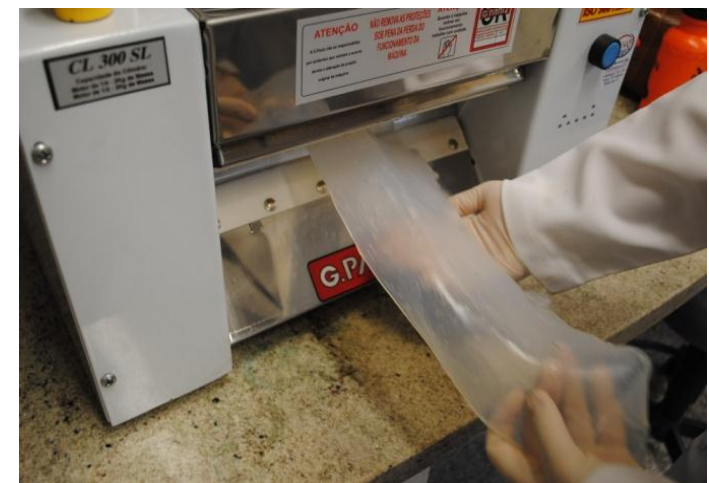

Figura 11 - Homogeneização do silicone no cilindro laminador.

O silicone foi acomodado na "caixa" de teflon e regularizado com o auxílio de um cilindro manual de teflon (Figuras 12 e 13) e então levado para polimerização em estufa à temperatura de $140^{\circ} \mathrm{C}$ por 30 minutos, seguindo as instruções do fabricante.

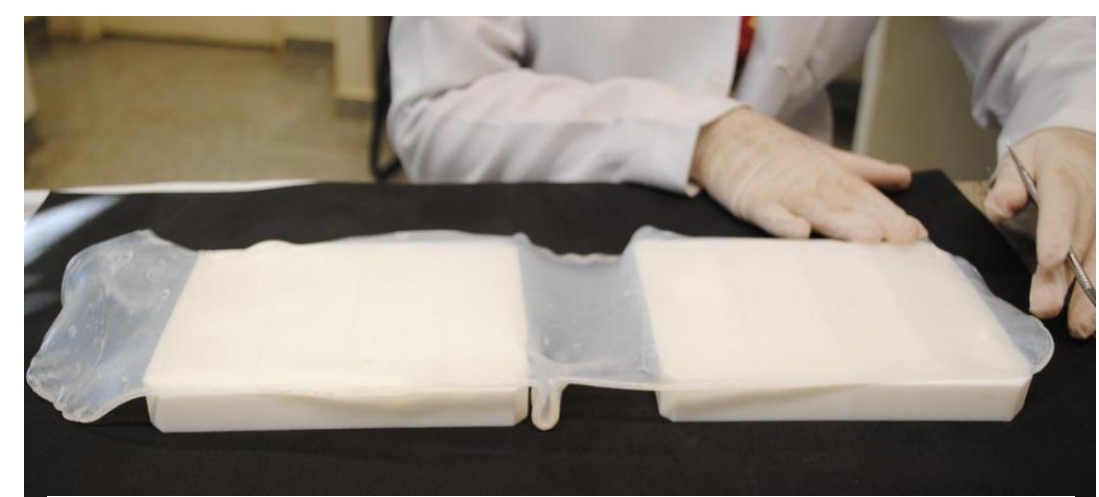

Figura 12 - Inserção do silicone BS na caixa de teflon. 


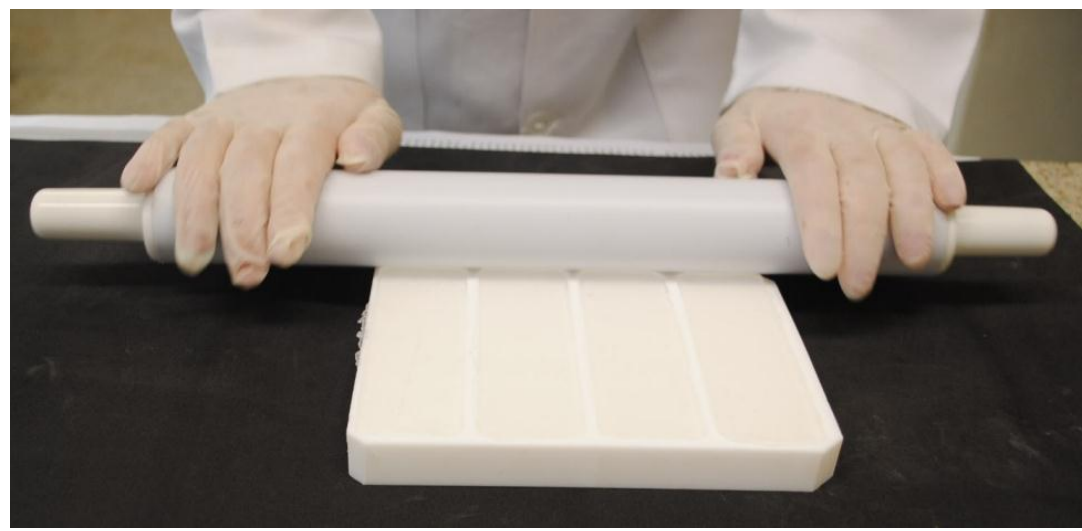

Figura 13 - Regularização do silicone BS com auxílio de cilindro manual.

Após a polimerização, os lençóis obtidos foram cortados com as respectivas matrizes metálicas de corte (Figuras 14 e 15). Este procedimento teve como objetivo a padronização dos espécimes em relação à manipulação e adição dos agentes pigmentantes.

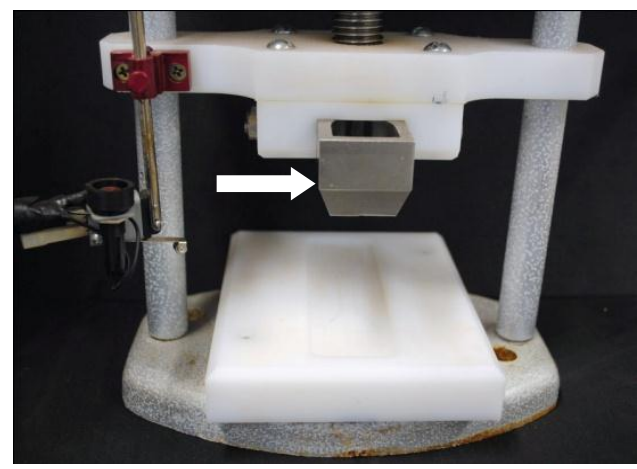

Figura 14 - Matriz metálica pré-fabricada em forma de haltere.

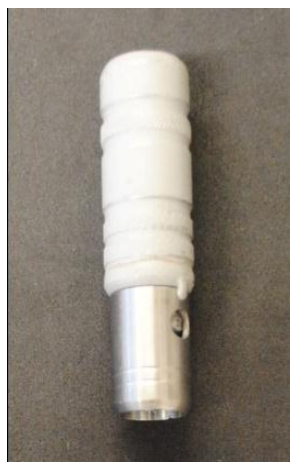

Figura 15 - Matriz metálica préfabricada circular.

\subsection{Formação dos grupos:}

\subsubsection{Grupo controle (sem pigmentação ou opacificador - SP)}

Para a confecção dos espécimes sem incorporação de pó de maquiagem ou opacificador, seguiu-se a técnica acima descrita, sem a incorporação dos pigmentos. 


\subsubsection{Grupo com pigmentação intrínseca (PI)}

Para a obtenção dos espécimes pigmentados com pó de maquiagem (Figura 16), os silicones foram manipulados acrescentando-se o pigmento intrínseco (PI) na proporção de $2 \mathrm{~g}$ de pigmento para 100g do silicone (Yu; Koran; Craig, 1980a; Figura 17). O pigmento foi adicionado à pasta base e após a incorporação dos dois materiais, acrescentou-se a pasta catalisadora para término da manipulação, em espatulador a vácuo para o silicone MDX, e no cilindro laminador para o silicone BS.

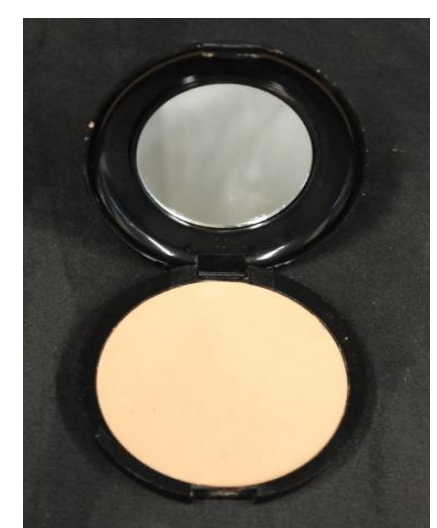

Figura 16 - Pó de maquiagem.

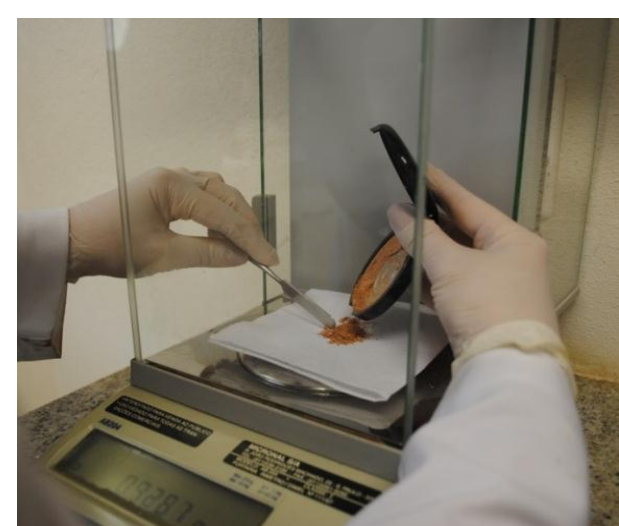

Figura 17 - Pesagem do pó de maquiagem.

\subsubsection{Grupo com opacificador (OP)}

Para a obtenção dos espécimes com opacificador (Figura 18), as mesmas condições foram seguidas, adicionando-se agora o $\mathrm{BaSO}_{4}$ equivalendo a $2 \%$ (2g de $\mathrm{BASO}_{4} / 100 \mathrm{~g}$ de silicone) do peso do silicone (Han et al., 2008; Figura 19). O opacificador foi adicionado à pasta base e após a incorporação dos dois materiais, acrescentou-se a pasta catalisadora para término da manipulação, em espatulador a vácuo para o silicone MDX, e no cilindro laminador para o silicone BS. 


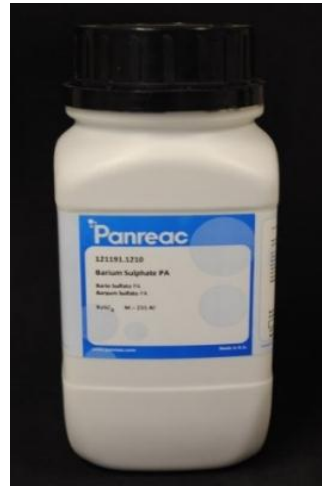

Figura 18 - Opacificador $\mathrm{BaSO}_{4}$

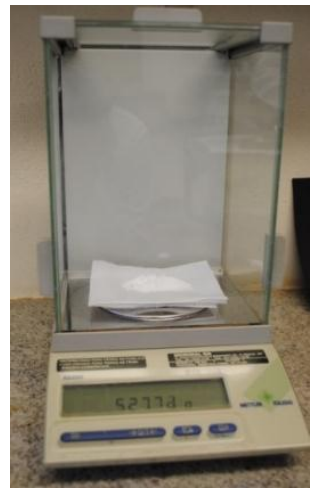

Figura 19 - Pesagem do opacificador.

4.4.4 Grupo associado (pigmentação intrínseca e opacificador - PIO)

Para o grupo que associa a PI e o OP, foi utilizada a seguinte proporção: $100 \mathrm{~g}$ de silicone (pasta base + catalisadora)/ $1 \mathrm{~g}$ de PI e $1 \mathrm{~g}$ de OP, equivalendo a $2 \%$ do peso da massa (Han et al., 2008; Figura 20). Os pigmentos foram adicionados à pasta base e após a incorporação entre eles, foi acrescentada a pasta catalisadora para manipulação no espatulador a vácuo ou no cilindro laminador, acondicionamento na caixa de teflon e polimerização.

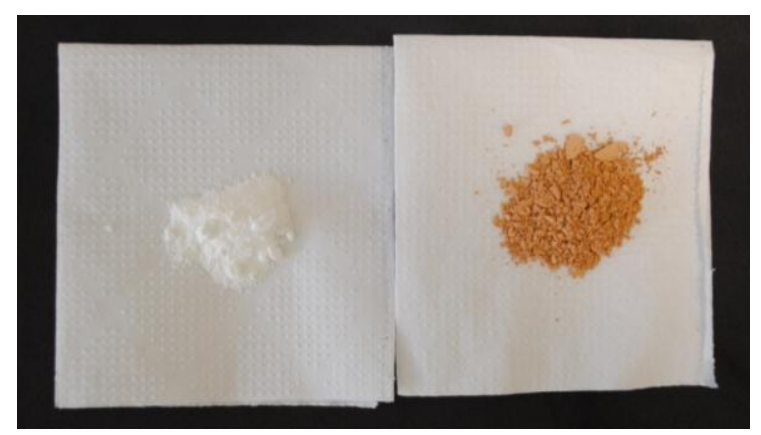

Figura 20 - Pigmentos já dosados para o grupo associado.

Finalizada a polimerização de cada grupo, os espécimes foram cortados (Figuras 21 e 22), as dimensões verificadas com o auxílio de um paquímetro digital e em seguida, foram aleatoriamente distribuídos em subgrupos para exposição ao envelhecimento. 


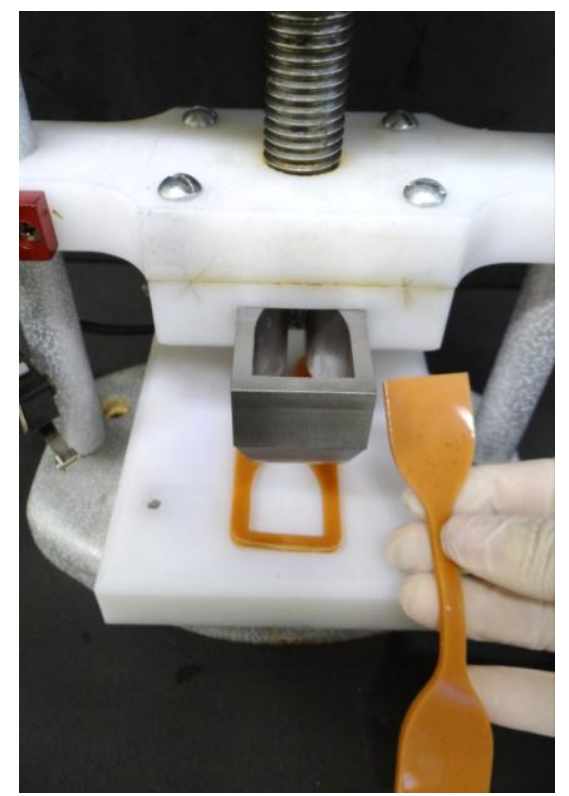

Figura 21 - Espécime em formato de haltere com pigmentação.

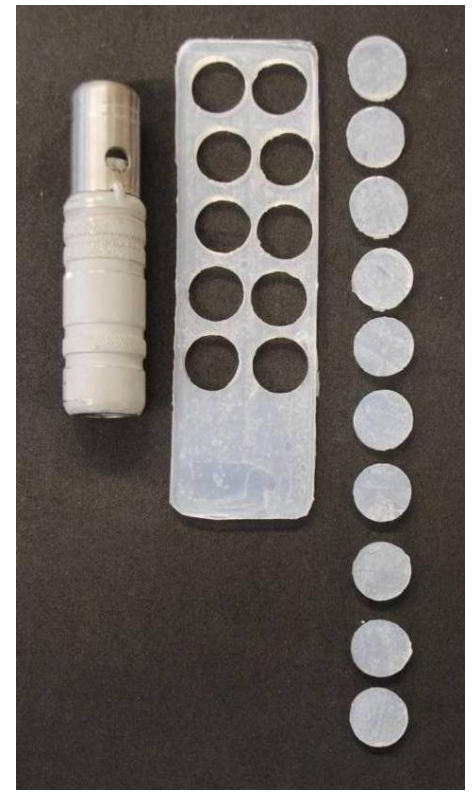

Figura 22 - Espécime circular, sem pigmentação.

\subsection{Envelhecimento}

O envelhecimento por luz ultravioleta (UV) foi realizado em câmara de envelhecimento acelerado (Figura 23) segundo a norma ASTM G154, para envelhecimento de não-metálicos. Os espécimes foram mantidos sob luz ultravioleta B e condensação por 480 horas, sendo 240 horas de UV-B e 240 horas de condensação à temperatura de $50^{\circ} \mathrm{C}$, simulando assim 12 meses.

Para o envelhecimento por luz natural (LN) que visa a simulação da exposição à luz e radiação solar, os espécimes foram expostos ao meio ambiente, no parapeito de uma janela que permaneceu aberta 24 horas por dia, por 12 meses consecutivos (Takamata; Moore; Chalian, 1989; Eleni et al., 2009; Polyzois; Eleni; Krokida, 2011a). Esta exposição foi realizada em Ribeirão Preto, $\mathrm{SP}$, com temperatura média anual de $21,7^{\circ} \mathrm{C}$, umidade relativa média de $80 \%$ e índice UV 9, classificado como muito alto. Sendo que os meses mais quentes, janeiro e fevereiro, contam com temperatura média de $24,0^{\circ} \mathrm{C}$, sendo a média máxima de $29,0^{\circ} \mathrm{C}$ e a mínima de $18,0^{\circ} \mathrm{C}$. E o mês mais frio, junho, com média de $17,8^{\circ} \mathrm{C}$, sendo $25,0^{\circ} \mathrm{C}$ e $12,0^{\circ} \mathrm{C}$ as médias máxima e mínima, respectivamente, segundo informações do Centro de Pesquisas Meteorológicas e Climáticas Aplicadas à Agricultura (CEPAGRI). 
Como controle (C), os espécimes foram mantidos em um recipiente hermeticamente fechado e na ausência total de luz por 12 meses consecutivos.

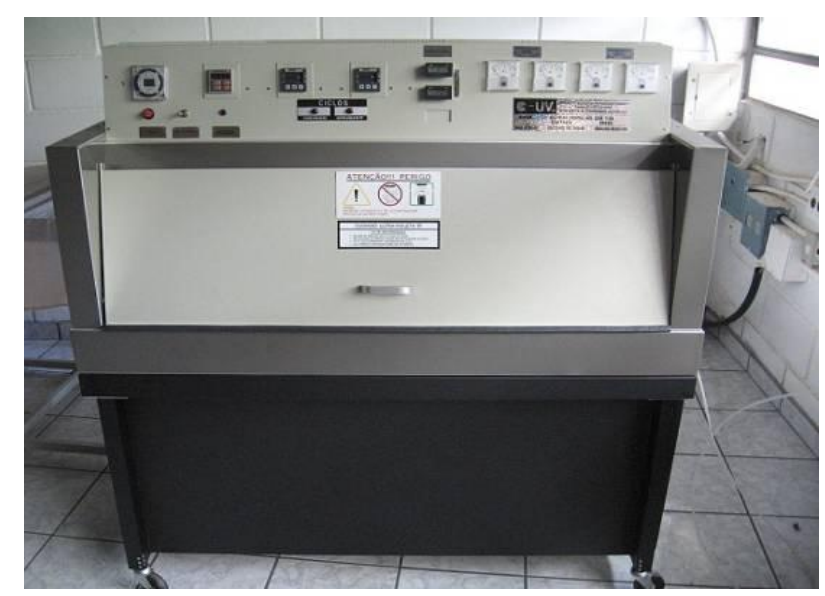

Figura 23 - Câmara de envelhecimento artificial acelerado.

\subsection{Realização dos ensaios físicos e mecânicos}

4.6.1 Ensaios de alteração de cor e dureza Shore A

A alteração de cor $(\Delta \mathrm{E})$ foi determinada com o auxílio de um espectrocolorímetro portátil (Figura 24), utilizando o sistema de cores Standart Commission Internationale de L Eclairage (CIE L*a*b*), recomendado pela American Dental Association. Esse sistema representa um espaço tridimensional de cor tendo componentes de clareza (L), vermelhoverde (a) e amarelo-azul (b). Um aspecto importante do sistema CIE L*a*b* é que a diferença de cor entre os tempos ( $\mathrm{Ti}$, imediatamente após a obtenção dos espécimes e Tf, após o envelhecimento) pode ser dada usando um parâmetro, $\Delta$ Eab. A alteração de cor entre cada espécime, cada uma dada em termos de $\mathrm{L}$, a e b, foi calculada pela seguinte fórmula: $\triangle E a b=$ $\left[(\Delta L)^{2}+(\Delta a)^{2}+(\Delta b)^{2}\right]^{1 / 2}$.

Os mesmos espécimes foram utilizados para avaliação da dureza Shore A. O ensaio permite verificar o grau de maciez dos silicones (Pinheiro et al., 2014). Foi utilizado um durômetro Shore A (Figura 25), que consiste em um penetrador com ponta sem corte ligado a 
uma escala por arranjo de alavanca com gravação de 0-100 unidades Shore A. Quanto mais o penetrador penetra o espécime, menor é o valor de dureza. A análise foi realizada com os espécimes posicionados sob a haste vertical do mesmo e submetido à força de $1 \mathrm{~kg}$ por $5 \mathrm{~s}$ (ASTM D2240) e a leitura foi tomada imediatamente após a obtenção de um firme contato do penetrador com a superfície do espécime. Foram realizadas cinco mensurações em cada espécime para obtenção de um valor médio (ASTM D2240) antes (Ti) e após o envelhecimento (Tf). As médias dos resultados foram fornecidas em unidades Shore A e a variação (Tf - Ti) foi considerada na análise estatística.

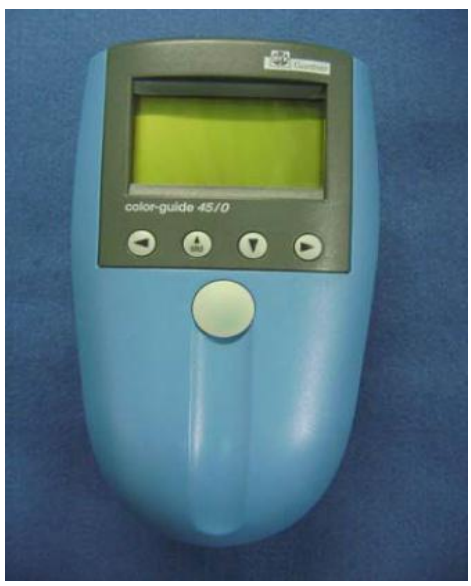

Figura 24 - Espectrocolorímetro portátil.

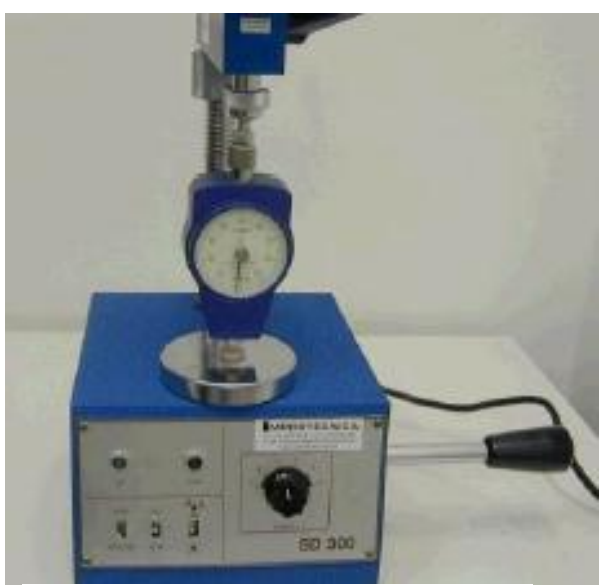

Figura 25 - Durômetro Shore A.

\subsubsection{Ensaio de resistência à tração}

O ensaio de resistência à tração foi realizado tendo como base a norma descrita pela Associação Americana para Testes e Materiais (ASTM) D412. A espessura e largura de cada espécime foi medida 3 vezes com auxílio do paquímetro e o valor médio foi utilizado para o cálculo da área do corte transversal. As extremidades dos espécimes foram aprisionadas a uma máquina de ensaio universal e o ensaio foi conduzido com uma taxa de separação de 500 $\mathrm{mm} / \mathrm{min}$ (Figura 26). A leitura final para cada espécime foi observada quando houve a ruptura com o valor da resistência máxima. A carga máxima antes da ruptura foi registrada em Newtons e a resistência à tração em $\mathrm{MPa}$, foi calculada pela fórmula: $R T=F / A$, em que a 
RT é a resistência à tração, F é a força no momento da ruptura, e A é a secção transversal em mm. Cabe salientar que, como este ensaio é destrutivo, a análise desta variável não foi vinculada ao mesmo espécime. Para cada grupo de pigmentação foram confeccionados 10 espécimes que foram submetidos ao ensaio de tração imediatamente após a sua obtenção para que os valores Ti e Tf pudessem ser comparados. A variável foi mensurada imediatamente após a obtenção dos espécimes (Ti) e após a exposição aos processos de envelhecimento (Tf), obtendo-se ao final, o valor da resistência à tração.

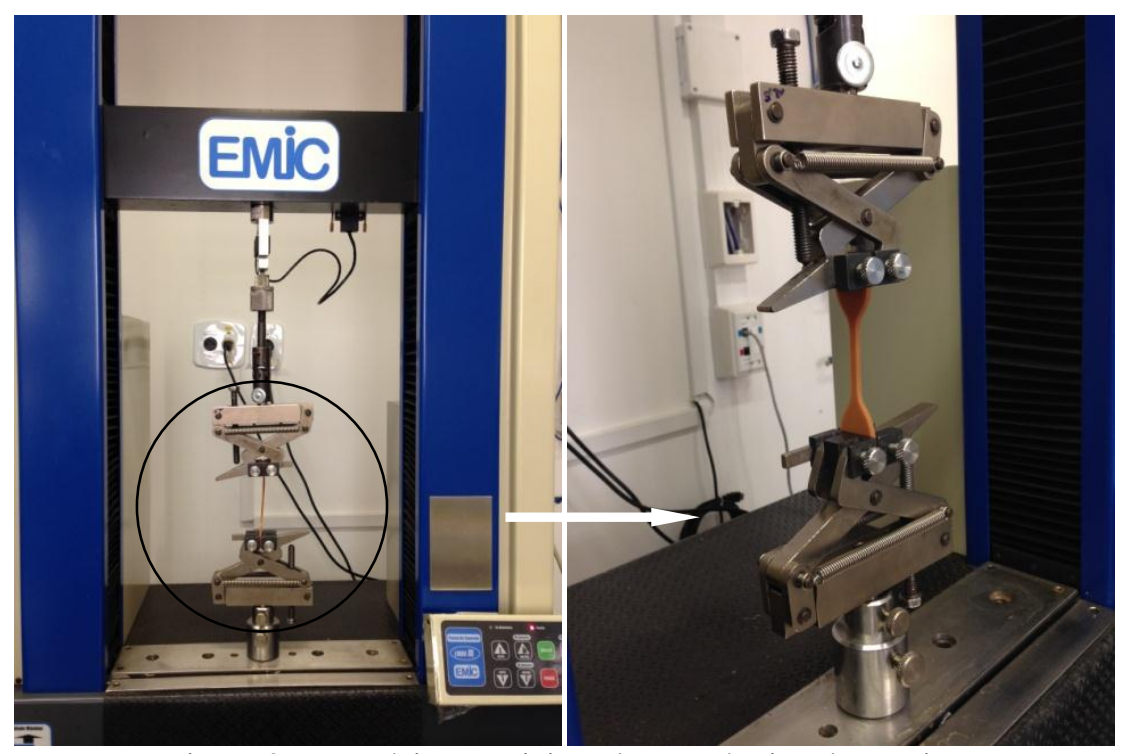

Figura 26 - Espécime posicionado na máquina de ensaio.

\subsection{Ensaio de Microscopia Eletrônica de Varredura e Espectroscopia por Energia Dispersiva para análise de superfície e composição química}

A Microscopia eletrônica de varredura (MEV) foi realizada com auxílio do Microscópio Eletrônico de Varredura. Um fragmento de $1 \times 1 \mathrm{~cm}$ de cada espécime de cada grupo foi utilizado e a leitura foi realizada sob aumento de 1000x. A espectroscopia de energia dispersiva (EDS) foi realizada concomitantemente à leitura de MEV, com auxílio do aparelho descrito acima equipado com um detector de raios- $\mathrm{x}$ a fim de se viabilizar o ensaio e detectar o tipo e a quantidade de cada elemento químico presente nos espécimes de silicone. 


\subsection{Análise dos dados}

Verificada a distribuição normal (Teste de Shapiro-Wilks) e homogênea (Teste de Levene) dos dados das variáveis quantitativas (alteração de cor, dureza Shore A e resistência à tração), empregou-se a Análise de Variância (considerando três fatores de variação: material em dois níveis, pigmentação em 4 níveis e envelhecimento em 3 níveis) e Teste Complementar de Tukey $(\mathrm{p}<0,05)$ para comparação das médias. Os resultados das análises de MEV e EDS foram apresentados em figuras, interpretados e discutidos. 


\section{Resultados}




\subsection{Resultados para as propriedades físico-mecânicas}

\subsubsection{Alteração de cor}

A tabela A1 (Apêndice) apresenta os valores de alteração de cor $(\Delta \mathrm{E})$ dos silicones sem pigmentação (SP), com pigmentação intrínseca (PI), com opacificador (OP) e com associação (PIO), após envelhecimento por luz natural, luz ultravioleta e grupo controle. A partir desta tabela foi realizada a análise de variância (Tabela 1) que indicou diferença entre todos os fatores (Figuras A1, A2, A3, Apêndice), bem como interação entre eles (Tabela 2).

Tabela 1 - Análise de variância dos dados de alteração de cor $(\Delta \mathrm{E})$.

\begin{tabular}{lccccc}
\hline Fatores de variação & Soma dos quadrados & G.L. & Quadrados médios & F & Sig. \\
\hline Material (M) &, 662 & 1 &, 662 & 4,209 &, 041 \\
Pigmentação (P) & 95,918 & 3 & 31,973 & 203,264 &, 000 \\
Envelhecimento (E) & 79,839 & 2 & 39,920 & 253,785 &, 000 \\
$\mathrm{M} * \mathrm{P}$ & 3,794 & 3 & 1,265 & 8,040 &, 000 \\
$\mathrm{M} * \mathrm{E}$ & 24,929 & 2 & 12,464 & 79,240 &, 000 \\
$\mathrm{P} * \mathrm{E}$ & 112,563 & 6 & 18,761 & 119,269 &, 000 \\
$\mathrm{M} * \mathrm{P} * \mathrm{E}$ & 29,154 & 6 & 4,859 & 30,891 &, 000 \\
Erro & 33,976 & 216 &, 157 & & \\
\hline
\end{tabular}

Tabela 2 - Comparação das médias (DP) da alteração de cor $(\Delta \mathrm{E})$ na interação entre materiais, pigmentação e envelhecimento.

\begin{tabular}{|c|c|c|c|c|c|c|c|c|c|c|c|c|}
\hline & \multicolumn{4}{|c|}{ Controle } & \multicolumn{4}{|c|}{ Luz Natural } & \multicolumn{4}{|c|}{ Luz Ultravioleta } \\
\hline & SP & PI & OP & PIO & SP & PI & OP & PIO & SP & PI & OP & $\mathrm{PIO}$ \\
\hline \multirow{3}{*}{ MDX } & 1,12 & 1,42 & 1,29 & 0,71 & 2,31 & 0,6 & 3,45 & 0,4 & 1,73 & 0,56 & 1,86 & 0,28 \\
\hline & $\pm 0,15$ & $\pm 0,33$ & $\pm 0,12$ & $\pm 0,21$ & $\pm 2,72$ & $\pm 0,30$ & $\pm 0,64$ & $\pm 0,33$ & $\pm 0,51$ & $\pm 0,35$ & $\pm 0,32$ & $\pm 0,57$ \\
\hline & $\mathrm{Aa}^{*}$ & $\mathrm{Aa}^{*}$ & $\mathrm{Aa}^{*}$ & $\mathrm{Aa}^{*}$ & $\mathrm{Ba} \bullet$ & $\mathrm{Aa} \bullet$ & $\mathrm{Ca} \bullet$ & $\mathrm{Aa}^{*}$ & $\mathrm{Ba}^{*}$ & $\mathrm{Aa} \bullet$ & $\mathrm{Ba} \diamond$ & $\mathrm{Aa}^{*}$ \\
\hline \multirow{3}{*}{ BS } & 0,38 & 0,76 & 0,46 & 0,48 & 4,95 & 0,84 & 4,22 & 0,56 & 0,92 & 0,97 & 1,16 & 1,31 \\
\hline & $\pm 0,27$ & $\pm 0,25$ & $\pm 0,53$ & $\pm 0,17$ & $\pm 0,82$ & $\pm 0,18$ & $\pm 0,33$ & $\pm 0,16$ & $\pm 0,39$ & $\pm 0,44$ & $\pm 0,41$ & $\pm 0,85$ \\
\hline & $\mathrm{Ab}^{*}$ & $\mathrm{Aa}^{*}$ & $\mathrm{Ab}^{*}$ & $\mathrm{Aa}^{*}$ & $\mathrm{Cb} \bullet$ & $\mathrm{Ab}^{*}$ & $\mathrm{Bb} \bullet$ & $\mathrm{Aa}^{*}$ & $\mathrm{Ab}^{*}$ & $\mathrm{Aa}^{*}$ & $A b \diamond$ & $\mathrm{Ab} \bullet$ \\
\hline
\end{tabular}

Letras/símbolos iguais = igualdade estatística. Letras maiúsculas = comparação entre colunas do mesmo bloco. Letras minúsculas = comparação entre linhas. Símbolo = comparação entre colunas de blocos diferentes. 
Para a análise de alteração de cor, os materiais apresentaram diferenças entre si para as pigmentações SP e OP do grupo Controle; SP, PI e OP do grupo Luz Natural; e SP, OP e PIO do grupo Luz Ultravioleta. Analisando a alteração de cor dos silicones em função da pigmentação, o silicone MDX apresentou maiores variações com os espécimes SP e OP envelhecidos por LN e UV. Para o BS, houve alteração significativa da cor dos espécimes SP e OP somente após o envelhecimento por LN. Comparando os grupos de mesma pigmentação, mas de diferentes envelhecimentos, para o silicone MDX, somente PIO não apresentou diferenças entre os envelhecimentos. Para o silicone BS, o grupo que não promoveu alteração de cor entre os envelhecimentos foi PI.

\subsubsection{Dureza Shore A}

As tabelas A2 e A3 (Apêndice) apresentam os valores (iniciais, finais e variação) de dureza Shore A dos espécimes confeccionados com o silicone MDX 4-4210 e com o silicone experimental - BS (Bio-Skin), respectivamente, sem pigmentação (SP), com pigmentação intrínseca (PI), com opacificador (OP) e com associação (PIO), após envelhecimento por luz natural, luz ultravioleta e grupo controle. A análise de variância (Tabela 3) indicou diferença entre todos os fatores (Figuras A4, A5 e A6 - Apêndice), bem como interação entre os fatores estudados. A comparação das médias encontra-se na tabela 4.

Tabela 3 - Análise de variância dos dados de dureza Shore A (resultados fornecidos em unidades Shore A).

\begin{tabular}{lccccc}
\hline Fatores de variação & Soma dos quadrados & G.L. & Quadrados médios & F & Sig. \\
\hline Material (M) & 63,243 & 1 & 63,243 & 14,637 &, 000 \\
Envelhecimento (E) & 143,336 & 2 & 71,668 & 16,587 &, 000 \\
Pigmentação (P) & 47,323 & 3 & 15,774 & 3,651 &, 013 \\
M * E & 72,136 & 2 & 36,068 & 8,348 &, 000 \\
M * P & 217,497 & 3 & 72,499 & 16,780 &, 000 \\
E*P & 86,444 & 6 & 14,407 & 3,335 &, 004 \\
M $*$ E*P & 254,908 & 6 & 42,485 & 9,833 &, 000 \\
Erro & 933,256 & 216 & 4,321 & & \\
\hline
\end{tabular}


Tabela 4 - Comparação das médias (DP) da dureza Shore A (resultados fornecidos em unidades Shore A) na interação entre os fatores material, pigmentação, envelhecimento.

\begin{tabular}{ccccc|cccc|cccc}
\hline \multicolumn{5}{c|}{ Controle } & \multicolumn{4}{c|}{ Luz Natural } & \multicolumn{4}{c}{ Luz Ultravioleta } \\
\hline SP & PI & OP & PIO & SP & PI & OP & PIO & SP & PI & OP & PIO \\
\hline MDX & $\pm 1,44$ & 5,06 & 7,6 & 4,66 & 4,56 & 3,82 & 7,98 & 6,58 & 0,58 & 3,88 & 3,9 & 3,98 \\
& $\pm 1,35$ & $\pm 1,56$ & $\pm 2,09$ & $\pm 1,82$ & $\pm 1,71$ & $\pm 2,24$ & $\pm 1,54$ & $\pm 1,64$ & $\pm 1,91$ & $\pm 2,56$ & $\pm 2,3$ \\
& $\mathrm{Aa}^{*}$ & $\mathrm{Aa}^{*}$ & $\mathrm{Ba}^{*}$ & $\mathrm{Aa}^{*}$ & $\mathrm{ABa}^{*}$ & $\mathrm{Aa}^{*}$ & $\mathrm{Ca}^{*}$ & $\mathrm{BCa}$ & $\mathrm{Aa}$ & $\mathrm{Ba}^{*}$ & $\mathrm{Ba}$ & $\mathrm{Ba}$ \\
\hline & 8,66 & 4,84 & 5,06 & 8,16 & 5,62 & 8,26 & 4,12 & 2,9 & 4,28 & 4,72 & 4,96 & 6,28 \\
$\mathrm{BS}$ & $\pm 1,71$ & $\pm 2,17$ & $\pm 2,07$ & $\pm 2,73$ & $\pm 2,34$ & $\pm 0,87$ & $\pm 1,25$ & $\pm 1,57$ & $\pm 2,06$ & $\pm 2,39$ & $\pm 4,3$ & $\pm 1,75$ \\
& $\mathrm{Bb}^{*}$ & $\mathrm{Aa}^{*}$ & $\mathrm{Ab}^{*}$ & $\mathrm{Bb}^{*}$ & $\mathrm{Ba}$ & $\mathrm{Cb} \cdot$ & $\mathrm{ABb} *$ & $\mathrm{Ab}$ & $\mathrm{Ab}$ & $\mathrm{Aa}^{*}$ & $\mathrm{Aa}^{*}$ & $\mathrm{Ab}^{*}$ \\
\hline
\end{tabular}

Letras/símbolos iguais $=$ igualdade estatística. Letras maiúsculas = comparação entre colunas do mesmo bloco. Letras minúsculas $=$ comparação entre linhas. Símbolo = comparação entre colunas de blocos diferentes.

Todos os materiais apresentaram aumento da dureza frente a todas as condições, visto que não foram detectados valores negativos (-) após o cálculo da variação da dureza (Tf-Ti). Os materiais apresentaram diferenças entre si para as pigmentações SP, OP e PIO no grupo Controle; PI, OP e PIO no grupo Luz Natural; e SP e PIO no grupo Luz Ultravioleta. Para o silicone MDX, o opacificador (OP) promoveu a maior variação da dureza nos grupos Controle e LN. Quando envelhecido por Luz Natural, os espécimes sem pigmentação (SP) e com os pigmentos associados (PIO) apresentaram valores intermediários e os com pigmentação intrínseca (PI), a menor variação. No grupo UV, a menor variação da dureza foi encontrada nos espécimes sem pigmentação (SP), sendo que as pigmentações foram semelhantes entre si. A pigmentação não promoveu diferenças para o silicone BS, quando envelhecido por UV. Os grupos do silicone MDX pigmentados com pó de maquiagem (PI) não apresentaram diferenças entre os envelhecimentos, sendo que as demais pigmentações apresentaram diferenças entre si em função do envelhecimento. Para o silicone BS, não foi detectada diferença na dureza dos espécimes, somente com o OP em função dos envelhecimentos.

\subsubsection{Resistência à tração}

A tabela A4 (Apêndice) apresenta os valores (iniciais e finais) de resistência à tração dos silicones estudados sem pigmentação (SP), com pigmentação intrínseca (PI), com 
opacificador (OP) e com associação (PIO), após envelhecimento por luz natural, luz ultravioleta e grupo controle. A partir desta tabela foi realizada a análise de variância (Tabela 5) que indicou diferença entre os fatores (Figuras A7, A8 e A9 - Apêndice), bem como interação entre eles. A comparação das médias encontra-se na tabela 6.

Tabela 5 - Análise de variância dos dados de resistência à tração (MPa).

\begin{tabular}{lccccc}
\hline Fatores de variação & Soma dos quadrados & G.L. & Quadrados médios & F & Sig. \\
\hline Material (M) & 2322,066 & 1 & 2322,066 & 6347,115 &, 000 \\
Envelhecimento (E) & 10,518 & 3 & 3,506 & 9,583 &, 000 \\
Pigmentação (P) & 20,946 & 3 & 6,982 & 19,084 &, 000 \\
M E & 2,585 & 3 &, 862 & 2,355 &, 072 \\
M $* \mathrm{P}$ & 7,258 & 3 & 2,419 & 6,613 &, 000 \\
$\mathrm{E} * \mathrm{P}$ & 8,757 & 9 &, 973 & 2,660 &, 006 \\
$\mathrm{M} * \mathrm{E} * \mathrm{P}$ & 6,265 & 9 &, 696 & 1,903 &, 050 \\
Erro & 105,364 & 288 &, 366 & & \\
\hline
\end{tabular}

Tabela 6 - Comparação das médias (DP) da resistência à tração (MPa) dos espécimes de silicone MDX 4-4210 e silicone experimental - BS (Bio-Skin) quando da interação entre os fatores material, pigmentação e envelhecimento.

\begin{tabular}{|c|c|c|c|c|c|c|c|c|c|c|c|c|c|c|c|c|}
\hline & \multicolumn{4}{|c|}{ Inicial } & \multicolumn{4}{|c|}{ Controle } & \multicolumn{4}{|c|}{ Luz Natural } & \multicolumn{4}{|c|}{ Luz Ultravioleta } \\
\hline & SP & PI & $\mathrm{OP}$ & $\mathrm{PIO}$ & SP & PI & $\mathrm{OP}$ & $\mathrm{PIO}$ & SP & PI & $\mathrm{OP}$ & $\mathrm{PIO}$ & SP & PI & $\mathrm{OP}$ & $\mathrm{PIO}$ \\
\hline \multirow{3}{*}{ MDX } & 2,28 & 2,32 & 1,82 & 1,86 & 1,87 & 2,13 & 1,8 & 2,13 & 1,75 & 1,98 & 1,97 & 2,02 & 2,41 & 2,74 & 2,03 & 2,14 \\
\hline & $\pm 0,22$ & $\pm 0,38$ & $\pm 0,32$ & $\pm 0,34$ & $\pm 0,40$ & $\pm 0,46$ & $\pm 0,30$ & $\pm 0,46$ & $\pm 0,27$ & $\pm 0,45$ & $\pm 0,38$ & $\pm 0,54$ & $\pm 0,57$ & $\pm 0,36$ & $\pm 0,41$ & $\pm 0,40$ \\
\hline & $\mathrm{Aa}^{*}$ & $\mathrm{Aa}^{*}$ & $\mathrm{Aa}^{*}$ & $\mathrm{Aa}^{*}$ & $\mathrm{Aa}^{*}$ & $\mathrm{Aa}^{*}$ & $\mathrm{Aa}^{*}$ & $\mathrm{Aa}^{*}$ & $\mathrm{Aa}^{*}$ & $\mathrm{Aa}^{*}$ & $\mathrm{Aa}^{*}$ & $\mathrm{Aa}^{*}$ & $\mathrm{Aa}^{*}$ & $\mathrm{Aa} \bullet$ & $\mathrm{Aa}^{*}$ & $\mathrm{Aa}^{*}$ \\
\hline \multirow{3}{*}{ BS } & 7,54 & 7,7 & 7,57 & 8,26 & 7,02 & 8,07 & 6,85 & 7,24 & 6,44 & 7,7 & 6,97 & 7,57 & 7,5 & 8,41 & 6,75 & 7,87 \\
\hline & $\pm 0,93$ & $\pm 0,7$ & $\pm 0,3$ & $\pm 0,6$ & $\pm 0,99$ & $\pm 1,09$ & $\pm 0,4$ & $\pm 0,78$ & $\pm 0,62$ & $\pm 1,23$ & $\pm 0,73$ & $\pm 0,54$ & $\pm 0,69$ & $\pm 0,49$ & $\pm 0,54$ & $\pm 0,82$ \\
\hline & $\mathrm{Ab}^{*}$ & $\mathrm{ABb}^{*}$ & $\mathrm{ABb}^{*}$ & $\mathrm{Bb}^{*}$ & $\mathrm{Ab}^{* \bullet}$ & $\mathrm{Bb}^{*}$ & $\mathrm{Ab}^{*} \bullet$ & $\mathrm{Ab} \bullet$ & $\mathrm{Ab} \bullet$ & $\mathrm{Cb}^{*}$ & $\mathrm{ABb}^{* \bullet}$ & $\mathrm{BCb}^{* \bullet}$ & $\mathrm{Bb}^{*}$ & $\mathrm{Cb}^{*}$ & $\mathrm{Ab} \bullet$ & $\mathrm{BCb}^{* \bullet}$ \\
\hline
\end{tabular}

Letras/símbolos iguais = igualdade estatística. Letras maiúsculas = comparação entre colunas do mesmo bloco. Letras minúsculas = comparação entre linhas. Símbolo = comparação entre colunas de blocos diferentes.

Os materiais apresentaram diferenças entre si para todos os envelhecimentos e pigmentações com os valores de resistência do silicone BS sempre superiores aos do MDX. O silicone MDX não sofreu influência significativa na resistência à tração por nenhuma das pigmentações ou envelhecimento, exceto quanto pigmentado com pó de maquiagem e envelhecido por UV, onde houve aumento da resistência. Quanto ao silicone BS, os maiores 
valores de resistência à tração foram encontrados com a PI e PIO em todos os grupos de envelhecimento.

5.2 Resultados para as análises de superfície (MEV) e composição química dos silicones (EDS)

As figuras abaixo (27 a 50) apresentam as informações obtidas por meio da Microscopia Eletrônica de Varredura (MEV) e Espectroscopia por Energia Dispersiva (EDS), sendo, gráfico com compostos identificados, imagem da superfície e porcentagem dos pesos dos elementos químicos identificados nos silicones MDX 4-4210 e silicone experimental BS (Bio-Skin) de todos os grupos de pigmentação após os processos de envelhecimento e controle.

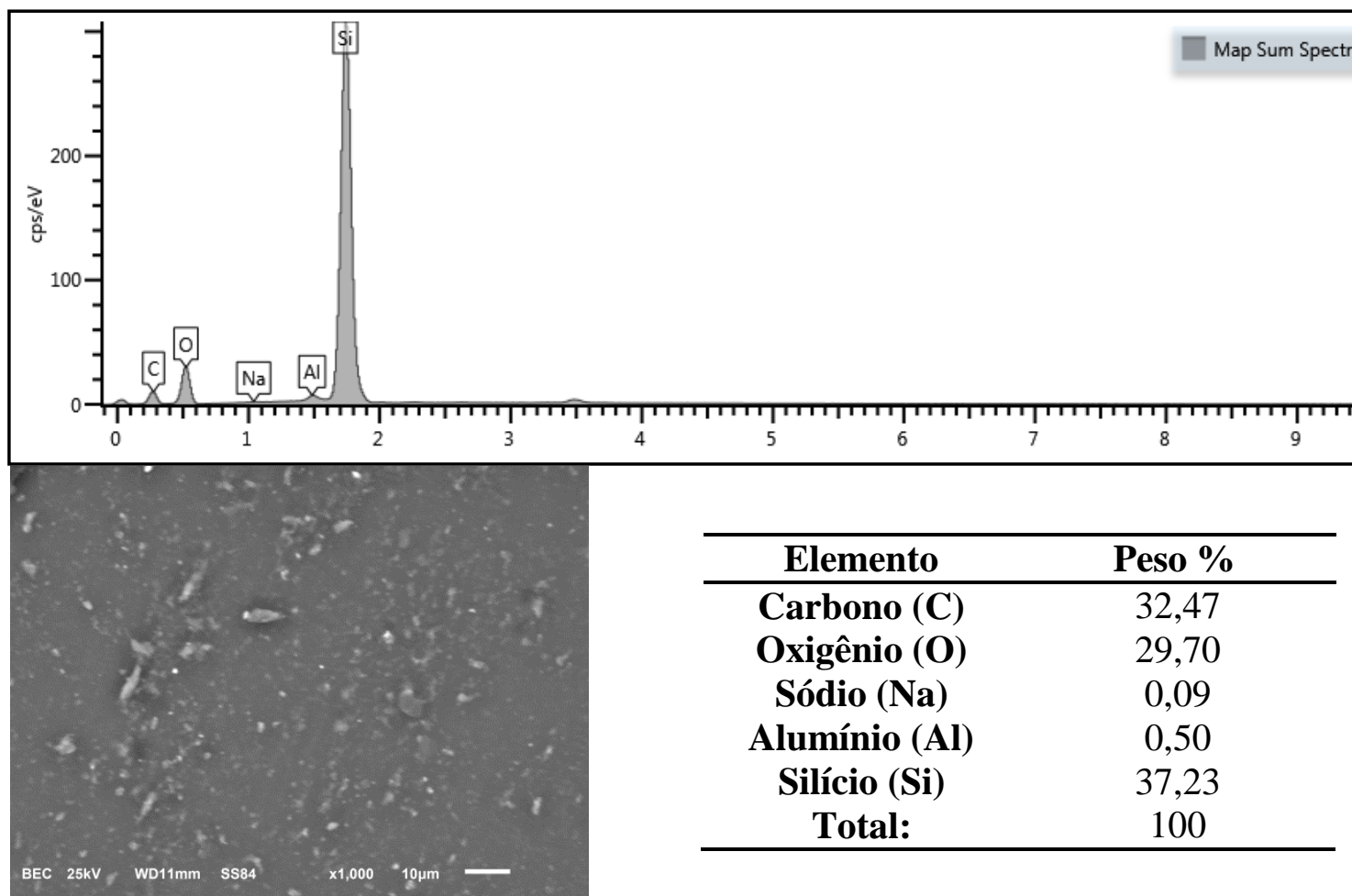

Figura 27 - Silicone MDX, Sem Pigmentação, Controle. 

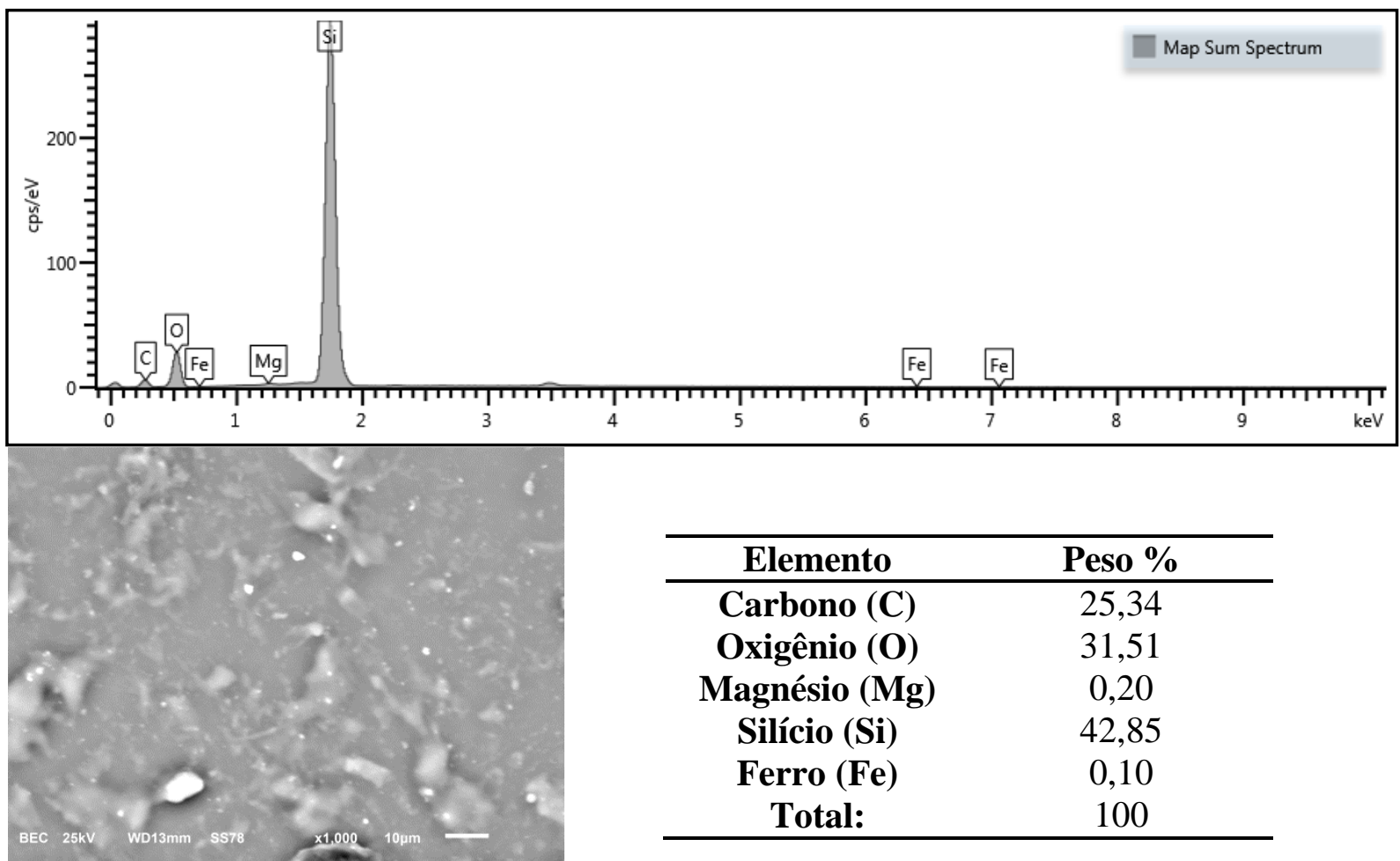

Figura 28 - Silicone MDX, Pigmentação Intrínseca, Controle.

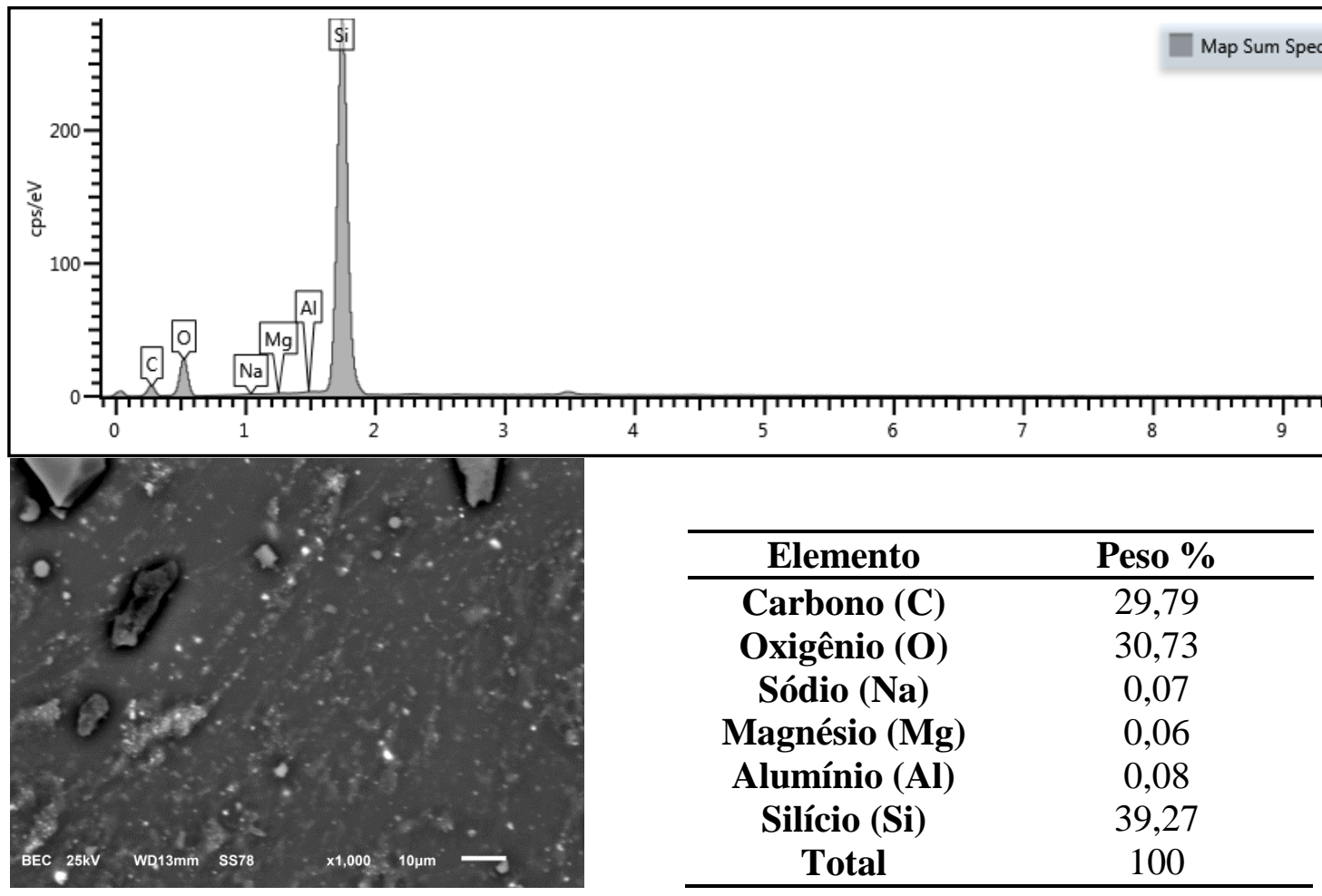

Figura 29 - Silicone MDX, Opacificador, Controle. 

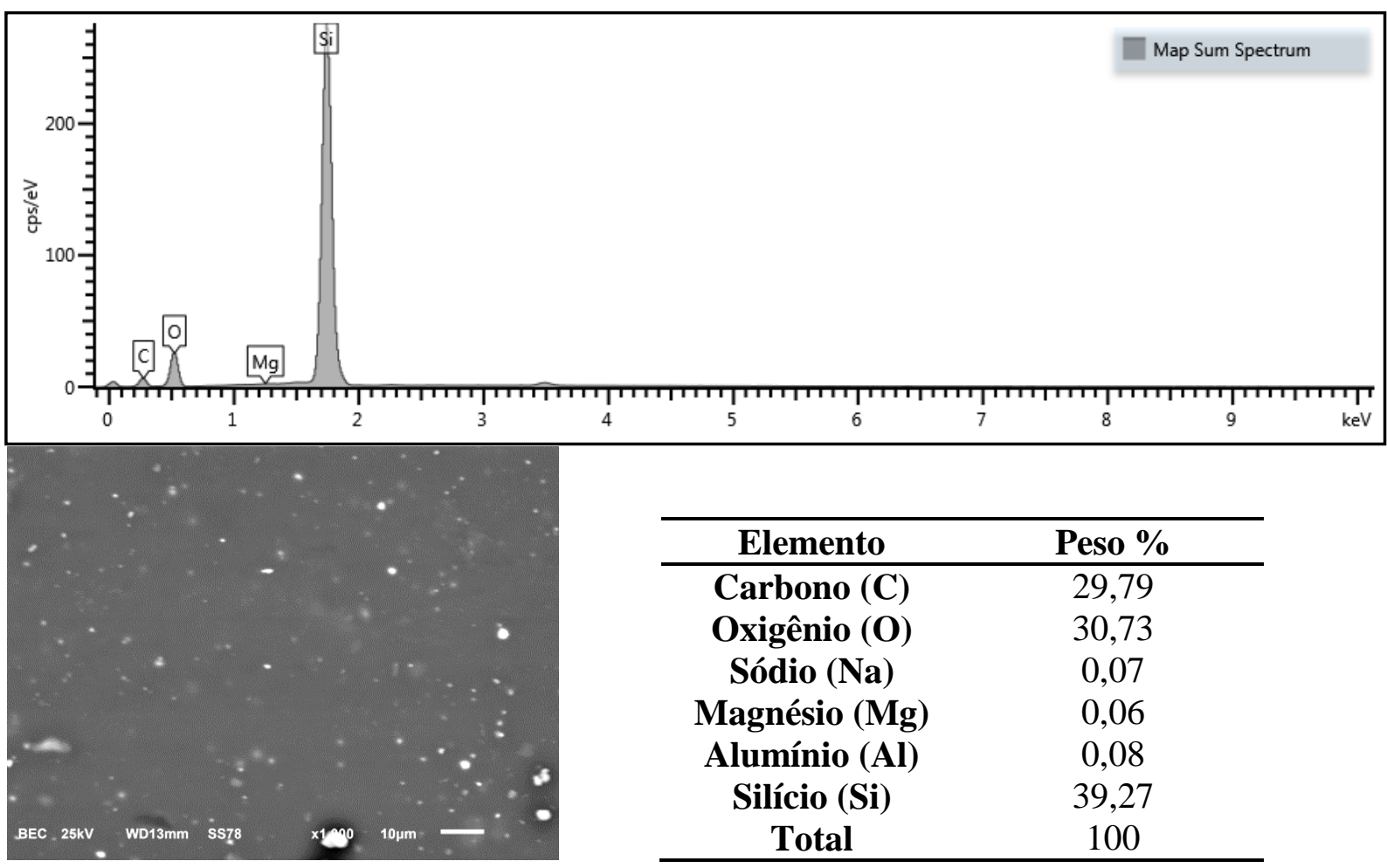

Figura 30 - Silicone MDX, Pigmentação Intrínseca + Opacificador, Controle.

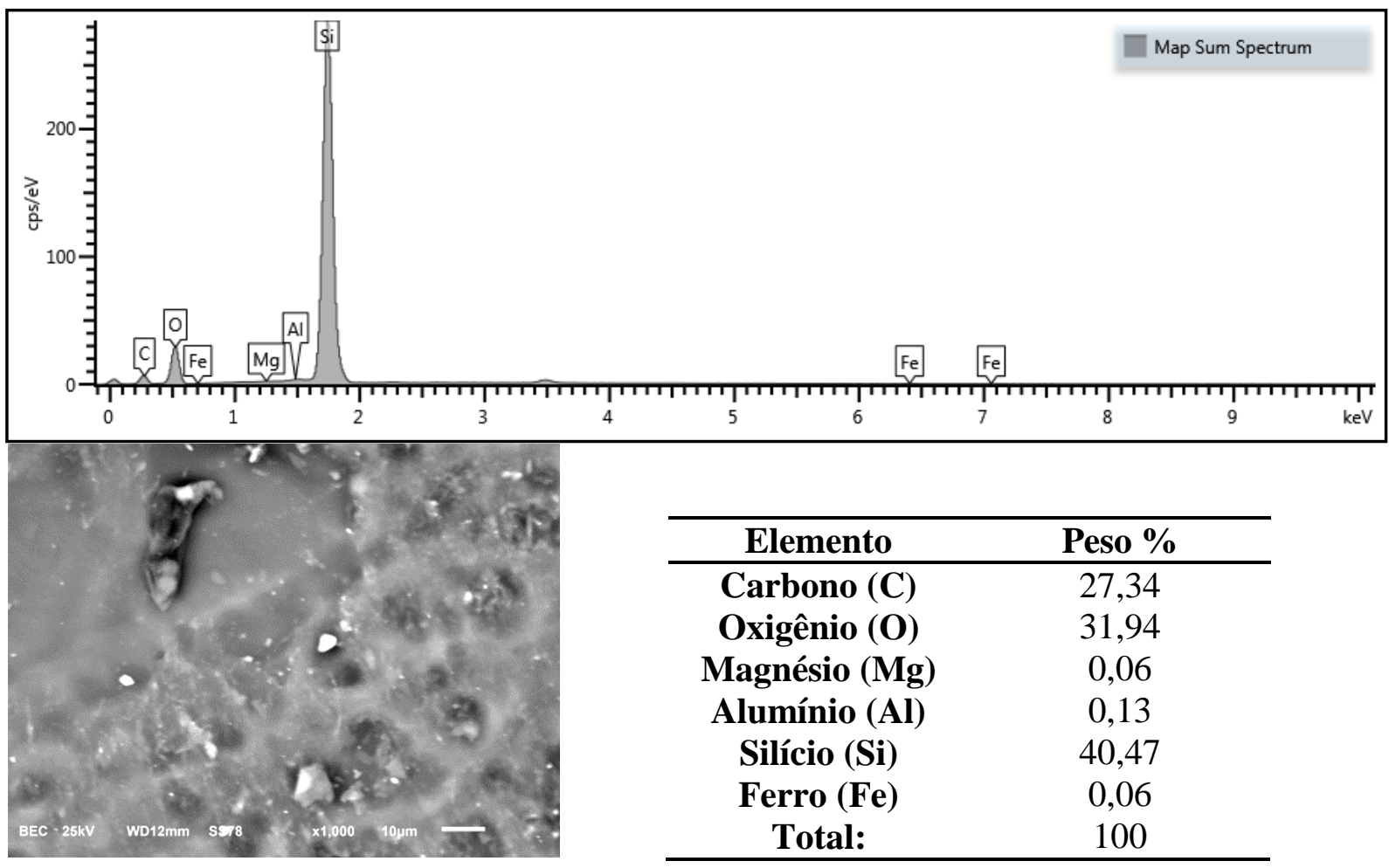

Figura 31 - Silicone BS, Sem Pigmentação, Controle. 


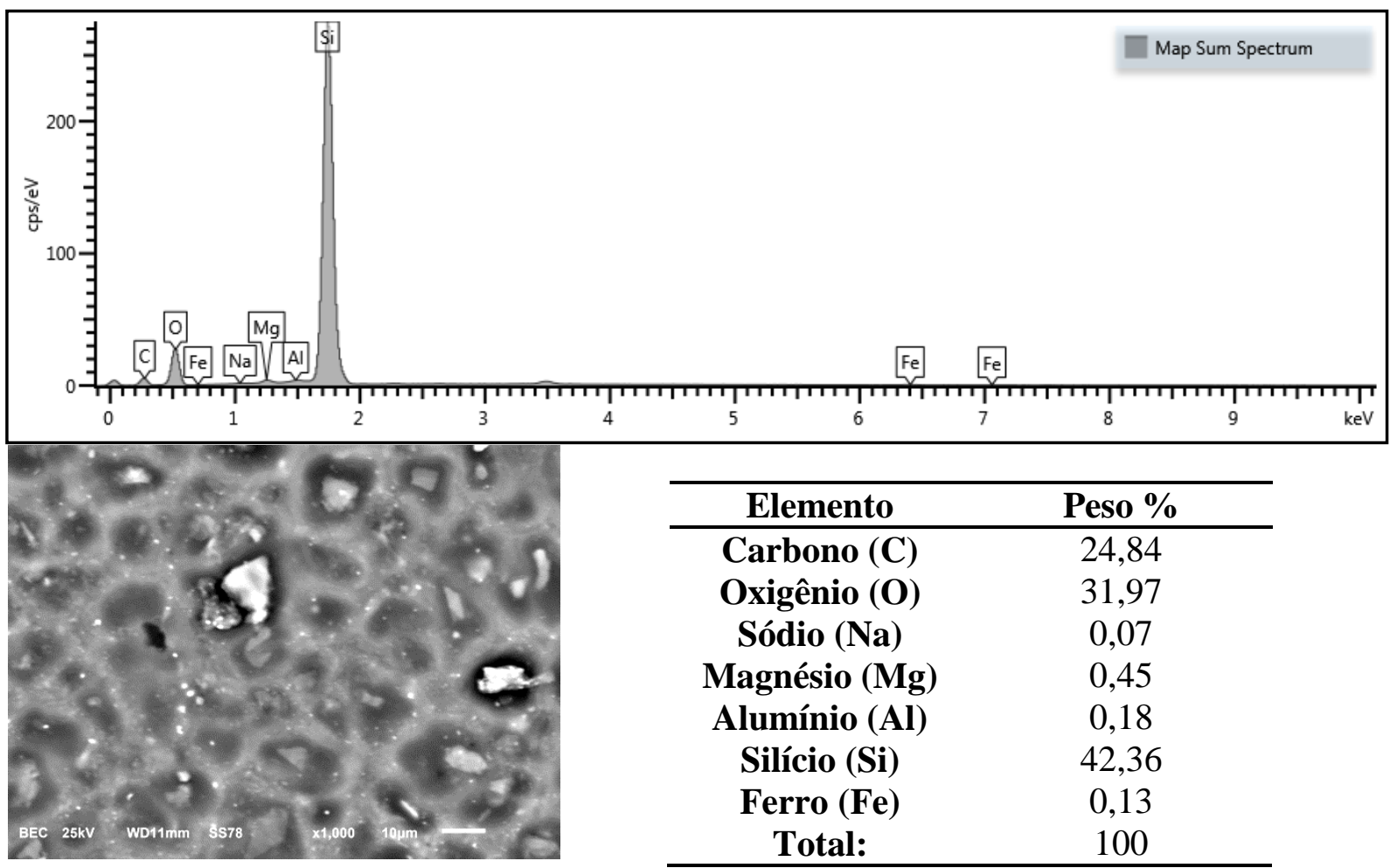

Figura 32 - Silicone BS, Pigmentação Intrínseca, Controle.

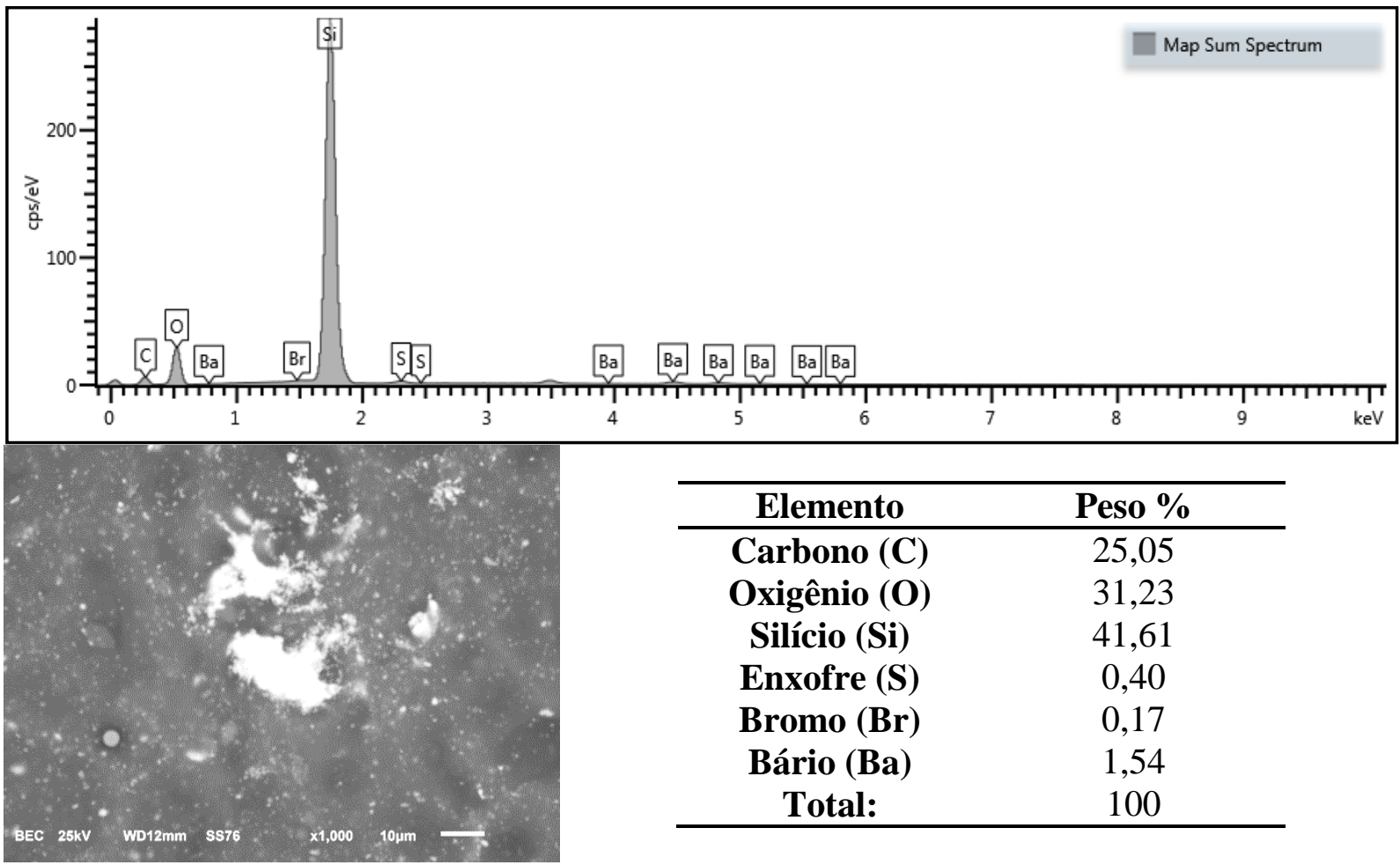

Figura 33 - Silicone BS, Opacificador, Controle. 


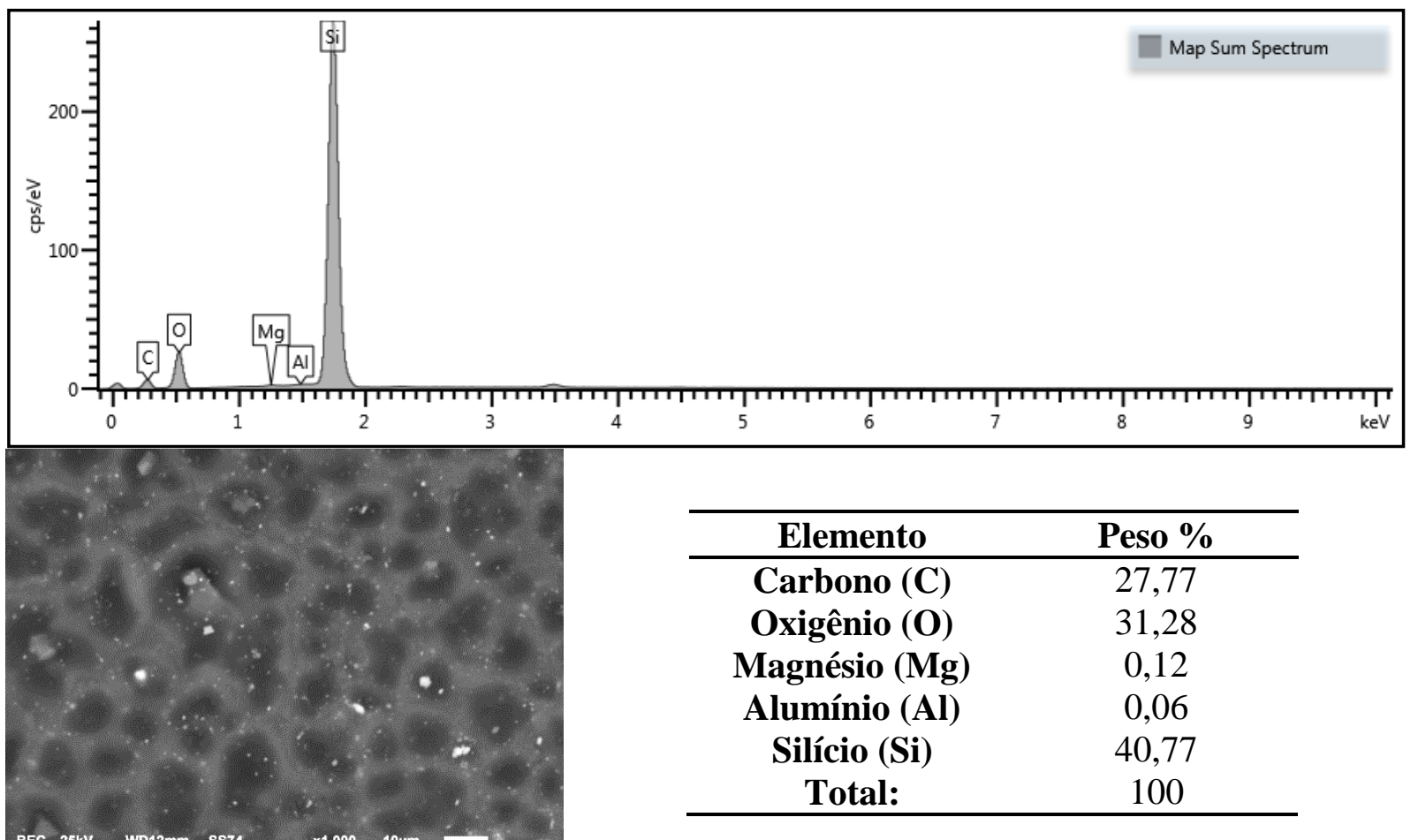

Figura 34 - Silicone BS, Pigmentação Intrínseca + Opacificador, Controle.

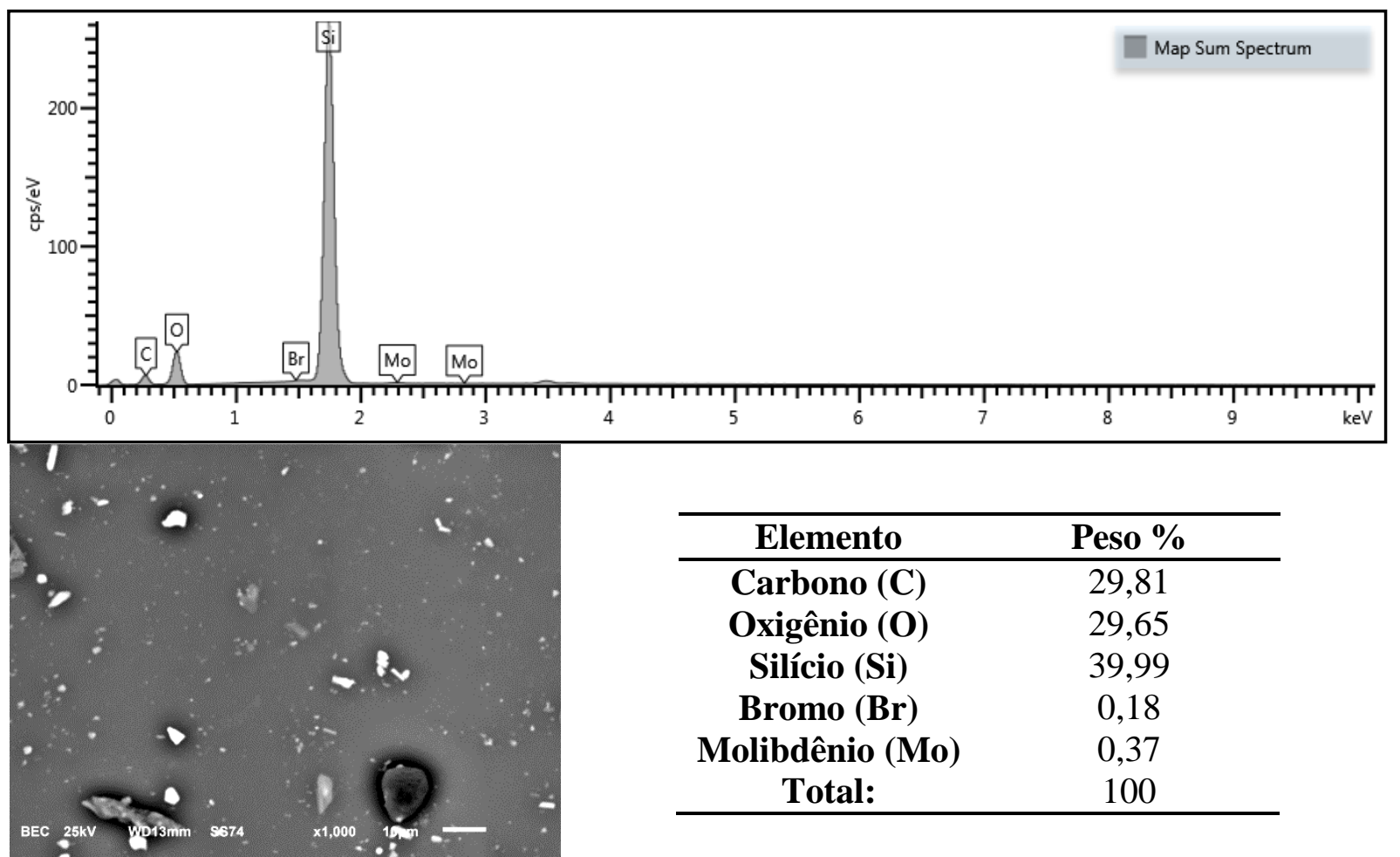

Figura 35 - Silicone MDX, Sem Pigmentação, Luz Natural. 


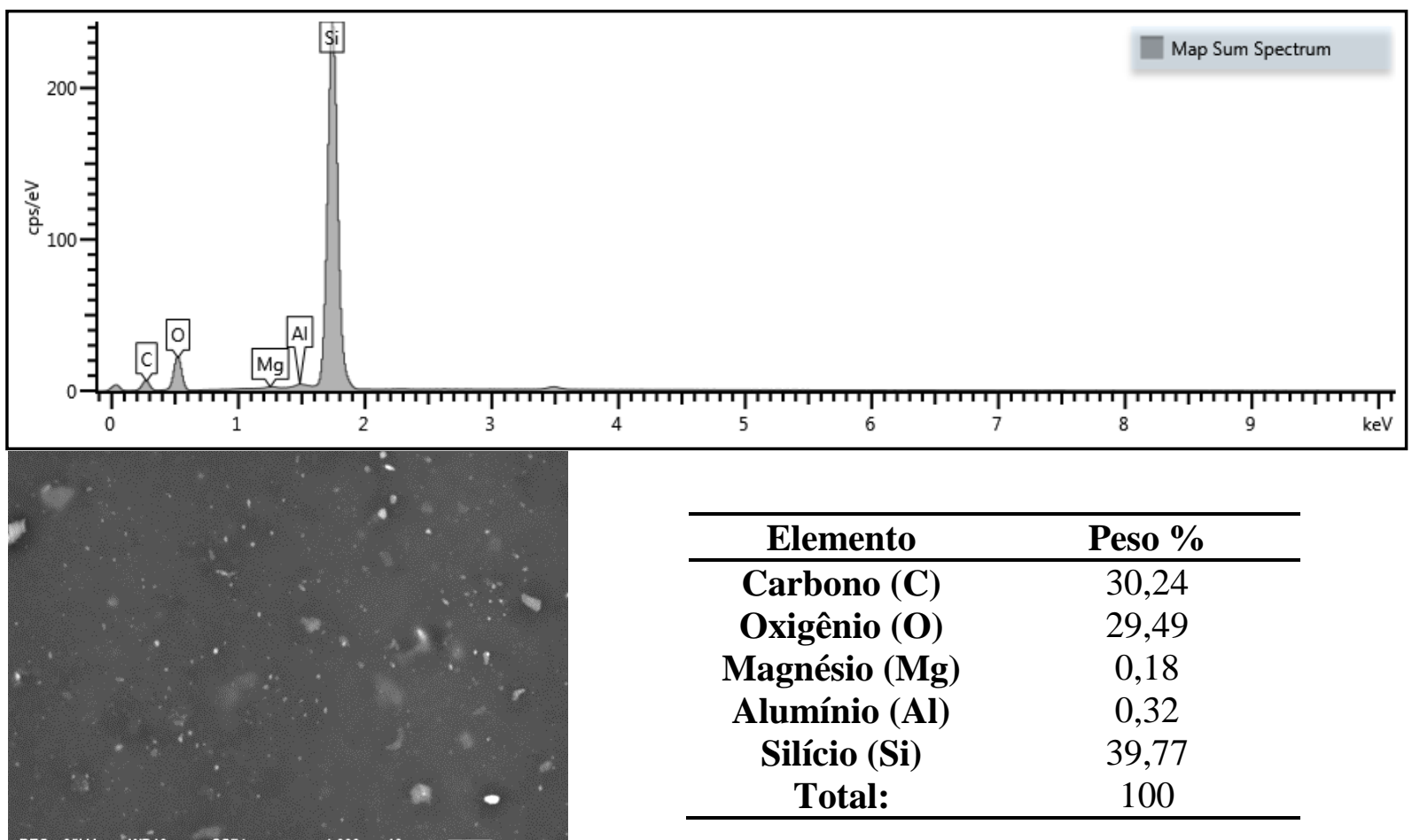

Figura 36 - Silicone MDX, Pigmentação Intrínseca, Luz Natural.

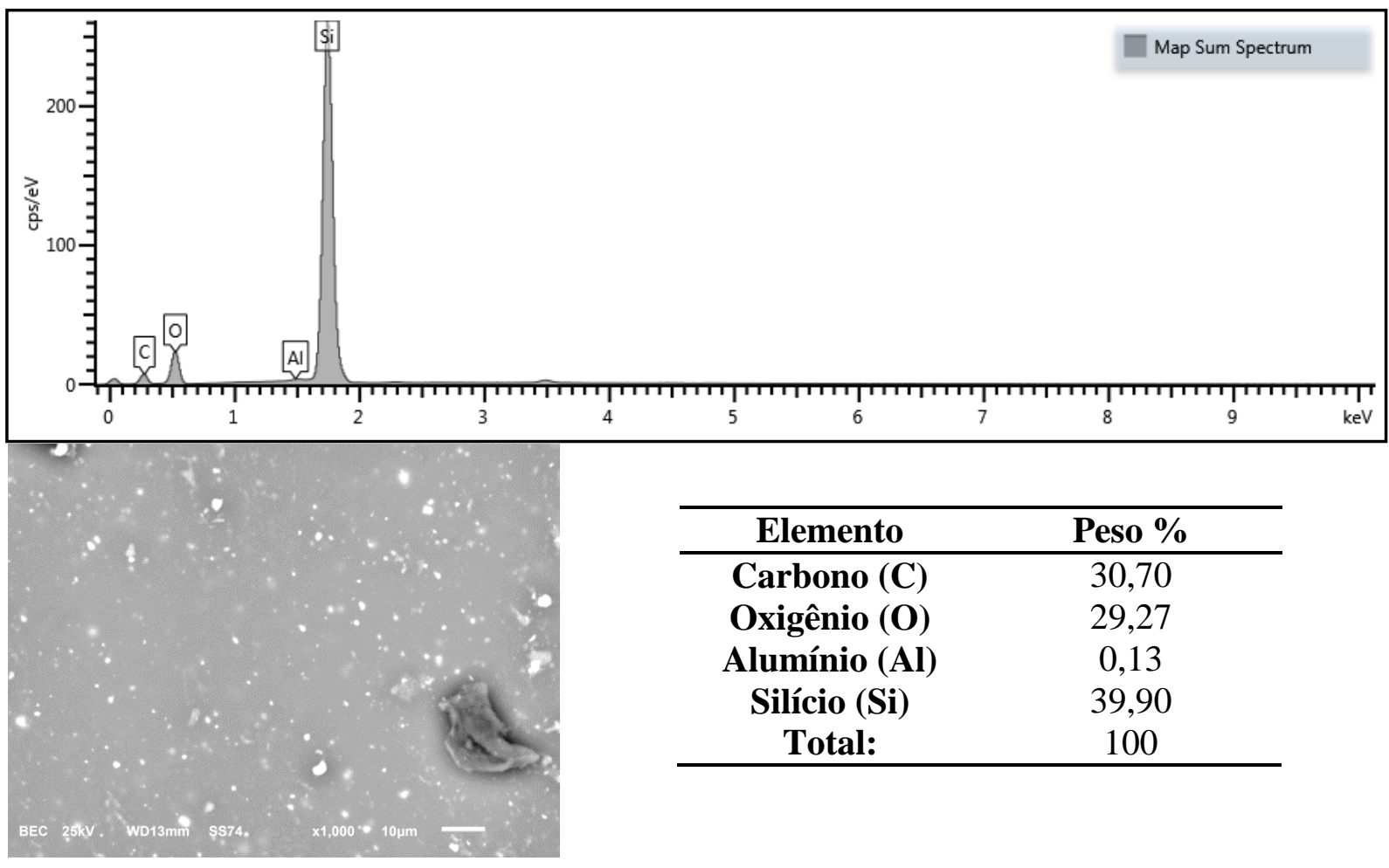

Figura 37 - Silicone MDX, Opacificador, Luz Natural. 


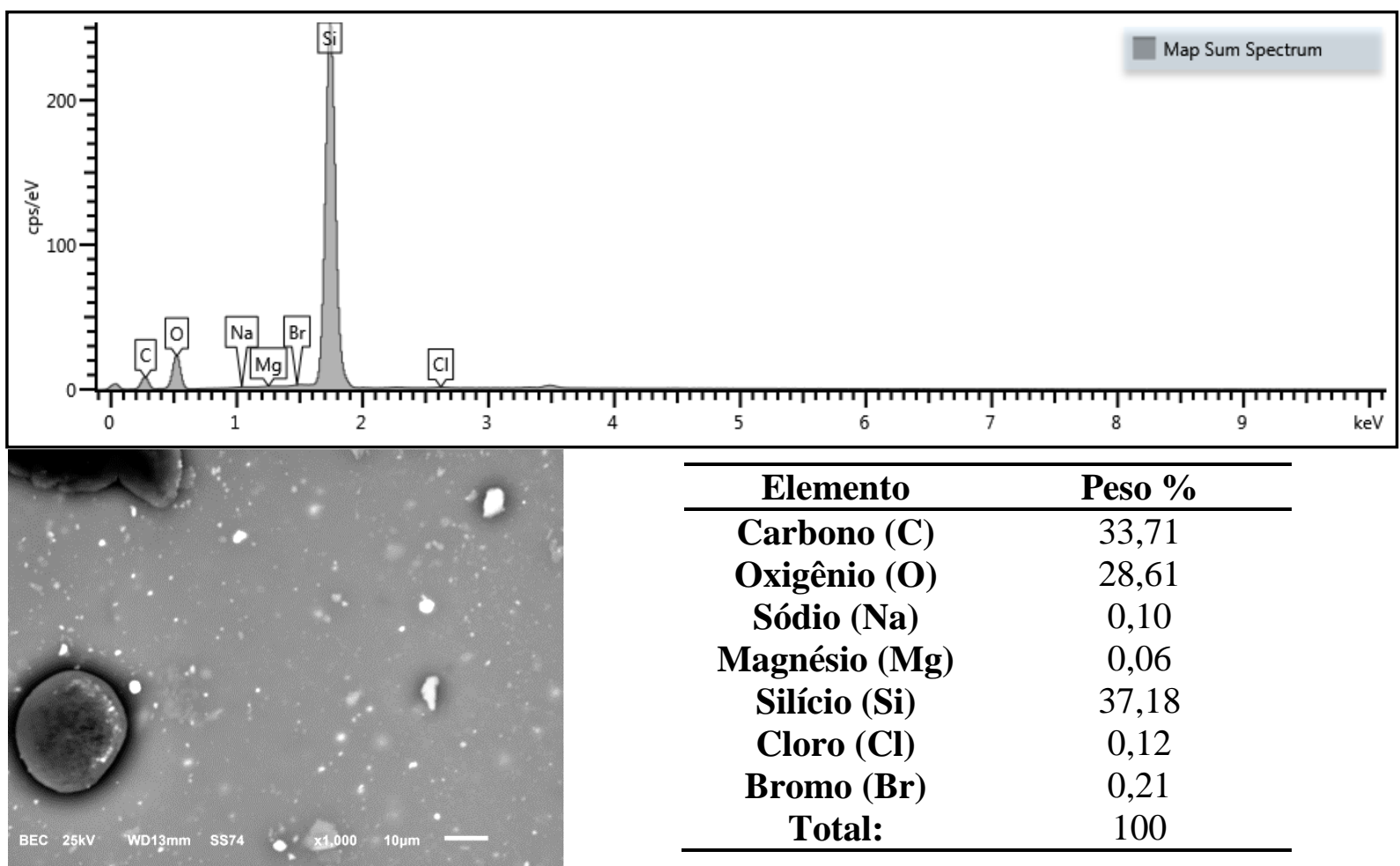

Figura 38 - Silicone MDX, Pigmentação Intrínseca + Opacificador, Luz Natural.

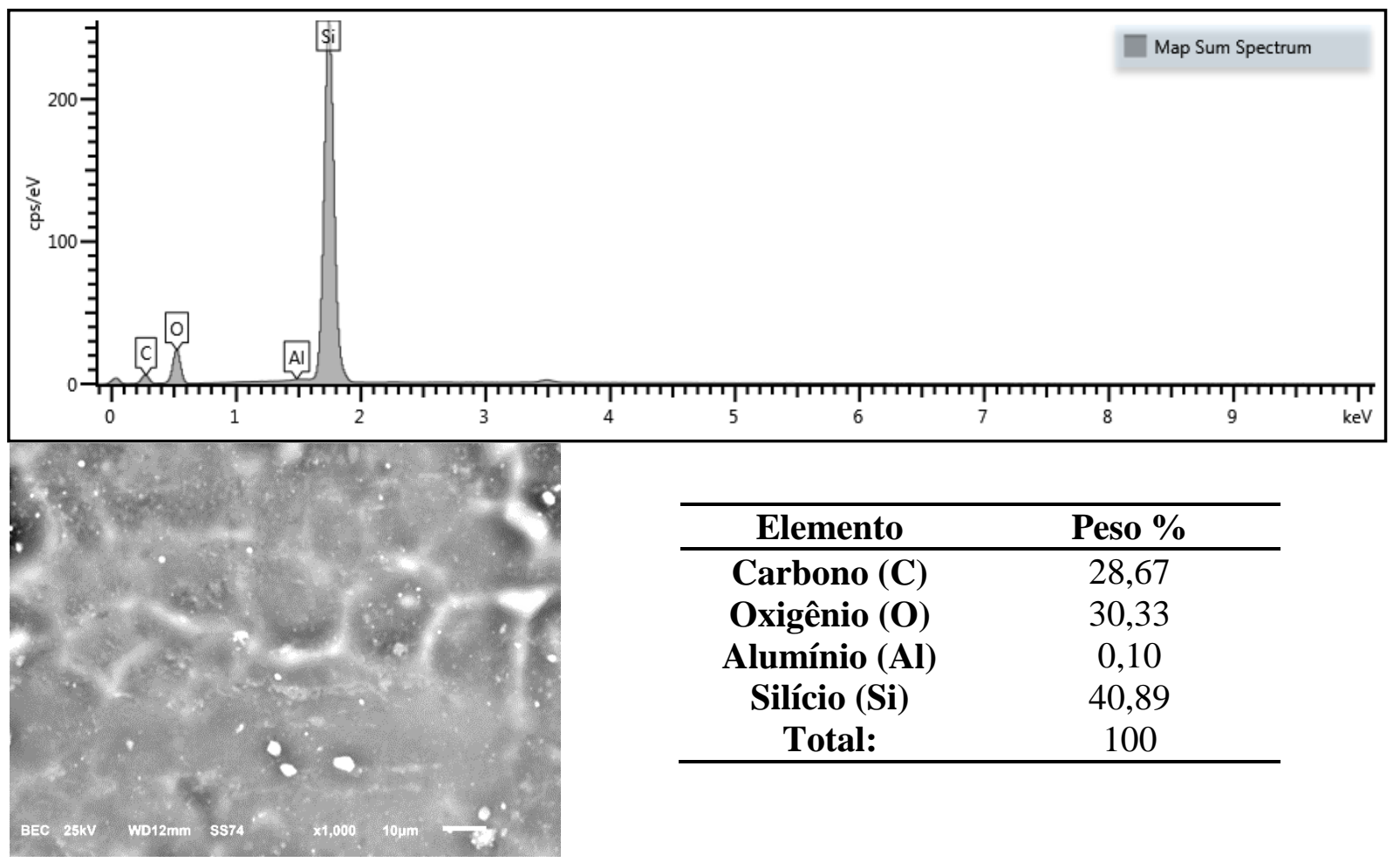

Figura 39 - Silicone BS, Sem Pigmentação, Luz Natural. 


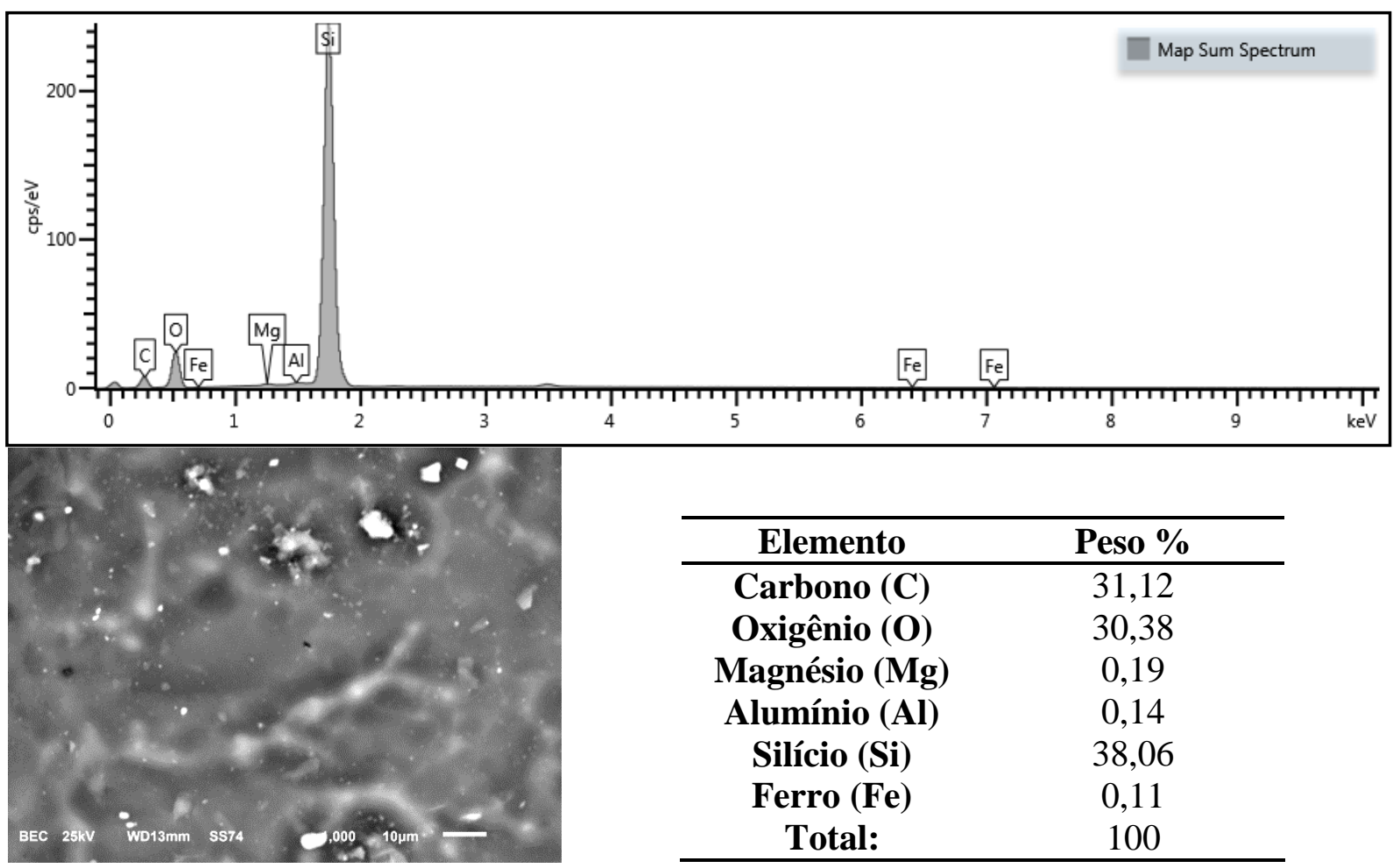

Figura 40 - Silicone BS, Pigmentação Intrínseca, Luz Natural.

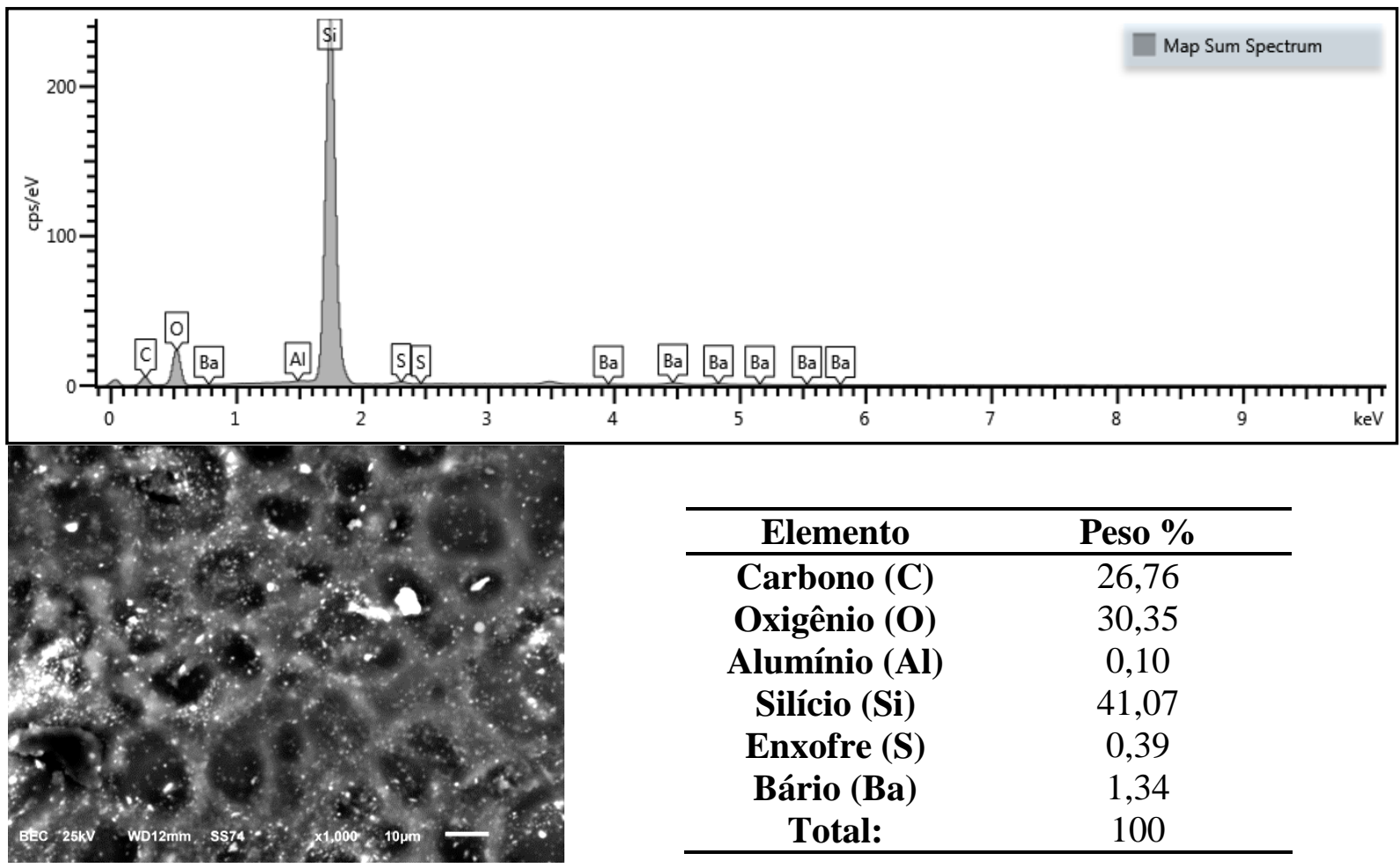

Figura 41 - Silicone BS, Opacificador, Luz Natural. 


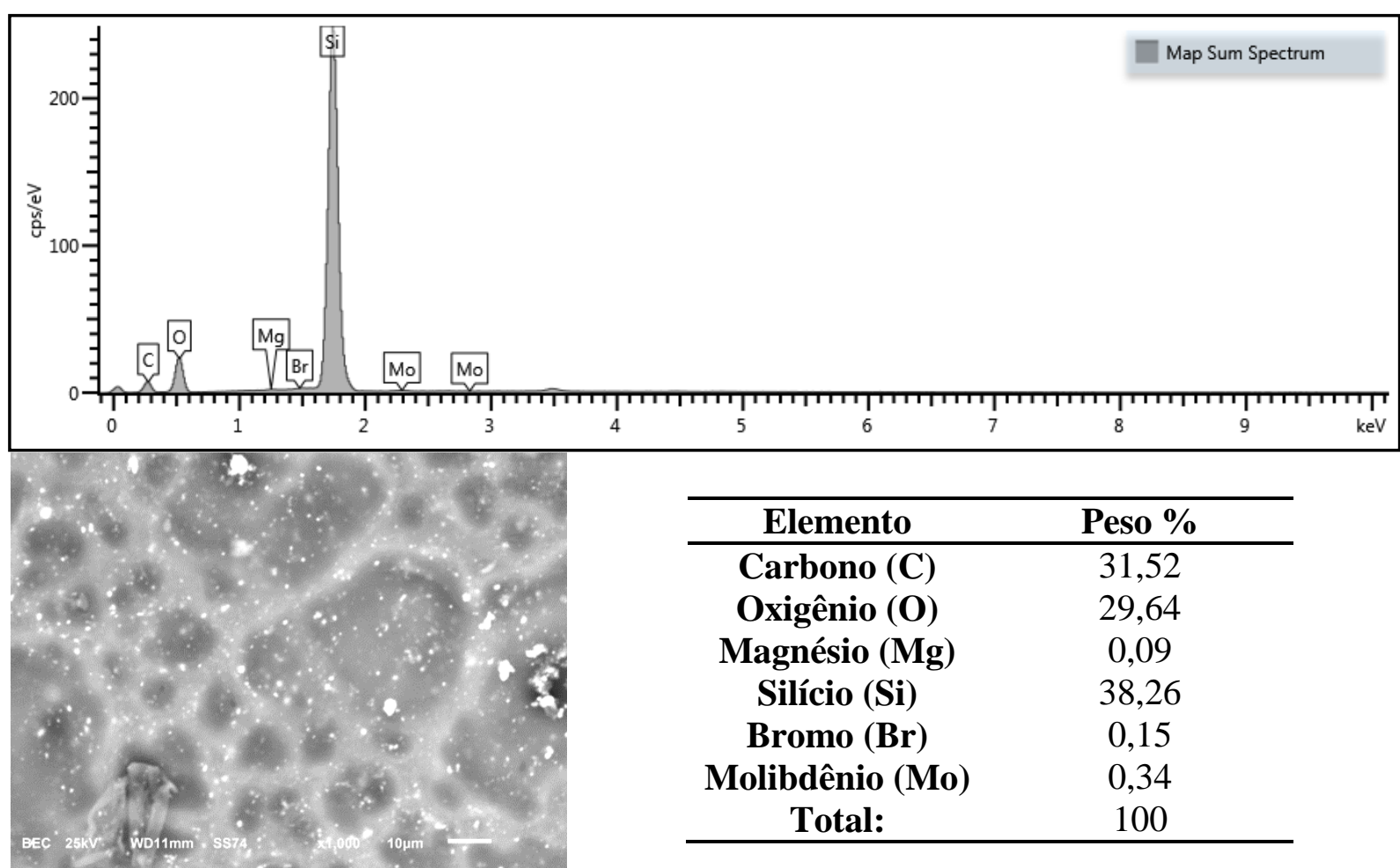

Figura 42 - Silicone BS, Pigmentação Intrínseca + Opacificador, Luz Natural.

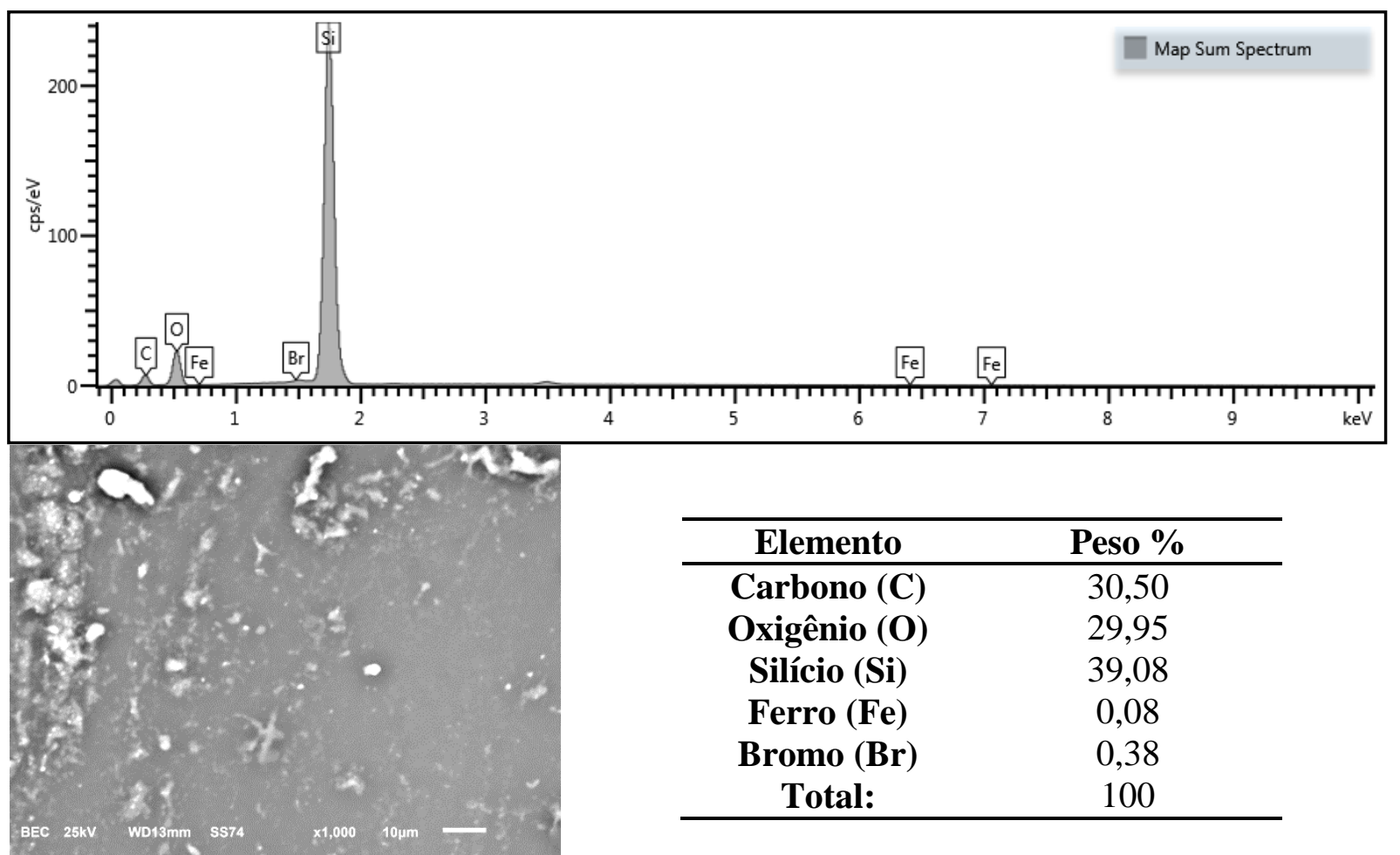

Figura 43 - Silicone MDX, Sem Pigmentação, Ultravioleta. 


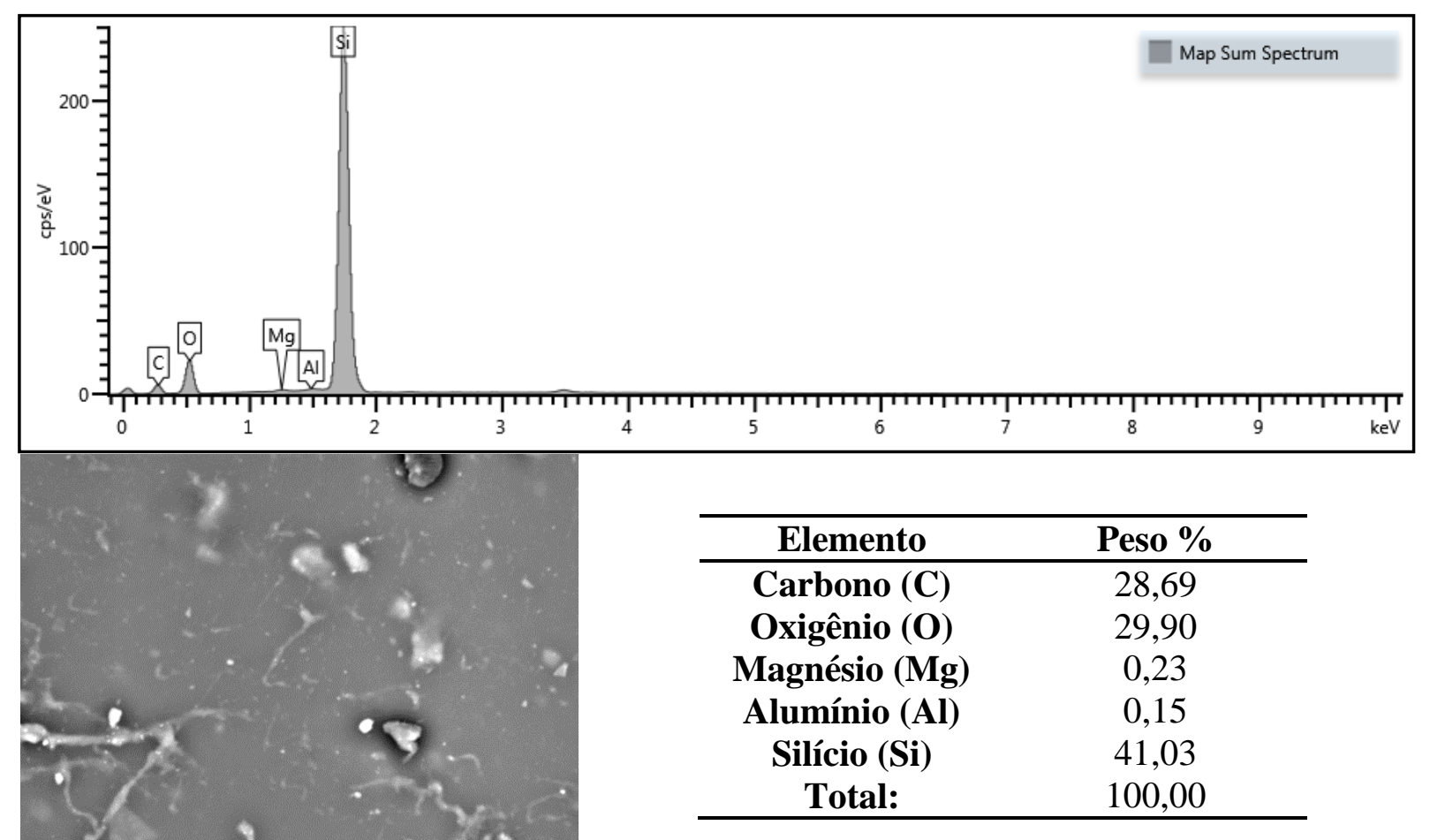

Figura 44 - Silicone MDX, Pigmentação Intrínseca, Ultravioleta.
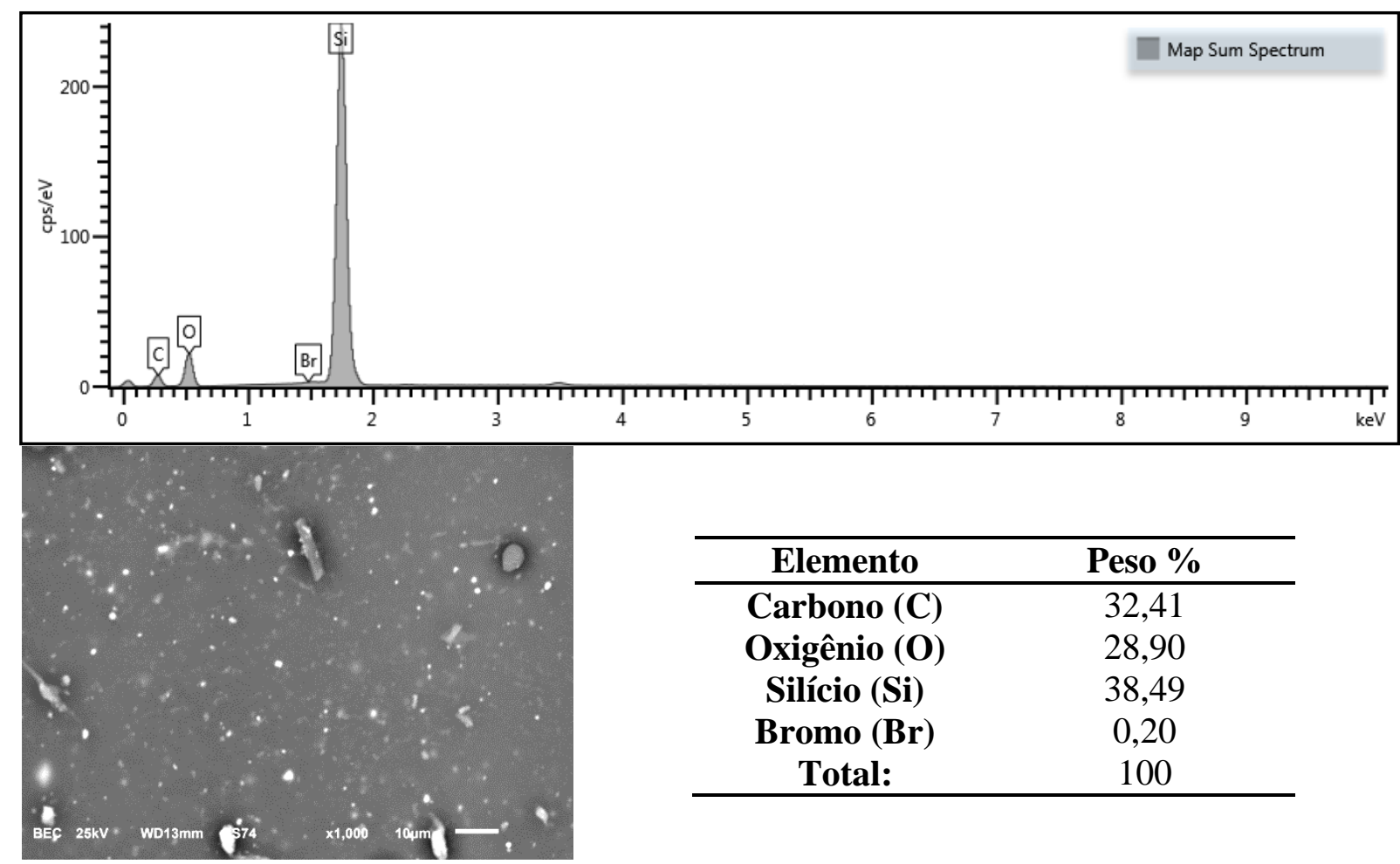

Figura 45 - Silicone MDX, Opacificador, Ultravioleta. 


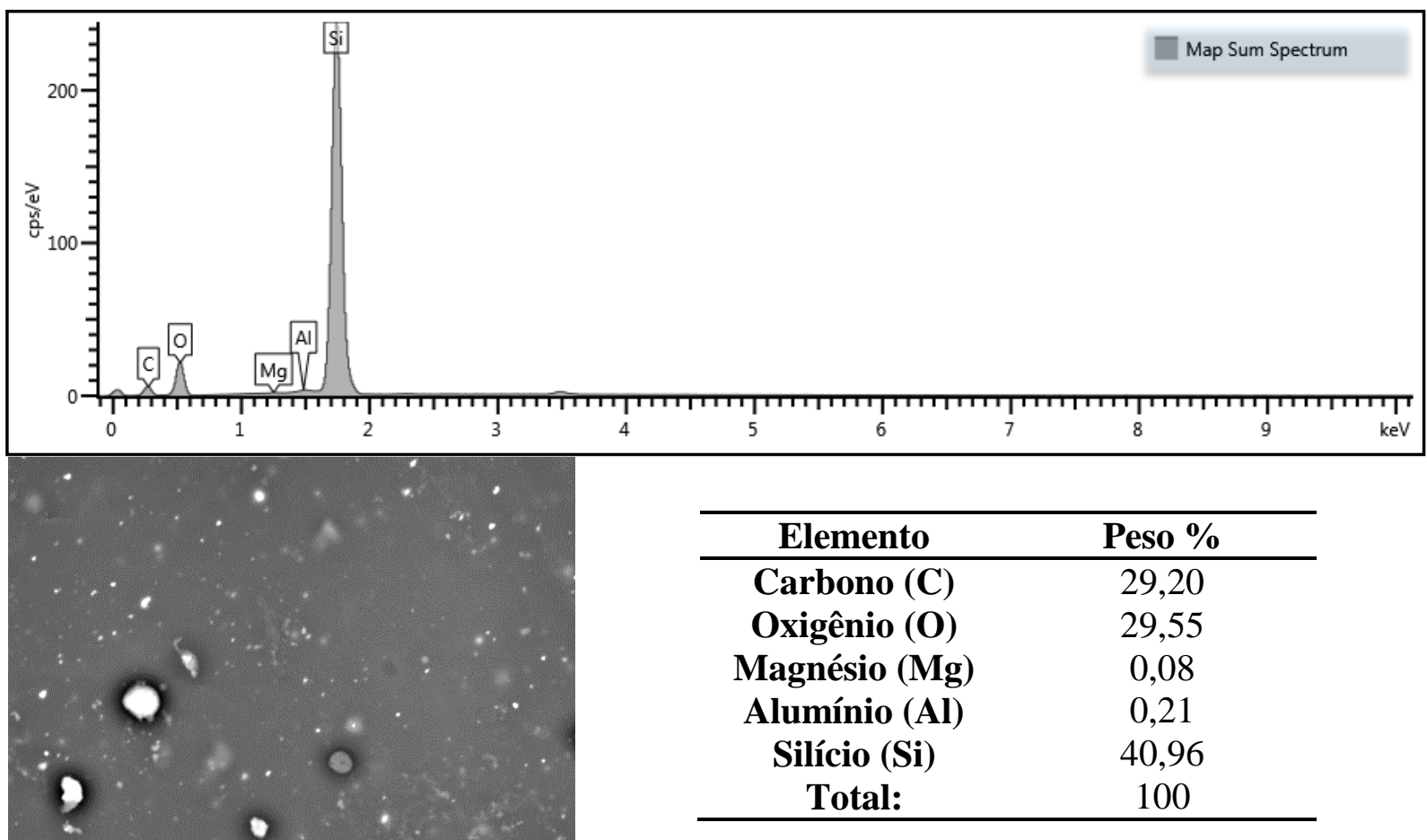

Figura 46 - Silicone MDX, Pigmentação Intrínseca + Opacificador, Ultravioleta.
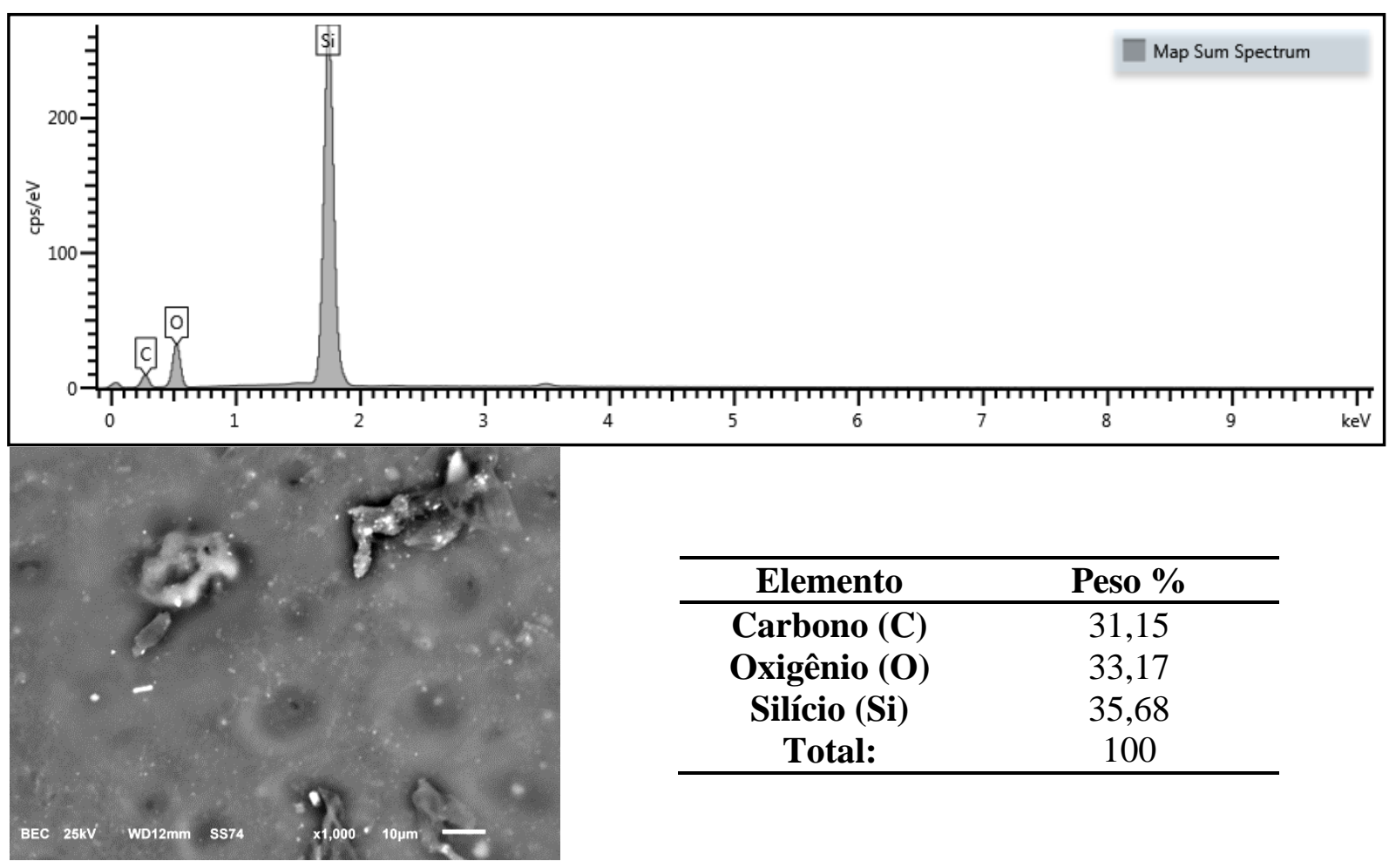

\begin{tabular}{cc}
\hline Elemento & Peso \% \\
\hline Carbono $(\mathbf{C})$ & 31,15 \\
Oxigênio $(\mathbf{O})$ & 33,17 \\
Silício $(\mathbf{S i})$ & 35,68 \\
Total: & 100 \\
\hline
\end{tabular}

Figura 47 - Silicone BS, Sem Pigmentação, Ultravioleta. 


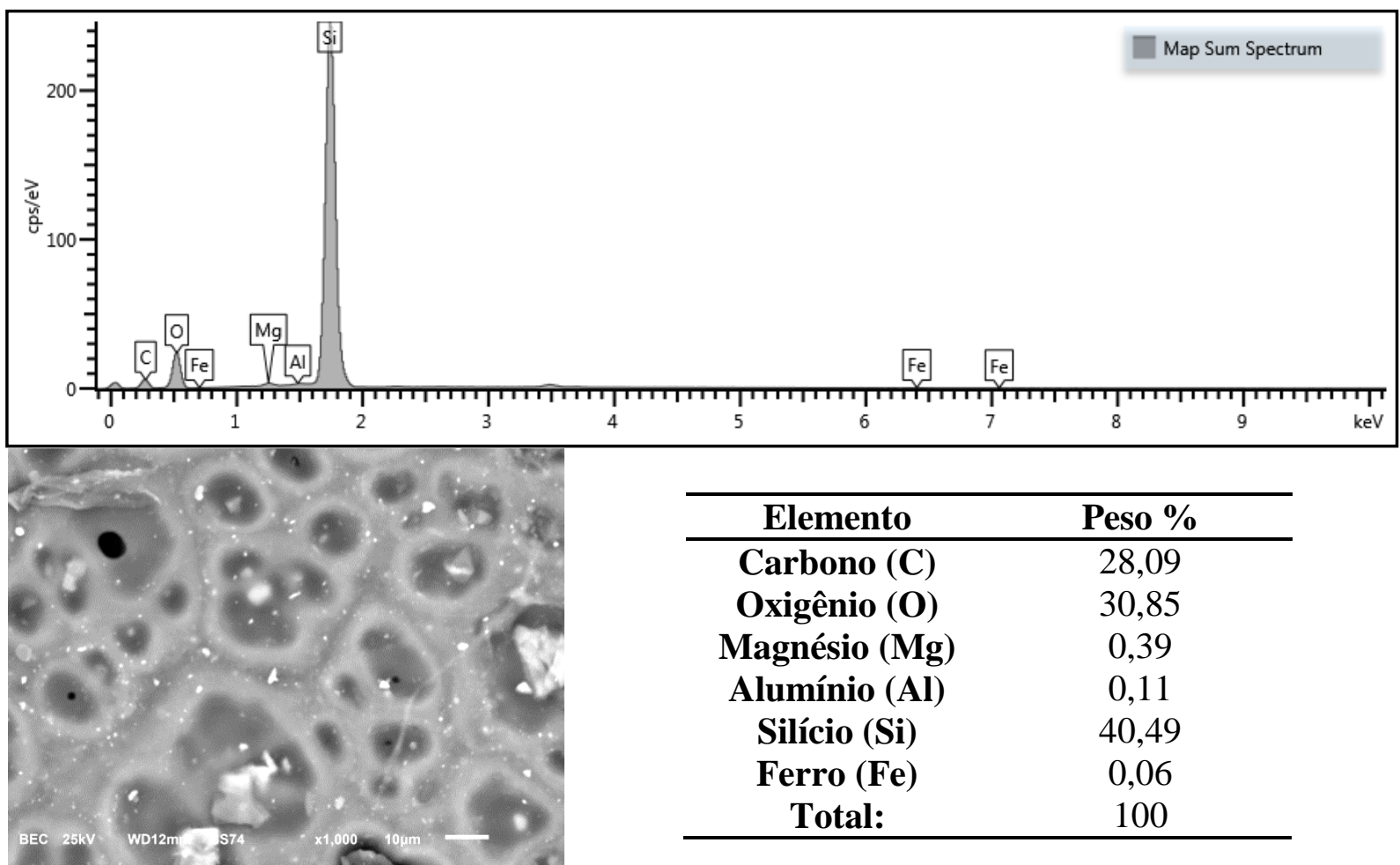

Figura 48 - Silicone BS, Pigmentação Intrínseca, Ultravioleta.

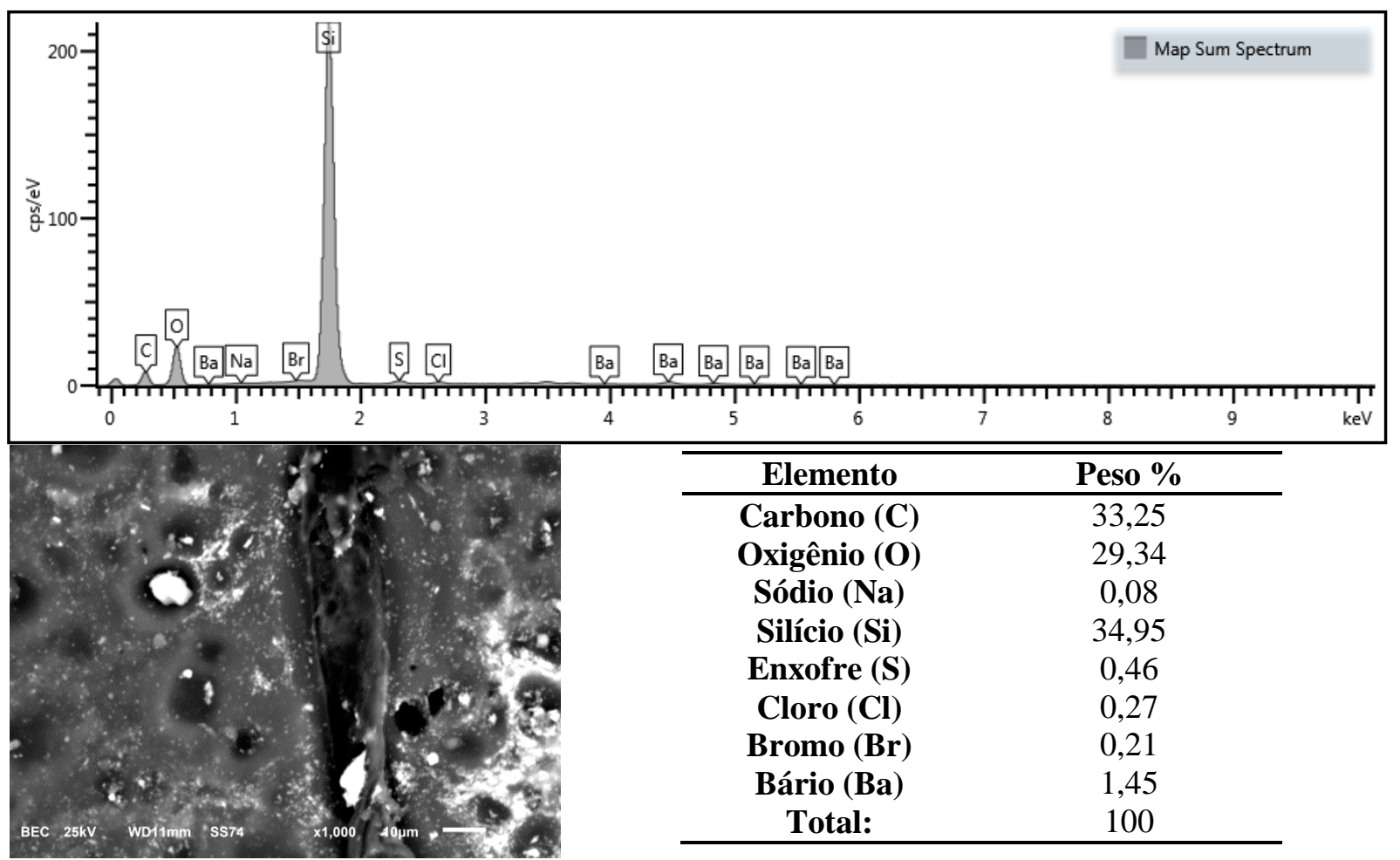

Figura 49 - Silicone BS, Opacificador, Ultravioleta. 


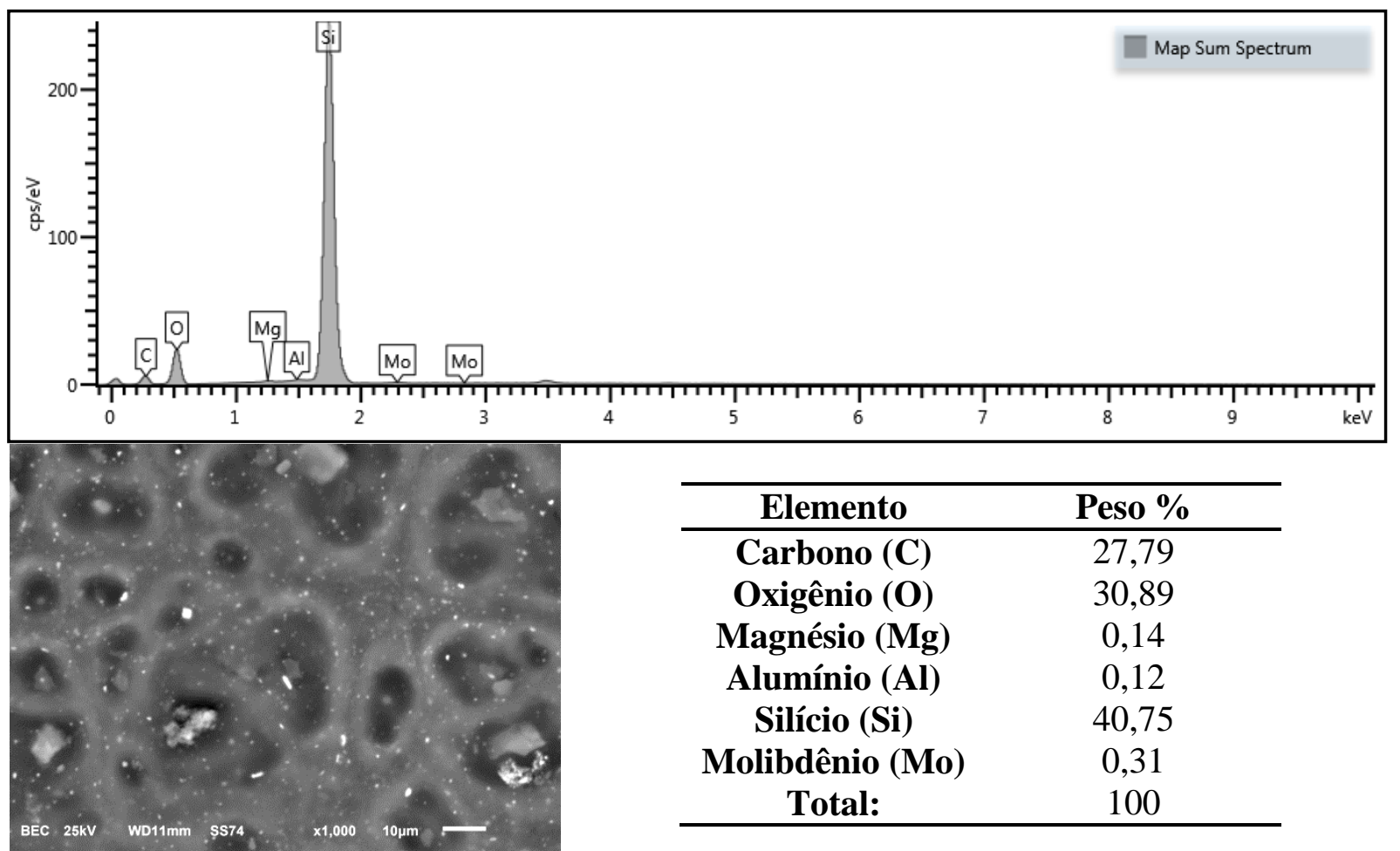

Figura 50 - Silicone BS, Grupo Associado, Ultravioleta.

De forma geral, as superfícies dos espécimes de silicone Bio-Skin apresentaram-se mais irregulares se comparadas às do silicone MDX. Na maioria das situações o silicone BS apresentou porcentagem de silício acima dos 40\%, enquanto o MDX apresentou situação inversa. 
6. Díscussão 
Em virtude da localização das próteses reabilitadoras bucomaxilofaciais, há uma grande exigência estética por parte dos profissionais e dos pacientes, o que demanda a necessidade de estabilidade dos materiais destinados a esse tipo de reabilitação. Segundo relatos da literatura, a durabilidade média das próteses faciais é de aproximadamente um ano (Jani; Schaaf, 1978; Polyzois; Eleni; Krokida, 2011b), o que torna importante o desenvolvimento de novos materiais, com estabilidade suficiente para aumentar a vida útil das próteses, melhorando o conforto ao usuário, reduzindo os custos para o serviço público e para a sociedade (Ariani et al., 2012).

Com base nestas necessidades o presente estudo avaliou um silicone ortopédico - BS (Bio-Skin) utilizado na reabilitação de pacientes com amputação parcial de pé, o qual foi chamado de experimental em função de seu potencial de uso em reabilitações faciais, uma vez que se trata de um material nacional, com custo acessível e, segundo o fabricante, apresenta propriedades e durabilidade adequadas. Para comparação das variáveis foi empregado um silicone padrão (MDX 4-4210), comumente usado nesse tipo de reabilitação e muito citado em trabalhos científicos (Kiat-Amnuay et al., 2006; Goiato et al., 2009a; dos Santos et al., 2010; Pesqueira et al., 2011; Nguyen et al., 2013; Pinheiro et al., 2014), devido a sua facilidade de manuseio, estabilidade em suas propriedades físicas e mecânicas, menor tendência à incorporação de bolhas durante a manipulação e menor susceptibilidade à contaminação (Kiat-Amnuay; Lemon; Powers, 2002). Entretanto, este material é importado e apresenta custo elevado, o que limita o acesso para a maioria dos profissionais e pacientes.

Os materiais foram submetidos a diferentes condições de envelhecimento e pigmentação e analisados quanto à alteração de cor, dureza Shore A e resistência à tração. Ainda, as características de superfície e composição química foram obtidas em ensaios de microscopia eletrônica de varredura (MEV) e espectroscopia por energia dispersiva (EDS). Estas análises são importantes, pois complementam e esclarecem os resultados para as alterações encontradas nos materiais quando expostos a diferentes situações ambientais e de manipulação. A microscopia eletrônica de varredura (MEV) fornece informações de alta resolução a respeito da textura da superfície para a avaliação da topografia superficial (Subaş1; İnan, 2012; Valian; Moravej-Salehi, 2014). Por definição, espectroscopia por energia dispersiva de raios X (EDS ou EDX) é uma técnica utilizada para a análise elementar ou caracterização química de uma amostra. Baseia-se na investigação da interação de excitação entre raios-X e a amostra. Ela identifica e caracteriza semiquantitativamente, os elementos 
químicos presentes em depósitos encontrados nas superfícies das amostras em questão (Prasad et al., 2014). No presente estudo, tal metodologia foi adotada visando avaliar se os dois silicones apresentavam diferenças em sua composição que poderiam justificar alterações em suas propriedades, e ainda, verificar se os pigmentos foram totalmente incorporados ao material ou se interagiram com a cadeia polimérica dos silicones.

Em virtude da durabilidade média das próteses bucomaxilofaciais, os materiais foram submetidos a um ano de envelhecimento, tanto por métodos de exposição natural, quanto por métodos artificiais por luz ultravioleta. Segundo Kiat-Amnuay, Lemon e Powers (2002) e Han et al. (2010), a deterioração das próteses tem sido atribuída a fatores ambientais, tais como radiação solar, temperatura e umidade. A radiação solar que atinge a superfície da terra consiste principalmente de radiação ultravioleta (UV), visível e infravermelha, a qual tem grande impacto sobre a estabilidade de cor das próteses bucomaxilofaciais, tornando-se um tema de crescente preocupação em função da destruição da camada de ozônio. Muitos pesquisadores usaram intemperismo artificial ou câmaras de envelhecimento que são úteis na avaliação da deterioração global desses materiais, para simular o ambiente ao ar livre. Ainda, segundo Polyzois, Eleni e Krokida (2011a) as alterações de cor após a confecção da prótese, podem ser causadas por alterações químicas do elastômero de silicone ou por perdas de cor que ocorrem com certos pigmentos que não são resistentes aos raios UV. Fatores de envelhecimento, como a passagem do tempo (envelhecimento natural) também degradam esses materiais, causando alterações de cor a longo prazo (Beatty et al., 1995). Mais precisamente, a deterioração é resultado de um ataque foto-oxidativo, isto é, a ação combinada de oxigênio e luz solar sobre a estrutura química de um material (Eleni et al., 2011).

Portanto, dentre as propriedades físico-mecânicas, a avaliação da cor é muito importante, uma vez que se trata do aspecto mais limitante das reabilitações faciais, devido à alteração precoce dos materiais existentes (Tran; Scarbecz; Gary, 2004; Mancuso; Goiato; dos Santos, 2009; Kiat-Amnuay et al., 2009; Goiato et al., 2011; Pesqueira et al., 2011; Pinheiro et al., 2011) e pela localização das lesões.

Comparando os materiais de modo geral, o silicone BS apresentou menores variações de cor se comparado ao MDX. Os silicones são compostos basicamente por silício e oxigênio (Si-O), elementos que formam sua cadeia polimérica. Esta formação estrutural é que responde pelas propriedades de excelente resistência à larga faixa de temperatura, bem como as de 
resistir a oxidação e a degradação pelo ozônio, oxigênio, intemperismo e irradiações. A análise por EDS indicou que o silicone experimental apresentou maior porcentagem de silício que o MDX4-4210, o que sugere que a menor alteração de cor do silicone experimental se deve à esta característica.

No presente estudo, ao avaliar o efeito da pigmentação sobre a alteração de cor dos materiais, nota-se que o MDX apresentou as maiores médias nos grupos SP e OP quando envelhecidos por LN e UV (Tabela 2). O silicone BS teve o mesmo comportamento, porém somente no grupo de envelhecimento por LN (Tabela 2). Estes resultados indicam que o uso isolado do opacificador não teve ação protetora contra a foto-oxidação promovida pela luz solar. O uso isolado do opacificador não promoveu resultados satisfatórios, embora seja um pigmento inorgânico considerado estável em relação à cor (Haug et al., 1992). Segundo KiatAmnuay et al. (2009), nem todos os pigmentos inorgânicos protegem os silicones da degradação de cor, uma vez que os resultados são dependentes da porcentagem de impurezas das substâncias misturadas nos opacificadores após o processamento. Além disso, nem todos os opacificadores são iguais, e podem interagir de modo diferente com diferentes tipos de elastômeros.

Bangera e Guttal (2014) confirmam que opacificadores podem eficientemente conferir propriedades de bloqueio de UV, reforçando a matriz do silicone. No entanto, a quantidade dessas nanopartículas na matriz deve ser mantida num nível apropriado. Se o nível for excedido, as nanopartículas tendem a se aglomerar, devido à sua alta energia de superfície e reatividade química. Portanto, a concentração de opacificador não deve ser superior a 2,5\%, já que a aglomeração pode reduzir a eficiência da blindagem de UV e também a resistência mecânica (Han et al., 2008). Esse fato é comprovado por estudos de microscopia eletrônica de varredura. Em nosso estudo, a porcentagem de opacificador utilizado foi de $2 \%$, estando portanto, dentro do limite recomendado. No entanto, nas fotomicrografias dos espécimes com opacificador, aglomerados podem ser visualizados. O efeito da incorporação desses nanoóxidos ainda deve ser avaliado. Além disso, por serem pós brancos, a sua utilização em próteses cor da pele precisa ser investigada em pesquisas futuras.

Leow et al. (2002) relatam que espécimes de silicone sem pigmentação registraram grande alteração de cor $(\Delta \mathrm{E}=14,88)$ a partir da exposição à radiação UV. Em nosso estudo, alterações também foram detectadas nos espécimes sem pigmentação. Segundo relatos da literatura, há limiares de perceptibilidade $(\Delta \mathrm{E}=1,1)$ e aceitabilidade $(\Delta \mathrm{E}=3,0)$ utilizados 
para caracterizar se o material é clinicamente aceitável em relação à alteração de cor (Paravina et al., 2009; Han; Powers; Kiat-Amnuay, 2013). Nos espécimes sem pigmentação e nos espécimes com opacificador os valores de alteração ultrapassaram os limiares de perceptibilidade e especificamente, no silicone BS, ultrapassaram o limiar de aceitabilidade. Todos os demais grupos apresentaram resultados aceitáveis. Cabe destacar que ambos os materiais exposto à luz natural, com PI e PIO, apresentaram valores abaixo do limiar de perceptibilidade. Este resultado é importante uma vez que esta situação é a que mais se aproxima da prática clínica.

Os materiais apresentaram comportamentos semelhantes em função do acréscimo de pigmento de pó de maquiagem nos grupos controle e UV e da associação PIO nos grupos controle e luz natural. Estes resultados sugerem que o uso da pigmentação isolada e a sua associação ao opacificador foi mais favorável e concordam com os achados de Haug, Andres e Moore (1999) e Kiat-Amnuay et al. (2006), demonstrando que a coloração intrínseca unida ao opacificador ajuda a proteger o elastômero de silicone da degradação da cor ao longo do tempo. A degradação de cor dos pigmentos dissolvidos no silicone é produto do processo químico que é causado pela reação com a luz UV. O agente opacificador tem como objetivo refletir a luz UV, por esta razão, durante as últimas décadas, os pesquisadores têm tentado adicionar absorvedores de luz UV em elastômeros de silicone para avaliar o seu potencial de proteção contra alterações de cor (Han; Powers; Kiat-Amnuay, 2013). Ainda que os nossos resultados e de outros estudos tenham obtido valores satisfatórios para a estabilidade de cor com a associação PIO, há relatos (Kiat-Amnuay; Lemon; Powers, 2002) de que esta associação não promoveu os resultados esperados, principalmente quando o pigmento cosmético for de cor vermelha. Também em contrapartida, Han, Powers e Kiat-Amnuay (2013) mostram que o agente opacificador afetou positivamente a estabilidade de cor do silicone MDX 4-4210, relatando que um opacificador eficaz deve melhorar não só as propriedades físicas, mas também as propriedades mecânicas do elastômero de silicone, discordando dos resultados obtidos neste estudo.

Comparando os envelhecimentos, a luz natural promoveu as maiores médias de alteração de cor para os dois materiais. Resultados semelhantes foram encontrados no estudo de Polyzois, Eleni e Krokida (2011a). No entanto, estes autores salientam que a degradação que ocorre em espécimes sob envelhecimento não depende apenas da irradiação, uma vez que as condições climáticas, como a poluição, o ar, a chuva e poeira também desempenham um 
papel crucial. Dos Santos et al. (2012) encontraram alteração de cor de resinas e silicone após o envelhecimento natural devido a fatores intrínsecos e extrínsecos. Os fatores intrínsecos envolvem a descoloração da matriz do material, que é uma ocorrência frequente com o envelhecimento devido às condições físico-químicas, tais como variações térmicas e de umidade. Fatores extrínsecos, tais como a absorção e adsorção de substâncias, também podem gerar descoloração (Abu-Bakr et al., 2000). Os achados da literatura concordam com os resultados obtidos no presente estudo, ou seja,que o envelhecimento por luz natural e passagem do tempo realmente alteram as propriedades dos silicones para próteses faciais.

Segundo Rabek (1995), o desgaste de polímeros leva a mudanças nas características físicas e químicas que causam a deterioração significativa nas propriedades mecânicas. A degradação foto-oxidativa que ocorre envolve as seguintes etapas: etapa de iniciação (formação de radicais livres), etapa de propagação (radicais livres do polímero reagem com o oxigênio, o que resulta na cisão da cadeia principal) e etapa de acabamento (diferentes radicais livres reagem uns com os outros, resultando na reticulação). As principais modificações estruturais nos polímeros irradiados são as mudanças na distribuição de peso molecular e produção de produtos de degradação voláteis (Dootz; Koran; Craig, 1993; Eleni et al., 2011). Esses fenômenos tendem a modificar as propriedades mecânicas dos materiais, afetando a rede estrutural do polímero de maneiras diferentes. A densidade da rede estrutural aumenta durante a reticulação, devido à formação de ligações entre os monômeros existentes, ou mesmo entre as cadeias. Portanto, a reticulação leva a materiais mais duros. Por outro lado, quando a cisão da cadeia é o mecanismo dominante, a quebra das ligações no interior da cadeia principal ou entre duas cadeias diferentes causa uma diminuição na densidade da rede estrutural e os materiais tornam-se mais macios (Eleni; Krokida; Polyzois, 2009).

A dureza é uma propriedade mecânica de extrema importância para a reabilitação com prótese bucomaxilofacial, já que é indicativa da textura e mede a flexibilidade do material (Saboya et al., 1997; Guiotti; Goiato; dos Santos, 2010). De acordo com a norma ASTM D2240, a dureza Shore A de materiais elastoméricos pode ser classificada como macia (0-35 unidades Shore A), meio macia (35-50 unidades Shore A) e meio dura (50-68 unidades Shore A). Em nosso estudo, os silicones avaliados apresentaram valores médios de dureza Shore A que os classificam como meio duros. No entanto, segundo Lewis e Castleberry (1980), a dureza ideal deve ser semelhante às características facias devido ao fato de que os tecidos perdidos são compostos de texturas moles e duras, sugerindo que medidas desejáveis de 
dureza estariam entre 25 a 35 unidades Shore A (Eleni et al., 2011; Kheur et al., 2012). Porém, esta orientação é baseada em estudos laboratoriais, sendo que estudos clínicos poderiam evidenciar quais valores de dureza seriam realmente desejáveis, uma vez que a adaptação das próteses às bordas das lesões pode ser prejudicada se a dureza do material sofrer influência de fatores como temperatura ambiental, extensão da lesão, meios de retenção e higienização. Considerando os países onde a incidência de raios solares é intensa, um maior valor de dureza pode ser benéfico para uma maior durabilidade da prótese, adaptação às margens da lesão e conforto do paciente. A incidência de luz, calor e umidade são fatores importantes que podem alterar a dureza do material, uma vez que promovem a separação da cadeia polimérica principal e contribuem para a produção de produtos voláteis de degradação (Seluk; Yu; Koran, 1987).

Limitações dos ensaios de dureza ocorrem em função da grande variedade de modelos e marcas de durômetro Shore A presentes no mercado, o que poderia influenciar a variação das leituras entre um estudo e outro, e ainda, da necessidade das mensurações serem realizadas sempre por um mesmo operador, uma vez que os durômetros funcionam mecanicamente e os resultados, em muito, dependem da força aplicada pelo operador sobre a haste de mensuração (Maida et al., 2011).

O silicone experimental apresentou valores inicias de dureza superiores ao MDX, o que pode ser explicado pela diferença de apresentação entre eles, sendo o Bio-Skin um silicone composto por duas massas densas e o MDX4-4210, por duas pastas viscosas, diferenças dadas, provavelmente pela variação no tamanho da cadeia polimérica de Si-O. Além disso, o aumento de 1 a 1,5 phr em quantidade de carga de silício ao silicone pode elevar a dureza em 1 unidade Shore A. O silicone BS apresentou maior porcentagem de silício que o MDX, o que pode explicar sua maior dureza Shore A. Ainda, de acordo com Mancuso, Goiato e dos Santos (2009), diferenças entre os materiais podem ser resultado de diferentes componentes utilizados na formulação original e/ou devido a diferenças no sistema de reticulação de cada polímero, de densidade, peso molecular, grau de concentração dos silicones e temperatura de polimerização.

Ao longo de todo o experimento, os dois materiais apresentaram um aumento da dureza em consequência da pigmentação e dos envelhecimentos (Tabela 4). Ao avaliar o efeito da pigmentação sobre o silicone MDX, as maiores médias foram encontradas quando da adição de opacificador (OP) nos grupos controle e LN. Para o silicone experimental, as 
maiores variações foram encontradas para os espécimes sem pigmento e com PIO no grupo controle e nos espécimes com PI do grupo envelhecido por LN. De modo geral, as menores variações foram encontradas com o envelhecimento artificial, o que indica que ao final do período a dureza dos espécimes apresentava-se próxima da dureza inicial.

Estes resultados sugerem que o sulfato de bário e o pigmento de pó de maquiagem atuaram como partículas de carga de reforço que elevam os valores de dureza. O sulfato de bário é utilizado na indústria de materiais para melhorar as propriedades ópticas, assegurando uma completa distribuição das partículas de pigmentos associados. Atuam como cargas capazes de produzir alto grau de impermeabilidade e durabilidade, evitando a absorção de umidade. Já o pigmento utilizado, ou seja, o pó de maquiagem apresenta sílica em sua composição.

Em geral, a maior média de variação da dureza ocorreu quando o material foi submetido ao envelhecimento por luz natural e quando mantidos no escuro (controle). Segundo Goiato et al. (2009b), o período de armazenamento pode causar um aumento significativo na dureza Shore A do silicone, devido à polimerização contínua desses materiais, em adição à evaporação de ácido acético e formaldeído, subprodutos formados durante esse processo (Anusavice, 2003). Guiotti, Goiato e dos Santos (2010) também encontraram um aumento na dureza Shore A de silicones para prótese bucomaxilofacial ao longo do tempo e concluíram que esses materiais tendem a apresentar uma maior dureza com o envelhecimento. Pinheiro et al. (2014) também relatam um aumento na dureza dos silicones testados, sendo que com o envelhecimento, os valores ultrapassaram a faixa considerada aceitável por Lewis e Castleberry (1980).

Um fator importante a ser considerado quando da escolha de um material é que os fabricantes só informam o valor mecânico do seu material sem a utilização de opacificadores ou pigmentos. Portanto, estas informações não são representativas para elastômeros de silicone utilizados em próteses faciais, as quais exigem esse tipo de adição para melhora da estética do paciente. Ao escolher um material, o profissional deve, portanto, tratar os valores dos fabricantes com cuidado, pois diferentes opacificadores e pigmentos alteram as propriedades dos elastômeros de silicone em diferentes graus.

A resistência à tração também tem sua importância já que é a propriedade que confere resistência global ao material, indicando sua durabilidade clínica (Hatamleh; Watts, 2010). No entanto, poucos estudos correlacionam essa propriedade com os efeitos da pigmentação e do 
envelhecimento. A resistência à tração do silicone experimental foi muito superior à do MDX, independente dos fatores de variação. Avaliando os materiais isoladamente, as médias de resistência à tração do silicone MDX não sofreram influência da pigmentação ou do envelhecimento, exceto no grupo PI envelhecido por luz ultravioleta artificial. Analisando o silicone BS, as maiores médias de resistência foram encontradas nos espécimes com PI em todos os grupos de envelhecimento. Estes resultados podem ser relacionados às partículas de carga presentes neste silicone, associadas às do pigmento e opacificador, como discutido anteriormente. Já para os espécimes confeccionados somente com opacificador, os valores de resistência do silicone experimental foram semelhantes aos dos espécimes sem pigmento. Embora as partículas do opacificador reforcem a matriz de elastômero de silicone, a resistência desse grupo foi menor. Segundo Watson, Beydoun e Scott (2004) é importante manter o teor de carga a um nível apropriado devido a sua energia superficial mais elevada e reatividade química, caso contrário, essas partículas de óxido nanométricas podem aglomerar. Aglomerados foram visualizados nas amostras analisadas por MEV. Porém, este resultado sugere que a resistência foi influenciada pelo processo de envelhecimento, uma vez que a quantidade de opacificador adicionada respeitou os limiares indicados (Han et al., 2008). Os processos de envelhecimento bem como a passagem do tempo, podem ter causado a degradação do material. Quando o silicone está sob forças externas, as partículas aglomeradas atuam como centros de concentração de estresse na matriz do material, diminuindo assim a resistência mecânica do silicone. Este fato ajuda a explicar a influência do opacificador na resistência à tração do silicone BS (Han et al., 2008), ressaltando a importância da correta manipulação e proporção dos pigmentos adicionados para que estes se incorporem de forma adequada ao silicone. Hatamleh et al. (2011) relatam que a resistência à tração só foi degradada após armazenagem de sebo sob envelhecimento acelerado da luz do dia durante 360 horas. Como já relatado, a degradação ou o aperfeiçoamento das propriedades do silicone é geralmente causada por modificações estruturais na distribuição das massas moleculares do polímero causadas pela cisão da cadeia do material, intensificação da reticulação ou aumento da densidade (Dootz; Koran; Craig, 1993). Sabe-se que maiores valores de resistência à tração são importantes para a durabilidade de próteses retidas por implantes, onde a força para remoção das mesmas será aplicada rotineiramente ao longo do período de vida útil das próteses. 
Comparando os envelhecimentos, os espécimes do grupo controle e LN influenciaram significativamente a resistência à tração. Isto pode ser explicado pelo fato de que quando os espécimes são submetidos a um ambiente de envelhecimento artificial as condições são controladas, diferentemente do que acontece com as próteses expostas ao meio ambiente, podendo causar estimativas incorretas quanto à durabilidade dos polímeros (Tran; Scarbecz; Gary, 2004; Eleni et al., 2009; Nguyen et al., 2013). Analisando a temperatura $\left(12^{\circ} \mathrm{C} \mathrm{a} 29^{\circ} \mathrm{C}\right)$, umidade local de $80 \%$ e incidência de radiação considerada muito alta (aproximadamente 9) onde se deu o desenvolvimento deste estudo (Cidade de Ribeirão Preto, SP), notam-se grandes variações, justificando os resultados obtidos pelo intemperismo.

A microscopia eletrônica de varredura foi realizada com o objetivo de analisar a presença de partículas da pigmentação que possam ter permanecido na superfície dos silicones, bem como avaliar possíveis degradações pelo envelhecimento. Segundo Han et al. (2008), a adição de nano-óxidos de forma adequada melhora as propriedades mecânicas do silicone, entretanto sem exceder a concentração recomendada de 2,5\%. Por meio da microscopia eletrônica de varredura, os autores observaram que, em uma concentração de $2,0 \%$, as partículas dos opacificadores foram bem distribuídas no silicone, mantendo o seu tamanho original. No entanto, quando a concentração foi aumentada para 3,0\%, as imagens demonstraram que todos os opacificadores utilizados no estudo tinham se aglomerado numa extensão diferente, o que resultou numa diminuição das propriedades mecânicas do silicone.

De forma geral, as superfícies dos espécimes do silicone Bio-Skin apresentaram-se mais irregulares se comparadas às do silicone MDX. Este fato pode ser atribuído à diferença na consistência entre os dois materiais, visto que o MDX é composto por duas pastas viscosas de fácil manipulação e deposição no interior das "caixas" de teflon. O silicone Bio-Skin é composto por duas massas densas que exigem manipulação vigorosa por meio do cilindro laminador. A acomodação do silicone no interior da "caixa" exigiu maior esforço com acomodação por meio do cilindro manual. Supõe-se que esta diferença poderia ser resolvida se o material fosse prensado no interior de moldes de gesso, obtendo-se maior uniformidade da superfície. O aparecimento de superfícies ásperas e porosas no silicone BS, também pode ser resultante da solubilização dos pigmentos que não foram incorporados, e que uma vez submetidos ao processo de calor e umidade, se soltaram do silicone, causando em sua superfície irregularidades, como pode-se observar nas imagens de MEV. 
Sabe-se que, de maneira geral, os silicones apresentam um baixo nível de energia coesiva (Anusavice, 2003) e, portanto, fraca interação molecular, fazendo com que pequenas partículas se agreguem à cadeia polimérica e, partículas maiores, separem-se do polímero, prejudicando o reforço do material. Ainda, Mancuso, Goiato e dos Santos (2009), relatam que particularmente, partículas constituintes de pós de maquiagem cosméticos são provavelmente grandes partículas, portanto, mais facilmente separadas da cadeia do silicone, o que explicaria a superfície observada nos espécimes pigmentados dessa maneira. Além disso, por ser um pigmento de origem orgânica, sofre maior degradação com o envelhecimento por dissolver-se quando em contato com a luz. No entanto, as características da superfície dos materiais não se correlacionam com os achados dos ensaios mecânicos, onde houve aumento da dureza e resistência à tração.

No presente estudo, também pode-se notar a influência do envelhecimento por UV, principalmente no silicone BS, onde a superfície dos espécimes mostraram-se diferentes dos demais envelhecimentos. Al-Dharrab, Tayel e Abodaya (2013), relatam que inicialmente uma superfície lisa foi observada no grupo controle, o que ser atribuída ao processo de polimerização contínuo até sua estabilização. No entanto, após seis meses em diferentes condições de armazenamento, a superfície do silicone tornou-se áspera com algumas irregularidades devido a pequenas fissuras superficiais. Uma limitação do presente estudo foi não ter realizado o ensaio de rugosidade superficial, o qual deverá ser alvo de estudos futuros.

A espectroscopia por energia dispersiva (EDS) revelou a presença de silício e oxigênio em grande quantidade, os quais são elementos constituintes da cadeia polimérica principal de ambos os silicones testados no presente estudo. Na maioria das situações o silicone BS apresentou porcentagem de silício acima dos 40\%, enquanto o MDX apresentou situação inversa, o que pode sugerir um menor comprimento da cadeia polimérica do MDX que o caracteriza como um material mais viscoso, com menores valores de dureza e resistência à tração.

Com base nos resultados obtidos, análises quanto ao comportamento do material experimental frente a métodos de higiene, adesão de microrganismos e métodos de obtenção das peças protéticas precisam ser realizadas para posterior avaliação clínica. 
Dentro das limitações deste estudo in vitro, pode-se concluir que:

1. O material experimental apresentou resultados favoráveis em relação à alteração de cor, dureza Shore A e resistência à tração para sua aplicação clínica em prótese bucomaxilofacial.

2. A associação da pigmentação intrínseca, por meio de pó de maquiagem, com opacificador, protegeu o silicone da alteração de cor e promoveu alterações aceitáveis nas propriedades mecânicas dos materiais.

3. Todos os processos de envelhecimento promoveram alterações nas propriedades dos materiais. 


\section{Referêncías Bibliográficas}


Abu-Bakr N, Han L, Okamoto A, Iwaku M. Color stability of compomer after immersion in various media. J Esthet Dent. 2000; 12(5):258-63.

Al-Dharrab AA, Tayel SB, Abodaya MH. The effect of different storage conditions on the physical properties of pigmented medical grade I silicone maxillofacial material. ISRN Dent. 2013 Mar 28;2013:582051.

Andres CJ, Haug SP, Munoz CA, Bernal G. Effects of environmental factors on maxillofacial elastomers: Part I--Literature review. J Prosthet Dent. 1992 Aug;68(2):327-30.

Anusavice KJ. Phillips' sciences of dental materials. $11^{\text {th }}$ ed. St. Louis: Elsevier. 2003.

Ariani N, Vissink A, van Oort RP, Kusdhany L, Djais A, Rahardjo TB, et al. Microbial biofilms on facial prostheses. Biofouling. 2012;28(6):583-91.

ASTM International. ASTM D412:2006. Standard test methods for vulcanized rubber and thermoplastic elastomers-tension. West Conshohocken: ASTM International; 2006. Disponível em: http://www.astm.org/Standards/D412.htm.

ASTM International. ASTM D2240-05:2010. Standard test method for rubber property durometer hardness. West Conshohocken: ASTM International; 2010. Disponível em: http://www.astm.org/Standards/D2240.htm.

ASTM International. ASTM G154:2006. Standard Practice for Operating Fluorescent Light Apparatus for UV Exposure of Nonmetallic Materials. West Conshohocken: ASTM International; 2006. Disponível em: http://www.astm.org/Standards/G154.htm.

Aziz T, Waters M, Jagger R. Analysis of the properties of silicone rubber maxillofacial prosthetic materials. J Dent. 2003a Jan;31(1):67-74.

Aziz T, Waters M, Jagger R. Development of a new poly(dimethylsiloxane) maxillofacial prosthetic material. J Biomed Mater Res B Appl Biomater. 2003b May 15;65(2):252-61.

Bangera BS, Guttal SS. Evaluation of varying concentrations of nano-oxides as ultraviolet protective agents when incorporated in maxillofacial silicones: An in vitro study. J Prosthet Dent. 2014 Dec;112(6):1567-72. 
Beatty MW, Mahanna GK, Dick K, Jia W. Color changes in dry-pigmented maxillofacial elastomer resulting from ultraviolet light exposure. J Prosthet Dent. 1995 Nov;74(5):493-8.

Bell WT, Chalian VA, Moore BK. Polydimethyl siloxane materials in maxillofacial prosthetics: evaluation and comparison of physical properties. J Prosthet Dent. 1985 Sep;54(3):404-10.

Bellamy K, Limbert G, Waters MG, Middleton J. An elastomeric material for facial prostheses: synthesis, experimental and numerical testing aspects. Biomaterials. 2003 Dec; 24(27):5061-6.

Craig RG, Koran A, Yu R, Spencer J. Color stability of elastomers for maxillofacial appliances. J Dent Res. 1978 Sep-Oct; 57(9-10): 866-71.

Craig RG, Koran A, Yu R. Elastomers for maxillofacial applications. Biomaterials. 1980 Apr;1(2):112-7.

Dootz ER, Koran A, Craig RG. Physical property comparison of 11 soft denture lining materials as a function of accelerated aging. J Prosthet Dent. 1993 Jan; 69(1): 114-9.

dos Santos DM, Goiato MC, Sinhoreti MA, Fernandes AU, Ribeiro Pdo P, Dekon SF. Color stability of polymers for facial prosthesis. J Craniofac Surg. 2010 Jan;21(1):54-8.

dos Santos DM, Goiato MC, Moreno A, Pesqueira AA, Haddad MF. Influence of pigments and opacifiers on color stability of an artificially aged facial silicone. J Prosthodont. 2011 Apr;20(3):205-8.

dos Santos DM, Goiato MC, Sinhoreti MA, Moreno A, Dekon SF, Haddad MF, et al. Influence of natural weathering on colour stability of materials used for facial prosthesis. $\mathrm{J}$ Med Eng Technol. 2012 Jul;36(5):267-70.

Eleni PN, Krokida MK, Polyzois GL. The effect of artificial accelerated weathering on the mechanical properties of maxillofacial polymers PDMS and CPE. Biomed Mater. 2009a Jun;4(3):035001.

Eleni PN, Katsavou I, Krokida MK, Polyzois GL, Gettleman L. Mechanical behavior of facial prosthetic elastomers after outdoor weathering. Dent Mater. 2009b Dec; 25(12):1493-502. 
Eleni PN, Krokida M, Polyzois G, Gettleman L, Bisharat GI. Effects of outdoor weathering on facial prosthetic elastomers. Odontology. 2011 Jan;99(1):68-76.

Gary JJ, Huget EF, Powell LD. Accelerated color change in a maxillofacial elastomer with and without pigmentation. J Prosthet Dent. 2001 Jun;85(6):614-20.

Goiato MC; Murakawa AC; Mancuso DN. Pigmentação de próteses bucomaxilofaciais. Rev Odontol. 2008;16(31):92-9.

Goiato MC, Pesqueira AA, dos Santos DM, Zavanelli AC, Ribeiro P do P. Color stability comparison of silicone facial prostheses following disinfection. J Prosthodont. 2009a Apr; 18(3):242-4.

Goiato MC, Pesqueira AA, Santos DM, Dekon SF. Evaluation of hardness and surface roughness of two maxillofacial silicones following disinfection. Braz Oral Res. 2009b JanMar; 23(1):49-53.

Goiato MC, Haddad MF, Santos DM, Pesqueira AA, Moreno A. Hardness evaluation of prosthetic silicones containing opacifiers following chemical disinfection and accelerated aging. Braz Oral Res. 2010 Jul-Sep;24(3):303-8.

Goiato MC, Haddad MF, Sinhoreti MA, dos Santos DM, Pesqueira AA, Moreno A. Influence of opacifiers on dimensional stability and detail reproduction of maxillofacial silicone elastomer. Biomed Eng Online. 2010 Dec 16;9:85.

Goiato MC, Haddad MF, Pesqueira AA, Moreno A, Dos Santos DM, Bannwart LC. Effect of chemical disinfection and accelerated aging on color stability of maxillofacial silicone with opacifiers. J Prosthodont. 2011 Oct;20(7):566-9.

Guiotti AM; Goiato MC. Avaliação de um silicone nacional para próteses nacionais em função do efeito do tempo de armazenagem, da desinfecção química e da pigmentação sobre a deterioração marginal e a dureza SHORE A. Cienc Odontol Bras. 2008; 11: 64-74.

Guiotti AM, Goiato MC, dos Santos DM. Evaluation of the Shore A hardness of silicone for facial prosthesis as to the effect of storage period and chemical disinfection. J Craniofac Surg. 2010 Mar;21(2):323-7. 
Haddad MF, Goiato MC, Dos Santos DM, Pesqueira AA, Moreno A, Pellizzer EP. Influence of pigment and opacifier on dimensional stability and detail reproduction of maxillofacial silicone elastomer. J Craniofac Surg. 2011 Sep;22(5):1612-6.

Han Y, Kiat-amnuay S, Powers JM, Zhao Y. Effect of nano-oxide concentration on the mechanical properties of a maxillofacial silicone elastomer. J Prosthet Dent. 2008 Dec; 100(6): 465-73.

Han Y, Zhao Y, Xie C, Powers JM, Kiat-amnuay S. Color stability of pigmented maxillofacial silicone elastomer: effects of nano-oxides as opacifiers. J Dent. 2010;38 Suppl 2:e100-5.

Han Y, Powers JM, Kiat-Amnuay S. Effect of opacifiers and UV absorbers on pigmented maxillofacial silicone elastomer, part 1: color stability after artificial aging. J Prosthet Dent. 2013 Jun;109(6):397-401.

Hatamleh MM, Watts DC. Mechanical properties and bonding of maxillofacial silicone elastomers. Dent Mater. 2010 Feb;26(2):185-91.

Hatamleh MM, Polyzois GL, Silikas N, Watts DC. Effect of extraoral aging conditions on mechanical properties of maxillofacial silicone elastomer. J Prosthodont. 2011 Aug;20(6):439-46.

Haug SP, Andres CJ, Munoz CA, Bernal G. Effects of environmental factors on maxillofacial elastomers: Part IV--Optical properties. J Prosthet Dent. 1992 Nov;68(5):820-3.

Haug SP, Moore BK, Andres CJ. Color stability and colorant effect on maxillofacial elastomers. Part II: weathering effect on physical properties. J Prosthet Dent. 1999 Apr;81(4):423-30.

Haug SP, Andres CJ, Moore BK. Color stability and colorant effect on maxillofacial elastomers. Part III: weathering effect on color. J Prosthet Dent. 1999 Apr;81(4):431-8.

Hermann C, Mesquita MF, Consani RL, Henriques GE. The effect of aging by thermal cycling and mechanical brushing on resilient denture liner hardness and roughness. J Prosthodont. 2008 Jun;17(4):318-22.

Jani RM, Schaaf NG. An evaluation of facial prostheses. J Prosthet Dent. 1978 May;39(5):546-50. 
Janousek, A. Regulatory aspects of sunscreens in Europe. In: Lowe NJ; Shaath NA; Pathak MA. Sunscreens: development, evaluation, and regulatory aspects. New York: Marcel Dekker. 1997; p.215-25.

Johnston WM, Ma T, Kienle BH. Translucency parameter of colorants for maxillofacial prostheses. Int J Prosthodont. 1995 Jan-Feb;8(1):79-86.

Karayazgan B, Gunay Y, Evlioglu G. Improved edge strength in a facial prosthesis by incorporation of tulle: a clinical report. J Prosthet Dent. 2003 Dec;90(6):526-9.

Kheur MG, Sethi T, Coward T, Jambhekar SS. A comparative evaluation of the change in hardness, of two commonly used maxillofacial prosthetic silicone elastomers, as subjected to simulated weathering in tropical climatic conditions. Eur J Prosthodont Restor Dent. 2012 Dec;20(4):146-50.

Khindria, SK; Bansal, S; Kansal, M. Maxillofacial prosthetic materials. J Indian Prosthodont Soc. 2012; 9(1): 2-5.

Kiat-Amnuay S, Lemon JC, Powers JM. Effect of opacifiers on color stability of pigmented maxillofacial silicone A-2186 subjected to artificial aging. J Prosthodont. 2002 Jun;11(2):10916.

Kiat-Amnuay S, Mekayarajjananonth T, Powers JM, Chambers MS, Lemon JC. Interactions of pigments and opacifiers on color stability of MDX4-4210/type A maxillofacial elastomers subjected to artificial aging. J Prosthet Dent. 2006 Mar;95(3):249-57.

Kiat-amnuay S, Beerbower M, Powers JM, Paravina RD. Influence of pigments and opacifiers on color stability of silicone maxillofacial elastomer. J Dent. 2009;37 Suppl 1:e4550 .

Koran A, Yu R, Powers JM, Craig RG. Color stability of a pigmented elastomer for maxillofacial appliances. J Dent Res. 1979 May; 58(5):1450-4.

Kulak-Ozkan Y, Sertgoz A, Gedik H. Effect of thermocycling on tensile bond strength of six silicone-based, resilient denture liners. J Prosthet Dent. 2003 Mar;89(3):303-10.

Lai JH, Wang LL, Ko CC, DeLong RL, Hodges JS. New organosilicon maxillofacial prosthetic materials. Dent Mater. 2002 May;18(3):281-6. 
Leow ME, Ow RK, Valiyaveettil S, Lee MH, Pho RW. Colourfast pigments in silicone hand and maxillofacial prostheses. Prosthet Orthot Int. 2002 Aug;26(2):124-34.

Lewis DH, Castleberry DJ. An assessment of recent advances in external maxillofacial materials. J Prosthet Dent. 1980 Apr;43(4):426-32.

Lontz JF. State-of-the-art materials used for maxillofacial prosthetic reconstruction. Dent Clin North Am. 1990 Apr;34(2):307-25.

Maida AFP, Daher C, Pinheiro JB, Paranhos HFO, Macedo AP, Silva CHL. Evaluation of the Hardness of a Medical Silicone with Potential Application in Facial Prosthesis. Rev Odontol Bras Central 2011; 20(55): 329-334.

Mancuso DN, Zuim PRJ, Rocha EP, Assunção WG, Goiato MC. Alteração da cor das próteses maxilofaciais: revisão de literatura. Rev Odontol UNESP. 2005;34(4):173-8.

Mancuso DN, Goiato MC, Santos DM. Color stability after accelerated aging of two silicones, pigmented or not, for use in facial prostheses. Braz Oral Res. 2009 AprJun;23(2):144-8.

Mayer R. The artist's handbook of materials and techniques. 5 ed. New York: Viking Penguin, 1991.

Montgomery PC, Kiat-Amnuay S. Survey of currently used materials for fabrication of extraoral maxillofacial prostheses in North America, Europe, Asia, and Australia. J Prosthodont. 2010 Aug;19(6):482-90.

Nguyen CT, Chambers MS, Powers JM, Kiat-Amnuay S. Effect of opacifiers and UV absorbers on pigmented maxillofacial silicone elastomer, part 2: mechanical properties after artificial aging. J Prosthet Dent. 2013 Jun;109(6):402-10.

Paravina RD, Majkic G, Del Mar Perez M, Kiat-Amnuay S. Color difference thresholds of maxillofacial skin replications. J Prosthodont. 2009 Oct;18(7):618-25.

Pesqueira AA, Goiato MC, dos Santos DM, Haddad MF, Ribeiro Pdo P, Coelho Sinhoreti MA, et al. Effect of disinfection and accelerated aging on color stability of colorless and pigmented facial silicone. J Prosthodont. 2011 Jun; 20(4): 305-9. 
Pinheiro JB, Daher C, Maida AFP, Leite VMF, Paranhos HFO, Silva CHL. Efeitos da pigmentacao e do envelhecimento acelerado na estabilidade de cor de um silicone medico com potencial de uso nas próteses maxilofaciais. Rev Odontol UNESP. 2011;40(3):125-30.

Pinheiro JB, Reis AC, Pisani MX, Leite VM, Souza RF, Paranhos HF, et al. Microstructural characterization and evaluation of the properties of polymeric materials for maxillofacial prosthetics. J Med Eng Technol. 2014 Mar;38(2):67-75.

Pinto JR, Mesquita MF, Nobilo MA, Henriques GE. Evaluation of varying amounts of thermal cycling on bond strength and permanent deformation of two resilient denture liners. $\mathrm{J}$ Prosthet Dent. 2004 Sep;92(3):288-93.

Prasad PS, Sam JE, Kumar A, Kannan. The effect of 5\% sodium hypochlorite, 17\% EDTA and triphala on two different rotary Ni-Ti instruments: An AFM and EDS analysis. J Conserv Dent. 2014 Sep;17(5):462-6.

Polyzois GL. Color stability of facial silicone prosthetic polymers after outdoor weathering. J Prosthet Dent. 1999 Oct;82(4):447-50.

Polyzois GL, Eleni PN, Krokida MK. Optical properties of pigmented polydimethylsiloxane prosthetic elastomers: effect of "outdoor" and "indoor" accelerating aging. J Craniofac Surg. 2011 Sep; 22(5):1574-8.

Polyzois GL, Eleni PN, Krokida MK. Effect of time passage on some physical properties of silicone maxillofacial elastomers. J Craniofac Surg. 2011 Sep;22(5):1617-21.

Rabek JF. Polymer photodegradation: mechanisms and experimental. Chapman and Hall: New York. 1995:24-25

Rezende JRV. Fundamentos da prótese bucomaxilofacial. São Paulo: Sarvier, 1997.

Rowe AH, Forrest JO. Dental impressions. The probability of contamination and a method of disinfection. Br Dent J. 1978 Sep;145(6):184-6.

Saboya ACL, Carvalho JCM, André M, Mattos BSC, Rossa R. Avaliação da dureza "Shore A" e da resistência ao rasgamento de alguns silicones acéticos modificados para uso em prótese facial. Rev Odontol USP. 1997;11(2):93-7. 
Seluk LW, Yu R, Koran A. Stability of ceramic pigments for maxillofacial applications. J Oral Rehabil. 1987 May;14(3):309-13.

Subaş1 MG, İnan Ö. Evaluation of the topographical surface changes and roughness of zirconia after different surface treatments. Lasers Med Sci. 2012 Jul;27(4):735-42.

Takamata T, Moore BK, Chalian VA. Evaluation of color changes of silicone maxillofacial materials after exposure to sunlight. Dent Mater J. 1989 Dec;8(2):260-70.

Tran NH, Scarbecz M, Gary JJ. In vitro evaluation of color change in maxillofacial elastomer through the use of an ultraviolet light absorber and a hindered amine light stabilizer. J Prosthet Dent. 2004 May;91(5):483-90.

Turner GE, Fischer TE, Castleberry DJ, Lemons JE. Intrinsic color of isophorone polyurethane for maxillofacial prosthetics. Part I: Physical properties. J Prosthet Dent. 1984 Apr;51(4):519-22.

Udagama A, Drane JB. Use of medical-grade methyl triacetoxy silane crosslinked silicone for facial prostheses. J Prosthet Dent. 1982 Jul; 48(1):86-8.

Valian A, Moravej-Salehi E. Surface treatment of feldspathic porcelain: scanning electron microscopy analysis. J Adv Prosthodont. 2014 Oct;6(5):387-94.

Watson S, Beydoun D, Scott J. Preparation of nanosized crystalline TiO2 particles at low temperature for photocatalysis. J Nano Res. 2004;6:193-207.

Wolfaardt JF, Chandler HD, Smith BA. Mechanical properties of a new facial prosthetic material. J Prosthet Dent. 1985 Feb;53(2):228-34.

Yu R, Koran A 3rd, Craig RG. Physical properties of maxillofacial elastomers under conditions of accelerated aging. J Dent Res. 1980a Jun;59(6):1041-7.

Yu R, Koran A 3rd, Craig RG. Physical properties of a pigmented silicone maxillofacial material as a function of accelerated aging. J Dent Res. 1980b Jul;59(7):1141-8. 
Apêndices 
Tabela A1 - Valores de alteração de cor $(\Delta \mathrm{E})$ dos espécimes confeccionados com o silicone MDX 4-4210 (controle/padrão ouro) e com o silicone experimental BS (Bio-Skin) dos seguintes grupos de pigmentação: sem pigmentação (SP), pigmentação intrínseca (PI), opacificador (OP) e grupo associado (PIO), após envelhecimento por luz natural, luz ultravioleta e grupo controle.

\begin{tabular}{|c|c|c|c|c|c|c|}
\hline & \multicolumn{3}{|c|}{ MDX 4-4210 } & \multicolumn{3}{|c|}{ BS } \\
\hline & $\mathrm{C}$ & $\mathrm{LN}$ & UV & $\mathrm{C}$ & $\mathrm{LN}$ & UV \\
\hline \multirow{10}{*}{ SP } & 0,79 & 2,08 & 2,051 & 0,55 & 4,00 & 1,171 \\
\hline & 1,26 & 2,47 & 0,829 & 0,13 & 4,01 & 1,041 \\
\hline & 1,01 & 1,91 & 1,965 & 0,26 & 4,90 & 0,866 \\
\hline & 1,22 & 2,54 & 0,957 & 0,30 & 4,67 & 0,828 \\
\hline & 1,07 & 1,99 & 1,557 & 0,44 & 4,11 & 0,704 \\
\hline & 1,00 & 2,16 & 1,926 & 0,08 & 4,86 & 0,789 \\
\hline & 1,13 & 2,39 & 1,523 & 0,76 & 6,20 & 0,744 \\
\hline & 1,25 & 2,33 & 2,173 & 0,89 & 5,71 & 0,721 \\
\hline & 1,23 & 2,48 & 2,411 & 0,16 & 4,89 & 0,477 \\
\hline & 1,24 & 2,77 & 1,894 & 0,25 & 6,10 & 1,881 \\
\hline \multirow{10}{*}{ PI } & 2,13 & 0,34 & 0,648 & 0,80 & 0,77 & 0,873 \\
\hline & 1,05 & 0,37 & 0,389 & 0,44 & 0,92 & 0,946 \\
\hline & 1,15 & 0,70 & 0,318 & 0,92 & 0,87 & 0,847 \\
\hline & 1,51 & 0,54 & 1,145 & 0,80 & 0,98 & 0,645 \\
\hline & 1,73 & 0,31 & 1,106 & 1,23 & 0,94 & 0,756 \\
\hline & 1,48 & 1,30 & 0,703 & 0,88 & 1,03 & 0,228 \\
\hline & 1,11 & 0,64 & 0,649 & 0,53 & 0,95 & 1,499 \\
\hline & 1,40 & 0,36 & 0,265 & 0,38 & 0,44 & 1,175 \\
\hline & 1,45 & 0,78 & 0,145 & 0,78 & 0,65 & 1,811 \\
\hline & 1,18 & 0,62 & 0,257 & 0,82 & 0,81 & 0,954 \\
\hline \multirow{10}{*}{$\mathrm{OP}$} & 1,15 & 3,55 & 1,849 & 1,41 & 4,71 & 1,231 \\
\hline & 1,12 & 2,64 & 1,991 & 0,15 & 3,82 & 1,537 \\
\hline & 1,41 & 2,80 & 1,873 & 0,25 & 4,12 & 0,869 \\
\hline & 1,33 & 3,18 & 1,595 & 0,50 & 3,65 & 1,133 \\
\hline & 1,29 & 3,05 & 2,387 & 0,07 & 4,20 & 1,289 \\
\hline & 1,17 & 3,06 & 2,163 & 1,46 & 4,24 & 1,177 \\
\hline & 1,43 & 4,75 & 1,678 & 0,27 & 4,39 & 0,752 \\
\hline & 1,38 & 3,58 & 1,852 & 0,18 & 4,24 & 1,995 \\
\hline & 1,40 & 3,97 & 1,982 & 0,20 & 4,16 & 0,566 \\
\hline & 1,26 & 3,93 & 1,213 & 0,14 & 4,65 & 1,005 \\
\hline \multirow{10}{*}{ PIO } & 1,08 & 0,30 & 0,242 & 0,67 & 0,45 & 2,307 \\
\hline & 0,43 & 0,45 & 0,299 & 0,34 & 0,42 & 1,481 \\
\hline & 0,79 & 0,64 & 0,262 & 0,34 & 0,42 & 0,865 \\
\hline & 0,58 & 0,40 & 0,397 & 0,29 & 0,53 & 0,363 \\
\hline & 0,87 & 0,33 & 0,342 & 0,43 & 0,65 & 0,576 \\
\hline & 0,48 & 0,40 & 0,259 & 0,77 & 0,58 & 0,538 \\
\hline & 0,63 & 0,36 & 0,266 & 0,50 & 0,65 & 0,848 \\
\hline & 0,70 & 0,35 & 0,254 & 0,68 & 0,89 & 1,436 \\
\hline & 0,95 & 0,49 & 0,252 & 0,32 & 0,62 & 1,658 \\
\hline & 0,63 & 0,30 & 0,195 & 0,44 & 0,34 & 3,015 \\
\hline
\end{tabular}


As figuras A1, A2 e A3 apresentam os gráficos em Box Plot dos fatores isolados (material, pigmentação e envelhecimento) para o ensaio de alteração de cor.

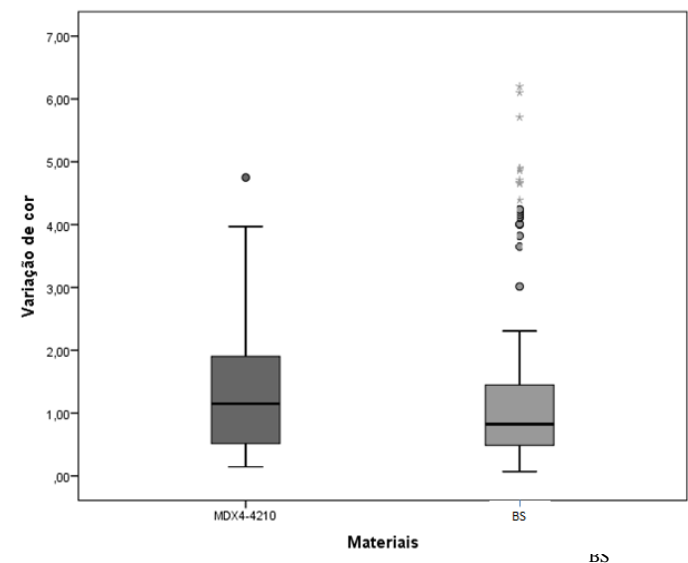

Figura A1 - Box plot do fator material para o ensaio de alteração de cor.

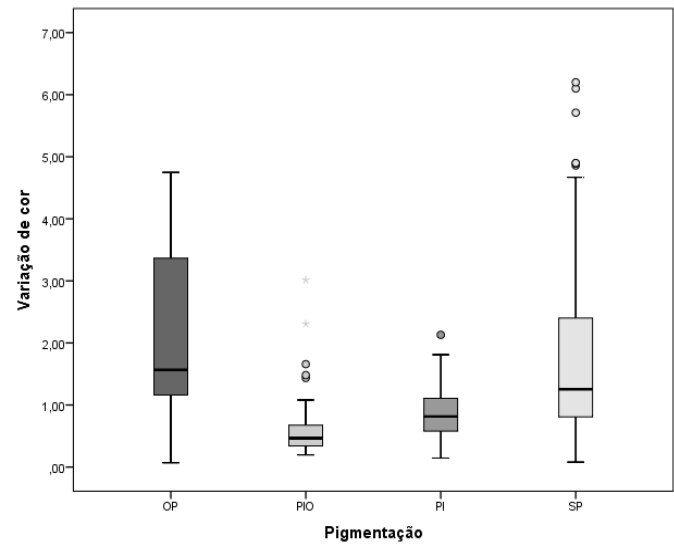

Figura A2 - Box plot do fator pigmentação para o ensaio de alteração de cor.

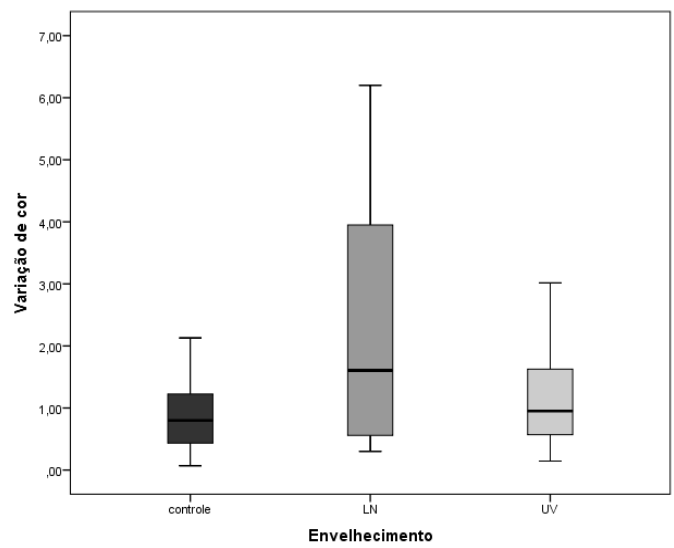

Figura A3 - Box plot do fator envelhecimento para o ensaio de alteração de cor. 
Tabela A2 - Valores de dureza Shore A (resultados fornecidos em unidades Shore A) dos espécimes confeccionados com o silicone MDX 4-4210 (controle/padrão ouro) dos seguintes grupos de pigmentação: sem pigmentação (SP), pigmentação intrínseca (PI), opacificador (OP) e grupo associado (PIO), após envelhecimento por luz natural, luz ultravioleta e grupo controle.

\begin{tabular}{|c|c|c|c|c|c|c|c|c|c|}
\hline & \multicolumn{9}{|c|}{ MDX } \\
\hline & \multicolumn{3}{|c|}{$\mathrm{C}$} & \multicolumn{3}{|c|}{ LN } & \multicolumn{3}{|c|}{ UV } \\
\hline & I & $\mathrm{F}$ & F-I & I & $F$ & F-I & I & $\mathrm{F}$ & F-I \\
\hline \multirow{10}{*}{ SP } & 49,8 & 51,8 & 2 & 46,4 & 55,2 & 8,8 & 54,2 & 53,8 & $-0,4$ \\
\hline & 48,8 & 52,8 & 4 & 49 & 54,8 & 5,8 & 52,8 & 52,2 & $-0,6$ \\
\hline & 47,8 & 48 & 0,2 & 48,6 & 52,6 & 4 & 54,4 & 52,8 & $-1,6$ \\
\hline & 51 & 54,2 & 3,2 & 48,6 & 53 & 4,4 & 55,8 & 57 & 1,2 \\
\hline & 52,6 & 53,6 & 1 & 51,4 & 55,6 & 4,2 & 56,2 & 55,4 & $-0,8$ \\
\hline & 49,8 & 53,8 & 4 & 49,6 & 53,4 & 3,8 & 54,8 & 56,8 & 2 \\
\hline & 52,6 & 56,6 & 4 & 49 & 54,2 & 5,2 & 52 & 55,6 & 3,6 \\
\hline & 52,6 & 56 & 3,4 & 54,4 & 56,2 & 1,8 & 53,8 & 53,4 & $-0,4$ \\
\hline & 50,6 & 53,6 & 3 & 51,8 & 55,8 & 4 & 52,2 & 54,4 & 2,2 \\
\hline & 50,8 & 55,4 & 4,6 & 51,4 & 55 & 3,6 & 54,4 & 55 & 0,6 \\
\hline \multirow{10}{*}{ PI } & 51,6 & 57,2 & 5,6 & 53 & 56,8 & 3,8 & 53,2 & 60,4 & 7,2 \\
\hline & 52,6 & 59,6 & 7 & 49,6 & 56 & 6,4 & 52 & 58,2 & 6,2 \\
\hline & 53 & 57 & 4 & 50,6 & 54,4 & 3,8 & 53,8 & 59,2 & 5,4 \\
\hline & 49,2 & 55,2 & 6 & 51 & 55 & 4 & 56 & 58,4 & 2,4 \\
\hline & 50 & 55,6 & 5,6 & 54,8 & 58,8 & 4 & 53 & 55,6 & 2,6 \\
\hline & 48,8 & 53 & 4,2 & 53 & 57,4 & 4,4 & 52,4 & 55,4 & 3 \\
\hline & 50,6 & 54,8 & 4,2 & 52 & 55 & 3 & 53,4 & 56 & 2,6 \\
\hline & 51,2 & 57,8 & 6,6 & 50 & 56,2 & 6,2 & 51,8 & 56,4 & 4,6 \\
\hline & 50,8 & 53,4 & 2,6 & 54,8 & 56,4 & 1,6 & 53,2 & 54,4 & 1,2 \\
\hline & 51,8 & 56,6 & 4,8 & 51 & 52 & 1 & 51,2 & 54,8 & 3,6 \\
\hline \multirow{10}{*}{$\mathrm{OP}$} & 46,4 & 54,6 & 8,2 & 47 & 51,8 & 4,8 & 52,2 & 56,8 & 4,6 \\
\hline & 50,6 & 58,4 & 7,8 & 51 & 56,8 & 5,8 & 53,6 & 53,4 & $-0,2$ \\
\hline & 48,6 & 57,8 & 9,2 & 49,2 & 58 & 8,8 & 54,2 & 55,4 & 1,2 \\
\hline & 48,4 & 55,6 & 7,2 & 50 & 57 & 7 & 52,6 & 57,4 & 4,8 \\
\hline & 48 & 56,2 & 8,2 & 46,4 & 56,4 & 10 & 54,4 & 55 & 0,6 \\
\hline & 47,2 & 55,4 & 8,2 & 46 & 57,2 & 11,2 & 51 & 57 & 6 \\
\hline & 48,2 & 54 & 5,8 & 49 & 55,4 & 6,4 & 50 & 57,6 & 7,6 \\
\hline & 47 & 52,4 & 5,4 & 48,2 & 59,4 & 11,2 & 50,4 & 56,4 & 6 \\
\hline & 46,6 & 56,8 & 10,2 & 48 & 54,8 & 6,8 & 51,8 & 55,8 & 4 \\
\hline & 46,6 & 52,4 & 5,8 & 45,4 & 53,2 & 7,8 & 51,2 & 55,6 & 4,4 \\
\hline \multirow{10}{*}{ PIO } & 50,8 & 57,2 & 6,4 & 49,2 & 57,4 & 8,2 & 49 & 56,2 & 7,2 \\
\hline & 50,8 & 56,2 & 5,4 & 51,4 & 58,4 & 7 & 49,2 & 54 & 4,8 \\
\hline & 49 & 55,8 & 6,8 & 50,2 & 57,8 & 7,6 & 49 & 56,8 & 7,8 \\
\hline & 49,8 & 56,2 & 6,4 & 50 & 57,2 & 7,2 & 47,8 & 53,6 & 5,8 \\
\hline & 51,6 & 51,6 & 0 & 49 & 54,8 & 5,8 & 54 & 55,8 & 1,8 \\
\hline & 51,6 & 54,8 & 3,2 & 49,6 & 56,2 & 6,6 & 50,8 & 52,2 & 1,4 \\
\hline & 51,4 & 55 & 3,6 & 50,8 & 54,2 & 3,4 & 51,2 & 54,4 & 3,2 \\
\hline & 51,8 & 57 & 5,2 & 48,8 & 57,2 & 8,4 & 50,6 & 52,8 & 2,2 \\
\hline & 50,4 & 54 & 3,6 & 49,6 & 54,4 & 4,8 & 51,2 & 53,4 & 2,2 \\
\hline & 47,4 & 53,4 & 6 & 51,2 & 58 & 6,8 & 50,8 & 54,2 & 3,4 \\
\hline
\end{tabular}


Tabela A3 - Valores de dureza Shore A (resultados fornecidos em unidades Shore A) dos espécimes confeccionados com o silicone experimental modificado (Bio-Skin) dos seguintes grupos de pigmentação: sem pigmentação (SP), pigmentação intrínseca (PI), opacificador (OP) e grupo associado (PIO), após envelhecimento por luz natural, luz ultravioleta e grupo controle.

\begin{tabular}{|c|c|c|c|c|c|c|c|c|c|}
\hline & \multicolumn{9}{|c|}{$\mathrm{BS}$} \\
\hline & \multicolumn{3}{|c|}{$\mathrm{C}$} & \multicolumn{3}{|c|}{$\mathrm{LN}$} & \multicolumn{3}{|c|}{ UV } \\
\hline & I & $\mathrm{F}$ & F-I & I & $\mathrm{F}$ & F-I & I & $\mathrm{F}$ & F-I \\
\hline \multirow{10}{*}{ SP } & 59,8 & 66,8 & 7 & 61,4 & 63 & 1,6 & 61,6 & 68,4 & 6,8 \\
\hline & 60,4 & 71,2 & 10,8 & 59,6 & 65 & 5,4 & 59,8 & 66,8 & 7 \\
\hline & 58,2 & 64 & 5,8 & 61,6 & 68,2 & 6,6 & 60,8 & 65,8 & 5 \\
\hline & 60 & 69 & 9 & 62,8 & 66,2 & 3,4 & 61,8 & 63,8 & 2 \\
\hline & 60,4 & 70,4 & 10 & 60,6 & 65,8 & 5,2 & 63,2 & 64,8 & 1,6 \\
\hline & 60,4 & 70,2 & 9,8 & 60,4 & 68,4 & 8 & 62,8 & 65,2 & 2,4 \\
\hline & 61,6 & 67,8 & 6,2 & 56,2 & 65,8 & 9,6 & 59,4 & 66,2 & 6,8 \\
\hline & 58 & 67,6 & 9,6 & 62,8 & 66,8 & 4 & 59,6 & 63,6 & 4 \\
\hline & 60,6 & 69,6 & 9 & 61,6 & 68,8 & 7,2 & 61 & 65,2 & 4,2 \\
\hline & 62,2 & 71,6 & 9,4 & 61,4 & 66,6 & 5,2 & 60,4 & 63,4 & 3 \\
\hline \multirow{10}{*}{ PI } & 62,8 & 70,8 & 8 & 61,4 & 70,2 & 8,8 & 66,8 & 69,2 & 2,4 \\
\hline & 62,8 & 67,8 & 5 & 61,2 & 69 & 7,8 & 67,4 & 67,2 & $-0,2$ \\
\hline & 61 & 69,6 & 8,6 & 63 & 70,8 & 7,8 & 65,2 & 70,8 & 5,6 \\
\hline & 64,8 & 72,4 & 7,6 & 62,6 & 69,6 & 7 & 63,8 & 69,4 & 5,6 \\
\hline & 61,2 & 69,6 & 8,4 & 61 & 68,2 & 7,2 & 64,8 & 68,4 & 3,6 \\
\hline & 61,6 & 68,6 & 7 & 59,8 & 69,2 & 9,4 & 63,4 & 70,8 & 7,4 \\
\hline & 62,2 & 66,4 & 4,2 & 60,2 & 69 & 8,8 & 64,6 & 68 & 3,4 \\
\hline & 57,8 & 68,6 & 10,8 & 59,4 & 69 & 9,6 & 64,2 & 70 & 5,8 \\
\hline & 61,6 & 71,6 & 10 & 59 & 67 & 8 & 62,8 & 70 & 7,2 \\
\hline & 61,4 & 70,2 & 8,8 & 60,6 & 68,8 & 8,2 & 65 & 71,4 & 6,4 \\
\hline \multirow{10}{*}{ OP } & 57,8 & 64,8 & 7 & 59,2 & 61,4 & 2,2 & 65,8 & 68 & 2,2 \\
\hline & 59,4 & 62,8 & 3,4 & 59,4 & 63,8 & 4,4 & 59,8 & 57 & $-2,8$ \\
\hline & 61,6 & 66,6 & 5 & 59,6 & 64,8 & 5,2 & 65,8 & 73,8 & 8 \\
\hline & 63,6 & 68,8 & 5,2 & 60,2 & 65,8 & 5,6 & 59,4 & 72,4 & 13 \\
\hline & 60 & 69 & 9 & 60 & 63,8 & 3,8 & 66 & 66,6 & 0,6 \\
\hline & 59 & 62,6 & 3,6 & 60 & 64,8 & 4,8 & 66 & 71,2 & 5,2 \\
\hline & 62,2 & 67,4 & 5,2 & 58,6 & 61 & 2,4 & 66,2 & 73,4 & 7,2 \\
\hline & 61,6 & 66,8 & 5,2 & 58,4 & 61,4 & 3 & 66,2 & 72 & 5,8 \\
\hline & 63 & 70 & 7 & 59,4 & 65 & 5,6 & 64,8 & 70,2 & 5,4 \\
\hline & 62,8 & 67,6 & 4,8 & 60,4 & 64,6 & 4,2 & 62,4 & 67,4 & 5 \\
\hline \multirow{10}{*}{$\mathrm{PIO}$} & 63,6 & 66,6 & 3 & 61,6 & 65 & 3,4 & 67,6 & 74 & 6,4 \\
\hline & 60,6 & 65 & 4,4 & 63,6 & 63,8 & 0,2 & 65,6 & 72,6 & 7 \\
\hline & 61 & 67,8 & 6,8 & 61,6 & 65 & 3,4 & 66,2 & 70,8 & 4,6 \\
\hline & 62,8 & 68,6 & 5,8 & 61,6 & 64,6 & 3 & 65,8 & 68,4 & 2,6 \\
\hline & 60,8 & 67,2 & 6,4 & 60,8 & 65,8 & 5 & 66,2 & 72,2 & 6 \\
\hline & 64 & 68 & 4 & 64,4 & 65,2 & 0,8 & 66,2 & 73,4 & 7,2 \\
\hline & 60,6 & 64,8 & 4,2 & 65,8 & 68,2 & 2,4 & 65,2 & 74,2 & 9 \\
\hline & 64,4 & 68,6 & 4,2 & 64,8 & 67,6 & 2,8 & 65,2 & 71,4 & 6,2 \\
\hline & 64,4 & 69,2 & 4,8 & 62,4 & 67,6 & 5,2 & 66,2 & 72,2 & 6 \\
\hline & 62,8 & 68,6 & 5,8 & 63 & 65,8 & 2,8 & 64,4 & 72,2 & 7,8 \\
\hline
\end{tabular}


As figuras A4, A5 e A6 apresentam os gráficos em Box Plot dos fatores isolados (material, pigmentação e envelhecimento) para o ensaio de dureza Shore A.

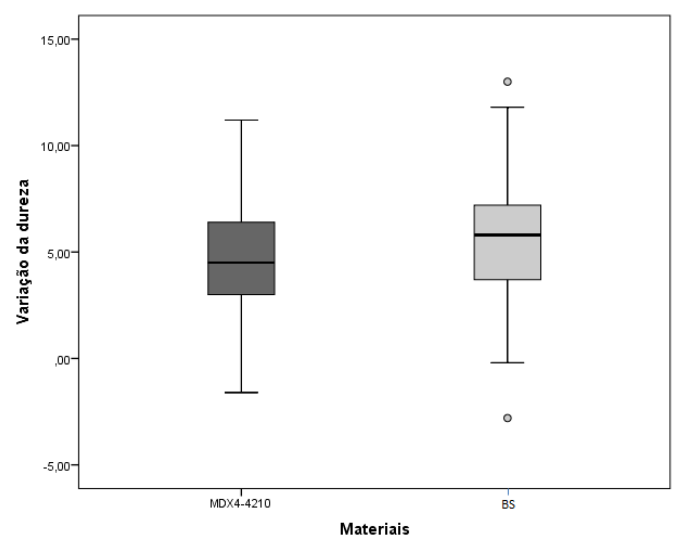

Figura A4 - Box plot do fator material para o ensaio de dureza Shore A.

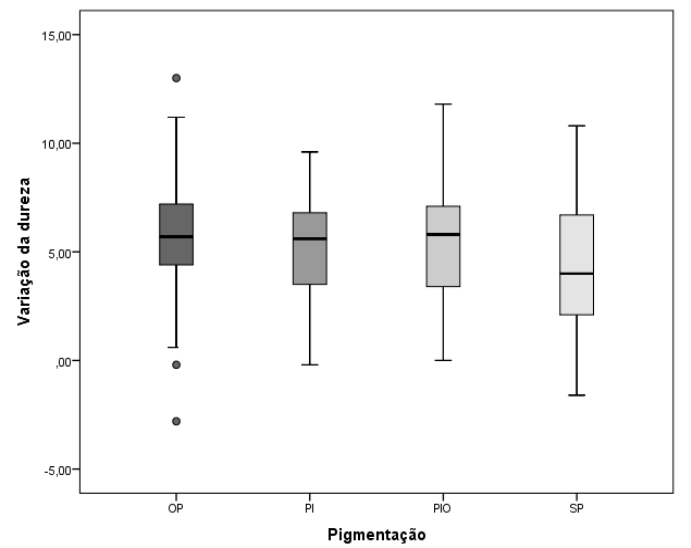

Figura A5 - Box plot do fator pigmentação para o ensaio de dureza Shore A.

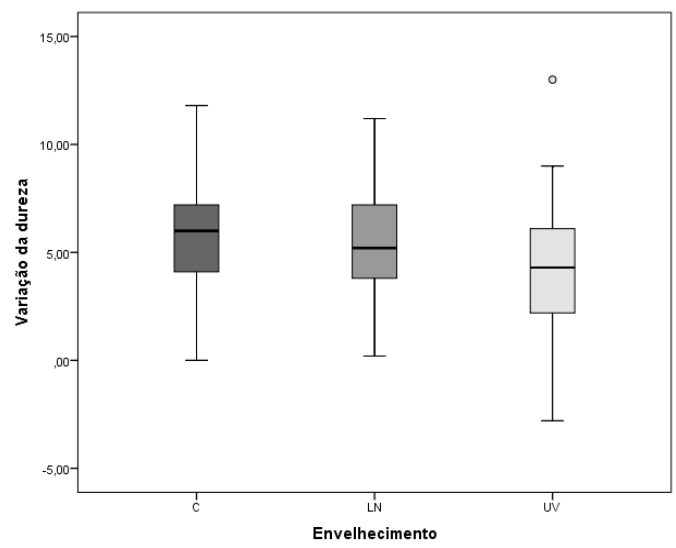

Figura A6 - Box plot do fator envelhecimento para o ensaio de dureza Shore A. 
Tabela A4 - Valores de resistência à tração (resultados fornecidos em Mpa) dos espécimes confeccionados com o silicone MDX 4-4210 (controle/padrão ouro) e com o silicone experimental modificado (Bio-Skin) dos seguintes grupos de pigmentação: sem pigmentação (SP), pigmentação intrínseca (PI), opacificador (OP) e grupo associado (PIO), após envelhecimento por luz natural, luz ultravioleta e grupo controle.

\begin{tabular}{|c|c|c|c|c|c|c|c|c|}
\hline & \multicolumn{4}{|c|}{ MDX } & \multicolumn{4}{|c|}{ BS } \\
\hline & I & $\mathrm{C}$ & $\mathrm{LN}$ & UV & I & $\mathrm{C}$ & $\mathrm{LN}$ & UV \\
\hline \multirow{10}{*}{ SP } & 2,54 & 2,05 & 2,02 & 2,03 & 7,62 & 7,81 & 5,82 & 8,27 \\
\hline & 2,61 & 1,85 & 1,53 & 1,56 & 7,47 & 6,26 & 6,6 & 7,34 \\
\hline & 2,18 & 2,01 & 1,8 & 2,04 & 5,31 & 6,53 & 7,15 & 6,71 \\
\hline & 2,04 & 2,42 & 1,88 & 2,38 & 8,14 & 7,31 & 5,43 & 7,58 \\
\hline & 2,06 & 1,4 & 2 & 2,55 & 7,96 & 6,98 & 6,16 & 8,35 \\
\hline & 2,19 & 1,41 & 1,69 & 2,55 & 6,79 & 7,18 & 6,27 & 7,24 \\
\hline & 2,03 & 1,91 & 1,35 & 3,33 & 7,82 & 5,89 & 5,93 & 7,49 \\
\hline & 2,23 & 1,27 & 2,06 & 2,55 & 7,49 & 5,52 & 7,34 & 6,18 \\
\hline & 2,52 & 2,4 & 1,35 & 1,84 & 8,1 & 8,29 & 6,86 & 8,19 \\
\hline & 2,39 & 2,02 & 1,85 & 3,22 & 8,67 & 8,47 & 6,87 & 7,66 \\
\hline \multirow{10}{*}{ PI } & 2,49 & 2,2 & 2,3 & 2,66 & 6,9 & 7,92 & 5,21 & 7,72 \\
\hline & 2,55 & 2,68 & 1,91 & 3,1 & 7,79 & 9,78 & 7,54 & 8,15 \\
\hline & 2,85 & 1,25 & 1,96 & 2,98 & 7,83 & 7,86 & 6,92 & 8,2 \\
\hline & 2,68 & 2,01 & 2,08 & 2,91 & 8,33 & 7,33 & 8,09 & 8,69 \\
\hline & 1,91 & 1,93 & 1,84 & 2,99 & 8,43 & 6,59 & 8,23 & 8,98 \\
\hline & 2,19 & 2,12 & 2,03 & 2,31 & 6,22 & 6,44 & 8,95 & 8,96 \\
\hline & 1,93 & 1,72 & 2,67 & 2,83 & 7,64 & 7,92 & 8,24 & 7,92 \\
\hline & 2,16 & 2,6 & 2,47 & 2,73 & 8,44 & 8,76 & 8,78 & 9,04 \\
\hline & 1,75 & 2,76 & 1,34 & 2,98 & 7,81 & 9,12 & 6,28 & 8,48 \\
\hline & 2,68 & 2,04 & 1,21 & 1,94 & 7,58 & 8,94 & 8,8 & 7,97 \\
\hline \multirow{10}{*}{ OP } & 1,6 & 1,81 & 1,77 & 1,5 & 7,19 & 7,38 & 7,64 & 6,65 \\
\hline & 1,46 & 1,89 & 1,97 & 2,05 & 7,38 & 6,78 & 7,16 & 6,1 \\
\hline & 2,47 & 1,17 & 2,25 & 2,03 & 7,89 & 7,68 & 7,38 & 6,24 \\
\hline & 1,89 & 1,48 & 1,71 & 1,67 & 7,36 & 6,73 & 6,82 & 6,65 \\
\hline & 1,47 & 2 & 2,13 & 2,09 & 7,9 & 6,72 & 7,4 & 7,39 \\
\hline & 1,81 & 1,87 & 2,09 & 1,86 & 7,48 & 6,84 & 5,16 & 6,54 \\
\hline & 1,52 & 2,16 & 2,3 & 2,6 & 7,23 & 6,95 & 7,7 & 6,17 \\
\hline & 1,97 & 1,63 & 2,28 & 1,7 & 7,87 & 6,63 & 6,84 & 6,87 \\
\hline & 2,02 & 1,99 & 2,14 & 1,99 & 7,96 & 6,36 & 6,79 & 7,72 \\
\hline & 2,01 & 2,06 & 1,06 & 2,83 & 7,41 & 6,47 & 6,78 & 7,17 \\
\hline \multirow{10}{*}{ PIO } & 1,64 & 1,51 & 1,18 & 2,73 & 7,72 & 7,66 & 7,49 & 7,02 \\
\hline & 2,12 & 2,21 & 2,8 & 2,41 & 8,73 & 7,57 & 7,94 & 8,01 \\
\hline & 1,83 & 2,33 & 2,53 & 2,05 & 7,92 & 7,37 & 7,98 & 7,56 \\
\hline & 1,88 & 1,7 & 2,21 & 2,06 & 8,34 & 7,6 & 8,65 & 6,14 \\
\hline & 1,94 & 2,65 & 1,62 & 2,33 & 8,66 & 5,55 & 7,61 & 7,99 \\
\hline & 2,56 & 1,64 & 2,38 & 1,78 & 8,57 & 6,83 & 7,06 & 8,84 \\
\hline & 1,92 & 2,29 & 1,68 & 2,45 & 8,43 & 6,34 & 7,73 & 8,13 \\
\hline & 1,27 & 2,71 & 1,93 & 1,3 & 8,15 & 7,92 & 7,28 & 8,9 \\
\hline & 1,92 & 2,57 & 2,48 & 2,02 & 9,12 & 7,49 & 6,91 & 8,25 \\
\hline & 1,56 & 1,64 & 1,41 & 2,24 & 6,99 & 8,08 & 7,03 & 7,87 \\
\hline
\end{tabular}


As figuras A7, A8 e A9 apresentam os gráficos em Box Plot dos fatores isolados (material, pigmentação e envelhecimento) para o ensaio de resistência à tração.

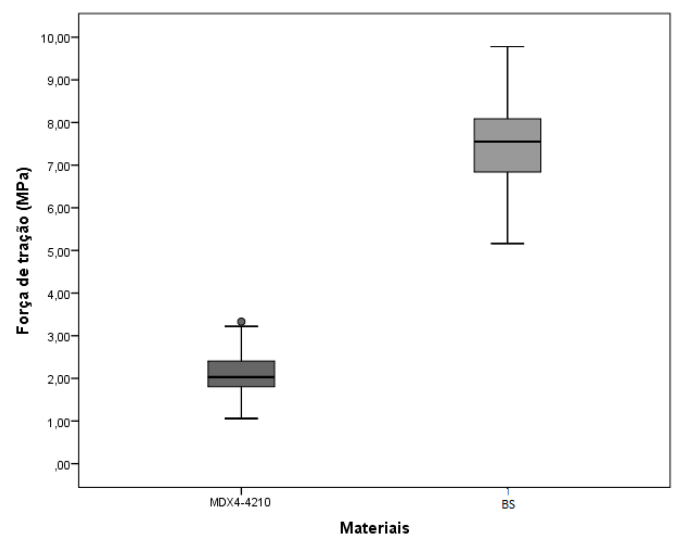

Figura A7 - Box plot do fator material para o ensaio de resistência à tração.

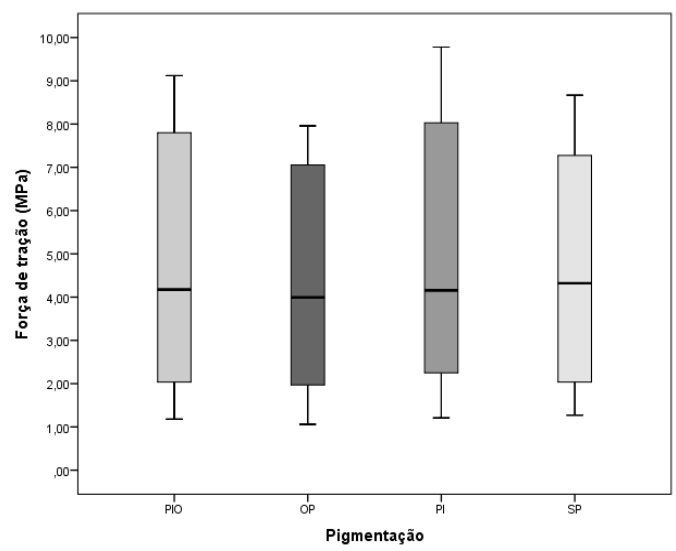

Figura A8 - Box plot do fator pigmentação para o ensaio de resistência à tração.

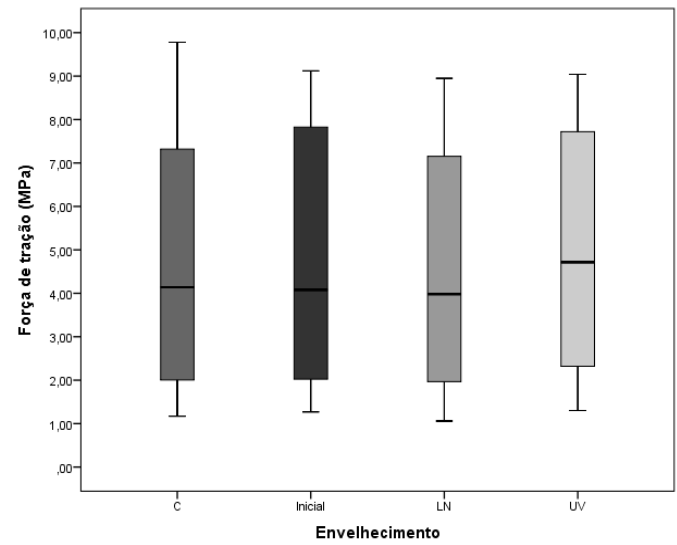

Figura A9 - Box plot do fator envelhecimento para o ensaio de resistência à tração. 